Illinois State University

ISU ReD: Research and eData

Theses and Dissertations

4-21-2014

\title{
Using Deuterium And Garp To Estimate Geographic Extents Of Source Populations Of Hoary (lasiurus Cinereus) And Eastern Red (lasiurus Borealis) Bats Killed At A Central Illinois Wind Facility
}

Rachael Anne Van Essen

Illinois State University, rvanessen@lc.edu

Follow this and additional works at: https://ir.library.illinoisstate.edu/etd

Part of the Biodiversity Commons, Biology Commons, Natural Resources and Conservation Commons, and the Natural Resources Management and Policy Commons

\section{Recommended Citation}

Van Essen, Rachael Anne, "Using Deuterium And Garp To Estimate Geographic Extents Of Source Populations Of Hoary (lasiurus Cinereus) And Eastern Red (lasiurus Borealis) Bats Killed At A Central Illinois Wind Facility" (2014). Theses and Dissertations. 180.

https://ir.library.illinoisstate.edu/etd/180

This Thesis is brought to you for free and open access by ISU ReD: Research and eData. It has been accepted for inclusion in Theses and Dissertations by an authorized administrator of ISU ReD: Research and eData. For more information, please contact ISUReD@ilstu.edu. 


\title{
USING DEUTERIUM AND GARP TO ESTIMATE GEOGRAPHIC EXTENTS OF SOURCE POPULATIONS OF HOARY (LASIURUS CINEREUS) AND EASTERN RED (LASIURUS BOREALIS) BATS KILLED AT A CENTRAL ILLINOIS WIND FACILITY
}

\author{
Rachael A. Van Essen
}

97 Pages

August 2014

High bat mortality at wind energy facilities is a widely cited conservation issue, but the population-level impacts are not understood. In Illinois, the main species affected are migratory tree bats like the Hoary (Lasiurus cinereus) and Eastern Red (Lasiurus borealis).This research used deuterium isotope analysis of hair combined with ecological niche modeling (GARP: Genetic Algorithm for Rule-set Prediction) in a novel way to map the geographic extents of Hoary and Eastern Red bat specimens salvaged at a single central Illinois wind facility from 2008-2010. Hair was chosen after determining that the claw is currently a problematic tissue due to a lack of knowledge about bats' claw growth rates. Hair samples from different sample sites on the body were not significantly different from each other, and there was no significant variation among hair samples from the same body sample site.

The proportions of isotopic extents of both bats' summer ranges revealed that the salvaged specimens came from areas that cover more than $50 \%$ of their summer ranges 
(hence, many populations). When males' and females' isotope extents were overlapped, Hoary bats had less than 50\% overlapping of the sexes while Eastern Red bats had over $50 \%$. Relationships among the salvage years and months were also examined. The percentage of overlap among specimen salvage years suggests that these bats utilize their complete range every summer. When each salvage month was examined, there was no evidence of a correlation between month of arrival at the wind facility and their summer geographic extent. This study shows the importance of specimens salvaged from wind facilities for studying both the population-level impacts of wind farm facilities and bat migratory biology. 
USING DEUTERIUM AND GARP TO ESTIMATE GEOGRAPHIC EXTENTS OF SOURCE POPULATIONS OF HOARY (LASIURUS CINEREUS) AND

EASTERN RED (LASIURUS BOREALIS) BATS KILLED

AT A CENTRAL ILLINOIS WIND FACILITY

RACHAEL A. VAN ESSEN

A Thesis Submitted in Partial Fulfillment of the Requirements for the Degree of

MASTER OF SCIENCE

School of Biological Sciences

ILLINOIS STATE UNIVERSITY 
Copyright 2014 Rachael A. Van Essen 
USING DEUTERIUM AND GARP TO ESTIMATE GEOGRAPHIC EXTENTS OF SOURCE POPULATIONS OF HOARY (LASIURUS CINEREUS) AND

EASTERN RED (LASIURUS BOREALIS) BATS KILLED

AT A CENTRAL ILLINOIS WIND FACILITY

RACHAEL A. VAN ESSEN

COMMITTEE MEMBERS:

Angelo P. Capparella, Chair

John C. Kostelnick

Steven A. Juliano 


\section{ACKNOWLEDGMENTS}

I would like to thank the members of my committee, Angelo Capparella, Steve Juliano, and John Kostelnick for their input and support throughout this entire project. Their influence and guidance has encouraged me to continue in the field of conservation biology and has enhanced my scientific thinking. I would also like to sincerely thank my family and friends who have supported me and never doubted my ability to complete my work. Thank you to Michael Murtaugh for his unwavering faith in me and for encouraging my desire for a higher degree. Thank you to everyone who acted as consultants and advisors when I needed help with methods and analyses. I would also like to thank my friends at Grace Church who have never ceased in their prayers and support. Thanks be to God for His provision and blessings in all things and for faith and perseverance.

This research was supported by the Illinois State University School of Biological Sciences, the Phi Sigma (Beta Lambda Chapter) R.D. Weigel grant, and a Sigma Xi Grants-In-Aid of Research grant.

R.V.E. 


\section{CONTENTS}

\section{Page}

ACKNOWLEDGMENTS

CONTENTS $\quad$ ii

TABLES $\quad \mathrm{v}$

FIGURES vi vi

CHAPTER

I. INTRODUCTION OF MORTALITY, SPECIES, AND DEUTERIUM 1

Introduction 2

Mortality of Bats in Wind Facilities 2

Bat Population Impacts 3

Hoary Bat (Lasiurus cinereus) 4

Eastern Red Bat (Lasiurus borealis)

Migration 6

Population Estimation $\quad 6$

Deuterium Analysis $\quad 7$

Deuterium Use in Migration Studies 9

Molting Studies and Tissue Analyses $\quad 11$

Research Initiatives $\quad 13$

$\begin{array}{ll}\text { Literature Cited } & 14\end{array}$

II. DEUTERIUM RATIO DIFFERENCES IN

BAT HAIR AND CLAW TISSUES 17

Introduction 18

$\begin{array}{ll}\text { Methods } & 20\end{array}$ 
Hair Sampling $\quad 20$

Claw Sampling $\quad 21$

Isotope Analysis $\quad 21$

$\begin{array}{ll}\text { Statistics } & 22\end{array}$

$\begin{array}{ll}\text { Results } & 23\end{array}$

Hoary Bats $\quad 23$

Eastern Red Bats $\quad 24$

Discussion $\quad 24$

Conclusions $\quad 26$

Literature Cited $\quad 27$

Tables $\quad 29$

III. DETERMINATION OF GEOGRAPHIC EXTENTS

OF SOURCE POPULATIONS OF HOARY

(LASIURUS CINEREUS) AND EASTERN

RED (LASIURUS BOREALIS) BATS KILLED AT

A CENTRAL ILLINOIS WIND FACILITY 31

Introduction $\quad 32$

$\begin{array}{ll}\text { Methods } & 38\end{array}$

Isoscape Development and Assignment 38

GARP Model Development 38

Sampling and Analysis $\quad 41$

Results $\quad 44$

Discussion $\quad 46$

Conclusions $\quad 50$

Literature Cited $\quad 52$

Tables $\quad 55$

$\begin{array}{lr}\text { Figures } & 60\end{array}$

IV. YEARLY AND MONTHLY VARIATIONS IN GEOGRAPHIC

EXTENTS OF HOARY (LASIURUS CINEREUS) AND

EASTERN RED (LASIURUS BOREALIS) BAT SPECIMENS 76

$\begin{array}{ll}\text { Introduction } & 77\end{array}$

$\begin{array}{ll}\text { Methods } & 78\end{array}$

$\begin{array}{ll}\text { Mapping of Separate Years } & 78\end{array}$ 
$\begin{array}{ll}\text { Results } & 79\end{array}$

$\begin{array}{ll}\text { Yearly } & 79\end{array}$

$\begin{array}{ll}\text { Monthly } & 80\end{array}$

$\begin{array}{ll}\text { Discussion } & 81\end{array}$

$\begin{array}{ll}\text { Yearly } & 81\end{array}$

$\begin{array}{ll}\text { Monthly } & 81\end{array}$

$\begin{array}{ll}\text { Conclusions } & 82\end{array}$

$\begin{array}{lr}\text { Literature Cited } & 84\end{array}$

$\begin{array}{lr}\text { Figures } & 85\end{array}$

APPENDIX: Geographic Extents of Bats Not Used in Analysis 93 


\section{TABLES}

$\begin{array}{lll}\text { Table } & \text { Page }\end{array}$

1. $\delta \mathrm{D}(\%)$ of hair and claw samples taken from 10 adult female Hoary bats 29

2. Random Complete Block Design analysis of intrasample variation of Hoary bat body sampling sites

3. Hoary bat nested ANOVA analysis of intrasample variation of hair samples within a sampling site

4. ANOVA analysis of 10 adult female Hoary bats for differences between claws of separate toes and differences among claws and the claw tips

5. $\delta \mathrm{D}(\%)$ of hair and claw samples taken from 9 adult female Eastern Red bats 30

6. Random Complete Block Design analysis of intrasample variation of 9 adult female Eastern Red bat body sampling sites

7. Eastern Red bat nested ANOVA analysis of intrasample variation of hair samples within a sampling site

8. The raw and converted $\delta \mathrm{D}_{\mathrm{h}}$ for Hoary bat hair

9. Duplicates of selected specimens of Hoary bat hair in Table 8

10. Raw $\delta \mathrm{D}_{\mathrm{h}}$ for Eastern Red bat hair 57

11. Duplicates of selected specimens of Eastern Red bat hair in Table $10 \quad 58$

12. Details of GARP variable sources including scale and years 58

13. Number of specimens analyzed for $\delta D_{h}$ and the number of specimens mapped to create geographic extents 


\section{FIGURES}

Figure $\quad$ Page

1. Deuterium of precipitation from 1960-2010 modeled in Isomap.org 60

2. Georeferenced Hoary bat specimen locations used to train and test the GARP model

3. Georeferenced Eastern Red bat specimen locations used to train and test the GARP model

4. GARP Hoary bat best 10 models

5. GARP Eastern Red bat best 10 models 64

6. The ArcMap process used for each specimen 65

7. The isotope assignment maps of 14 female adult Hoary bats 66

8. The isotope assignment maps of 22 male adult Hoary bats 67

9. The isotope assignment maps of 9 female adult Eastern Red bats 68

10. The isotope assignment maps of 17 male adult Eastern Red bats 69

11. The isotope assignments for female Hoary bats (green) overlaid onto the Hoary bat GARP model (blue)

12. The isotope assignments for male Hoary bats (green) overlaid onto the Hoary bat GARP model (blue)

13. The isotope assignments for female Eastern Red bats (green) overlaid onto the Eastern Red bat GARP model (blue)

14. The isotope assignments for male Eastern Red bats (green) overlaid onto the Eastern Red bat GARP model (blue) 
15. The $45.13 \%$ overlap of geographic extents of male and female Hoary bats

16: The $63.49 \%$ overlap of geographic extents of male and female Eastern Red 75 bats

17. Number of specimen sample years (2008-2010) overlapping extents for female Hoary bats

18. Number of specimen sample years (2008 and 2009) overlapping extents for 86 male Hoary bats

19. Number of specimen sample years (2008 and 2010) overlapping extents for female Eastern Red bats

20. Number of specimen sample years (2008-2010) overlapping extents for male Eastern Red bats

21. Overlap of specimen sample months (August-October) for female Hoary bats

22. Overlap of specimen sample months (August and September) for male Hoary bats

23. Overlap of specimen sample months (August and September) for female Eastern Red bats

24. Overlap of specimen sample months (July-October) for male Eastern Red bats

25. The three female Hoary bats not included in the analysis

26. The single male Hoary bat specimen not included in the analysis

27. The two female Eastern Red bats not included in the analysis

28. The seven male Eastern Red bats not included in the analysis 


\section{CHAPTER I}

INTRODUCTION TO MORTALITY, SPECIES, AND DEUTERIUM 


\section{Introduction}

\section{Mortality of Bats in Wind Facilities}

Wind energy is viewed as an eco-friendly alternative energy source. Commercial facilities use turbines that are typically 60-100 meters high, with spinning blades up to 50 meters long (Altringham 2011) that rotate up to 180 miles per hour at the tips (Cohn 2008). However, negative ecological impacts of such facilities have become evident. Jain et al. (2010) concluded that wind facilities in agricultural fields in the Midwest can kill an estimated 4.45-7.14 bats per turbine per year. In Canada and the United States, migratory tree bats suffered significantly more fatalities than other species of bats. The Eastern Red (Lasiurus cinereus) and Hoary (Lasiurus borealis) bats comprised 20.0$60.9 \%$ and $9.0-88.1 \%$ of fatalities, respectively, at each wind facility studied across the contiguous United States (Arnett et al. 2007). However, it is difficult to achieve an accurate estimate of total bat mortality in wind facilities across the continent due to differences in survey methods and a lack of representative sampling of all facilities across the country (Huso and Dalthrop 2014).

There is evidence (Winhold et al. 2008) that the Eastern Red bat is showing signs of decline. In a paired netting survey in southern Lower Michigan that took place in 1978-1979 and then again in 2004-2006, they reported overall a 52-85\% decline in

netting captures per night. Some possible causes of this decline include habitat loss and fragmentation, effects from pesticides, and their tendency to be killed in high numbers at wind facilities (Winhold et al. 2008). This could have severe population impacts because bats tend to reproduce slowly and be long lived (Fleming and Eby 2003). Slow reproduction and long life spans in animals are often traits of species that take a longer 
time to recover from unnaturally high mortality events.

\section{Bat Population Impacts}

Bat populations can have an incredible impact on their ecosystems through the control of insect populations. A single Little Brown bat (Myotis lucifugus), smaller (12 g) than the Eastern Red (16 g) and Hoary bats (36 g), can eat 4-8 g of insects each night (Hofmann 2008). A colony of 150 Big Brown bats (Eptesicus fuscus) (26 g) can eat an estimated 1.3 million insect pests each year (Boyles et al. 2011). Two studies conducted in the Neotropics used exclusion methods to assess both bird and bat predation importance. In Panama, it was found that bats had a greater effect on arthropod populations than birds. Without bats, arthropod populations increased by $84 \%$ (Williams-Guillén et al. 2008). In Mexico, a similar pattern was seen with $84 \%$ reduction in arthropods due to bats and only 58\% reduction due to birds (Kalka et al. 2008).

This potentially has significant influence not only on the ecosystem but also on the agricultural economy. For example, it is estimated that bats save U.S. agriculture $\$ 22.9$ billion per year through decreasing insect pest populations, lowering the cost of pesticide use (Boyles et al. 2011). With their impact on ecosystems and economies, the loss of bat populations is a phenomenon that needs to be further understood. Although the Eastern Red and Hoary species are not listed as species of concern by the IUCN Red List (Arroyo-Cabrales et al. 2008, Gonzalez and Arroyo-Cabrales 2008 ), in Illinois these bats are killed regularly by wind turbines with the highest mortality occurring during their autumn migrations (Arnett et al. 2007). 


\section{Hoary Bat (Lasiurus cinereus)}

The Hoary bat is a species found throughout Illinois (Hofmann 2008), and its range encompasses the U.S. and large portions of Canada (Cryan 2003). Although they are considered long-distance migrants, they can be found throughout most of their range all year, albeit with changes in densities among the regions. Cryan (2003) used museum specimens and live captures to map monthly distributions of Hoary bats throughout the continental U.S. and southern parts of Canada. In the winter, many are found throughout the southern U.S. During their spring migrations, they move northward to their summer ranges. From June to August, they can be found throughout the Midwest, western states, and southern Canada with a lesser number in the northeastern U.S. Throughout Illinois during this time, there is a high density of females with some males as well. As they migrate in the fall, they move southward back into their wintering grounds (Cryan 2003). There are reports that some individuals stay north and hibernate, but migrations of large groups occur in pulses, with waves of bats migrating through an area in intervals (Shump and Shump 1982a). It is during these fall months that they mate and females store sperm over the winter (Whitaker Jr. and Mumford 2009). In their summer range, Hoary bat females give birth in roosts along forest edges, including areas near human habitations (Fleming and Eby 2003). Willis and Brigham (2005) found that when females have pups, they tend to choose roosts that are below 1,200 meters in elevation and are abundant in white spruce trees (Picea glauca). They also found that the directional orientation, forest density and canopy cover were all important factors for maternity roost site selection. They suggested that these factors provide a safe environment with a stable microclimate for pup rearing (Willis and 
Brigham 2005). In an Arkansas study, Perry and Thill (2007) found two maternity roosts in shortleaf pines (Pinus echinata) while other male and female roosts were found in white (Quercus alba) and post (Quercus stellate) oaks. All the roosting trees were taller and had a larger diameter and canopy than surrounding trees.

\section{Eastern Red Bat (Lasiurus borealis)}

The Eastern Red bat is found throughout the central and eastern U.S. and southern Canada (Shump and Shump 1982b) and is common throughout Illinois (Hofmann 2008). They roost in edge habitats along streams, fields and even in suburban areas (Shump and Shump 1982b). They roost primarily in hardwoods like oaks (Quercus), hickories (Carya), and poplars (Populus) even when conifers are available (O'Keefe et al. 2009), and they prefer more mature trees with diameters greater than $30 \mathrm{~cm}$ (Mager and Nelson 2001).

According to Cryan (2003), Eastern Red bats are most commonly found in the eastern and southeastern states during the winter months of December through February. In the spring, they move northward and westward up to the Midwest and Canada. In Illinois during the summer months, both males and females are found in high densities. There is evidence that suggests the sexes separate at a more local scale according to temperature and elevation differences (Cryan 2003). Males tend to stay in the higher, cooler elevations, while females choose areas of warmer temperatures and lower elevations. It is believed that these differences are attributed to the dissimilar physiological demands of males and females during times of rearing young (Ford et al. 2002). In autumn, they migrate back towards the eastern and southeastern states (Cryan 2003) and mate during the months of August and September (Hofmann 2008) along the 
migration routes (Britzke et al. 2009).

\section{Migration}

In North America, the Hoary and Eastern Red bats travel over 1,000 km between seasonal roosting regions. These migratory bats develop fat deposits but, unlike birds, this fat is used for both migration and winter torpor, and they typically cannot store enough fat for the entire journey. Stopovers are critical for rest and for feeding to reconstitute enough fat for overwintering by replenishing what is lost in migration (Racey and Entwistle 2003), but the energy required during migratory movement can be reduced during stopovers by the use of short-term torpor (McGuire et al. 2012). It is reported that bats are almost completely nocturnal during their migrations, and their stopovers must be frequent so they can rest during the day. According to their study of Silver-haired bats (Lasionycteris noctivagans), another long-distance migratory tree bat, their times at stopover sites were typically just one day and feeding occurred at the sites upon arrival or just before departure (McGuire et al. 2012).

\section{Population Estimation}

Estimating populations of any bat species can be problematic for various reasons. For example, the Eastern Red and Hoary bats are largely solitary for much of the year, even during the pupping season when many other species form large maternity colonies. It is this solitary behavior that makes censuses of these two species particularly difficult (Whitaker Jr. and Mumford 2009). Banding studies have been attempted in bats, but recapture rates of banded individuals are extremely rare, making the amount of information gathered considerably less than the effort and cost involved. Radio transmitters have also been attempted, but models light enough to be carried by bats 
without disrupting their behaviors or putting them at risk do not have enough range for migratory species (Cryan et al. 2004). All of these factors add to the difficulty of estimating population size and fluctuation throughout the seasons of migratory bats, and why the use of deuterium ratio analysis as a tool to track migratory animals is so appealing for bats, especially when coupled with the large sample sizes available from wind turbine mortality

\section{Deuterium Analysis}

Deuterium is a heavy isotope of hydrogen and, although it has the same atomic number, its chemical behavior is slightly different due to physical properties related to its heavier atomic mass (Ben-David and Flaherty 2012). Deuterium falls as precipitation in patterns due to temperature-driven forces related to latitude and elevation (Bowen et al. 2005). In the Northern Hemisphere, as latitude or elevation increase, less deuterium is incorporated into the precipitation, leading to depletion and a more negative deuterium:hydrogen ratio (SD) signature (Ben-David and Flaherty 2012).

The $\delta \mathrm{D}$ is conserved throughout trophic levels and is incorporated into tissues during their syntheses. Feathers, hair and claws are all keratinized tissues and are metabolically inert after formation, allowing the isotopic signature of the nonexchangeable hydrogen to remain for long time periods after the initial deposition in the tissue (Fraser et al. 2010). Some of the hydrogen remains exchangeable with the atmosphere (Wassenaar and Hobson 2006); therefore, before analysis, samples and standards are allowed to equilibrate with the air for several weeks. During analysis, standards are used to calibrate a relationship between exchangeable and nonexchangeable hydrogen allowing for the reporting of only non-exchangeable hydrogen 
in the samples. Standards are also used as a measure of precision during analysis. An accepted range of deviation among standards is no more than $\pm 2 \%$ (C. Macdonald, University of Wyoming Isotope Laboratory, pers. comm. 2014). If the standard deviation of the standards is higher, then the reliability of the samples is decreased.

Deuterium can be used in migratory studies if the organism moves between sites of different isotope ratios. It can then provide a way to reconstruct their movements through time (Bowen et al. 2005). However, keratin deuterium $\left(\delta \mathrm{D}_{\mathrm{k}}\right)$ does not reflect deuterium levels of precipitation $(\delta \mathrm{Dp})$ at a one-to-one ratio. Due to fractionation in the food web, $\delta \mathrm{D}_{\mathrm{k}}$ typically is more depleted than $\delta \mathrm{D}_{\mathrm{p}}$ (Fraser et al. 2010).

There are two types of fractionation, equilibrium and kinetic. Equilibrium fractionation is due to differences in chemical reactions because heavier isotopes create stronger bonds. Kinetic fractionation is the more pronounced type and occurs when a molecule changes phase or undergoes a non-reversible reaction like evaporation, diffusion, or enzymatic reactions. The term fractionation is now restricted to describe changes in a single event, such as a single enzymatic reaction. The differences among $\delta \mathrm{D}_{\mathrm{p}}$ and $\delta \mathrm{D}_{\mathrm{k}}$ is called discrimination because there are multiple and unknown processes that lead to the differences (Ben-David and Flaherty 2012). Even with this phenomenon, the use of hydrogen isotopes has been effective for many wildlife forensic studies (Bowen et al. 2005). One of the ways this discrimination can be compensated for is through the use of regression equations to convert $\delta \mathrm{D}_{\mathrm{k}}$ to $\delta \mathrm{D}_{\mathrm{p}}$, which can then be mapped on a deuterium precipitation isoscape, a map of isotopic changes across a geographic area. 


\section{Deuterium Use in Migration Studies}

Many researchers have utilized $\delta D_{k}$ in feathers and other tissues to track migrating birds to their seasonal geographic origins (Mazerolle et al. 2005, Wunder et al. 2005, Rocque et al. 2006, Hobson et al. 2007, Langin et al. 2007, Fraser et al. 2008, De Ruyck et al. 2013). It has also been increasing in popularity as a method to track migration and distribution patterns of bats (Britzke et al. 2009, Fraser et al. 2010, Fraser et al. 2012, Ossa et al. 2012, Popa-Lisseanu et al. 2012, Sullivan et al. 2012).

Cryan et al. (2004) sampled 265 Hoary bats that were captured from across North America from 1894 to 2002. These were examined to determine their molting period. The bats within the molting period were sampled, their deuterium ratios of bat hair $\left(\delta \mathrm{D}_{\mathrm{h}}\right)$ and the $\delta \mathrm{D}_{\mathrm{p}}$ were correlated using the samples' geographic locations, and this data were used to create a regression model that correlated $\delta \mathrm{D}_{\mathrm{h}}$ with $\delta \mathrm{D}_{\mathrm{p}}, \delta \mathrm{D}_{\mathrm{p}}=$ $\delta \mathrm{D}_{\mathrm{h}}+24.81 / 0.7884$. This technique was also used more recently by Ossa et al. (2012). They used six non-migratory species and sampled in a similar way to Cryan et al. (2004). They had mixed correlations between $\delta D_{h}$ and $\delta D_{p}$ with some exhibiting a positive correlation, and some with none or a negative correlation. Even with these differences, they derived one regression equation from the six species $\left(\delta \mathrm{D}_{\mathrm{p}}=\right.$ $35.7+0.66 * \delta \mathrm{D}_{\mathrm{h}}$ ) that had significant predictive power. They discussed several possible explanations for the mixed results, notably small sample size, high variability in $\delta \mathrm{D}_{\mathrm{p}}$ within a sampling location, using annual $\delta \mathrm{D}_{\mathrm{p}}$ instead of the $\delta \mathrm{D}_{\mathrm{p}}$ for the molting months, and/or the bats being more prone to migration movements than believed. Fraser et al. (2012) used North American museum specimens showing molt to conduct deuterium ratio analysis of Tri-colored bats (Perimyotis subflavus) and to determine their molting 
period. They derived quadratic regression equations linking $\delta D_{h}$ and $\delta D_{p}$ for males $\left(\delta \mathrm{D}_{\mathrm{h}}=-0.036 * \delta \mathrm{D}_{\mathrm{p}}{ }^{2}-1.789 * \delta \mathrm{D}_{\mathrm{p}}-45.607\right)$ and females $\left(\delta \mathrm{D}_{\mathrm{h}}=-0.034 * \delta \mathrm{D}_{\mathrm{p}}{ }^{2}-1.606 * \delta \mathrm{D}_{\mathrm{p}^{-}}\right.$ 40.375) separately. They concluded that there were significant correlations between $\delta \mathrm{D}_{\mathrm{h}}$ and $\delta \mathrm{D}_{\mathrm{p}}$ and a correlation with latitude of collection site. They also found evidence of latitudinal migration by some of the specimens which was a significant finding for this species that was once thought to strictly be a short-distance regional migrant.

Ossa et al. (2012) used museum specimens of six non-migratory African species, to determine correlations between $\delta \mathrm{D}_{\mathrm{h}}$ and $\delta \mathrm{D}_{\mathrm{p}}$, and then used this correlation to determine migratory movements of the Straw-colored bat (Eidolon helvum). Even on the African continent, which is comparatively homogeneous in isotope ratios, they were able to detect migratory movements and found that using hydrogen isotopes had a high predictive power for geographic assignment. Popa-Lisseanu et al. (2012) sampled from five species of sedentary bats in Europe and also concluded that there were significant positive correlations between $\delta \mathrm{D}_{\mathrm{h}}$ and $\delta \mathrm{D}_{\mathrm{p}}$ for all five species. Sullivan et al. (2012) used the technique of isotope analysis of hair to understand movement patterns of bats to hibernacula and to estimate the connectivity of different habitats used by hibernating bats throughout the year.

Fraser et al. (2010) used both hair and claw tissue to understand the altitudinal migration of five species of Neotropical bats of varying diets. However, seasonal shifts in $\delta \mathrm{D}_{\mathrm{p}}$, unknown molting times and differences in diets made interpretation difficult. Britzke et al. (2009) looked at the long-distance migrating (>500 km) Eastern Red bat (Lasiurus borealis), along with three regional migrating species which only move 100$500 \mathrm{~km}$, and found a correlation between latitude and $\delta \mathrm{D}_{\mathrm{h}}$. However, they suggested that 
there can be high variation and that pooling across species, sex and age classes should be avoided. They also suggested that diet may cause variation in $\delta \mathrm{D}_{\mathrm{h}}$ within a location. If bats feed primarily over different habitats, such as over an aquatic versus terrestrial ecosystem, they may have different ratios (Britzke et al. 2009).

The use of deuterium in migratory studies is based on some important assumptions. One is that there is a clear relationship between the $\delta \mathrm{D}_{\mathrm{p}}$ and $\delta \mathrm{D}$ in the analyzed tissue. This assumption has been supported for bat hair (Cryan et al. 2004, Fraser et al. 2012, Ossa et al. 2012, Popa-Lisseanu et al. 2012, Sullivan et al. 2012). Secondly, that there is little variation in $\delta \mathrm{D}_{\mathrm{k}}$ among individuals at a given site. Britzke et al. (2009) replicated $10 \%$ of the samples and found that the duplicate varied no more than $\pm 4 \%$ o from its sample. Although this may seem like a large variation, Wassenaar and Hobson (2006) found that even in samples of the same feather taken from chickens fed a homogeneous diet, there was a range of $\delta D_{k}$ values of $\pm 3 \%$.

\section{Molting Studies and Tissue Analyses}

Since deuterium is incorporated into hair during growth, knowledge of molting patterns is very important. Cryan et al. (2004) suggested that the molt for the Hoary bat is between June and August based on examination of when the $\delta \mathrm{D}_{\mathrm{h}}$ was most like the $\delta \mathrm{D}_{\mathrm{p}}$ of the location of specimen collection. A three month molt period is a wide range of time and could be problematic if the bats are migrating during the latter part of the summer. There is also some debate about molt and what affects its timing. Studies done by Constantine (1957, 1958) on Mormoops megalophylla senicula (Family Mormoopidae), Tadarida brasiliensis (Family Molossidae) and Myotis velifer (Family Vespertilionidae) found the patterns of each of these bats' molting. The different areas 
of the bats' bodies molt in a very similar pattern, with only a few minor differences in the shape of each area in molt. It begins along the sides and progresses into the scapular area and rump then further inward onto the dorsal surface. The ventral surface molts differently, starting on the chin, legs and neck. It then moves along the sides and towards the posterior end. Because molting patterns across different families are the same in overall pattern and have only minor differences, I assume that the molting pattern of Myotis velifer (within the same family as Eastern Red and Hoary bats) is the same for my two study species. Bats molt once a year, but males typically molt earlier than females (Constantine 1957); there is evidence that reproductive females delay molting until their young are weaned (Cryan et al. 2004).

In previous $\delta \mathrm{D}$ studies using bat hair, sampling was done from the scapular region (Cryan et al. 2004, Britzke et al. 2009, Fraser et al. 2010). According to Constantine's molting diagrams $(1957,1958)$, that area is one of the last to molt. If the bat migrates during molt there could be areas of the body that contain hair from the previous year, and it is uncertain if these bats exhibit philopatry. In Britzke et al. (2009), they mention that sampling before and during the yearly molt might have influenced their results. It could also be problematic if they are migrating during their molt. Different sections of the bats would have varying $\delta D_{h}$, and sampling an area grown during autumn migration could skew the geographic placement away from their summer range.

Using claws as a sample instead of hair is a method that would eliminate the issue of molting period. Fraser et al. (2008) found that claws in Neotropical warblers had a change in $\delta \mathrm{D}$ of $-0.4 \%$ per day. They concluded that it would take $16-17$ weeks 
for the claw tip to reflect the $\delta \mathrm{D}$ of the local habitat. If this change rate in $\delta \mathrm{D}$ is comparable to bats, then the deuterium in the claw tips of bats salvaged in the autumn would show the $\delta \mathrm{D}$ of the summer roosting areas. Fraser et al. (2010) further studied Neotropical bats and found differences between claw tips and hair deuterium ratios. If bat claw growth is similar to other mammalian claw growth, then the keratinized tissue grows outward and forward in layers from the epidermal germinal matrix. The claw can be divided into two layers. The subunguis is a soft keratin that forms the ventral side and the unguis is a harder keratin that forms the dorsal portion. Once at the tip of the claw, both layers are present (Ethier et al. 2010).

\section{Research Initiatives}

The focus of this research is to determine the geographic extent of the source populations of bats killed in autumn at a central Illinois wind facility and whether the mortality is affecting a small versus a large portion of the bats' summer ranges. Such information is critical for future studies assessing how much additive mortality these populations can sustain. I investigated differences in hair and claw tissues by first determining if there are significant differences in $\left.\delta D_{k} 1\right)$ among hair from different body areas and 2) between hair and claw tissues. The results of this study then determined the tissue type and sampling procedure of the remaining bats to examine 1) the geographic extents of source populations, 2) overlap of those geographic extents between males and females, and 3) yearly and monthly differences in extents. 


\section{Literature Cited}

Altringham, J. D. 2011. Conservation. Pages 260-267 in Altringham, J. D. Bats from evolution to conservation second ed. Oxford University Press.

Arnett, E. B., W. K. Brown, W. P. Erickson, J. K. Feidler, B. L. Hamilton, T. H. Henry, A. Jain, G. D. Johnson, J. Kerns, R. R. Koford, C. P. Nicholson, T. J. O'Connell, M. D. Piorkowski, and R. D. Tankersley Jr. 2007. Patterns of bat fatalities at wind energy facilities in North America. Journal of Wildlife Management 72:61-78.

Arroyo-Cabrales, J., B. Miller, F. Reid, A. D. Caurón, and P. C. Grammont. 2008. Lasiurus borealis. In: IUCN 2012. IUCN Red List of Threatened Species. Version 2012.1. www.iucnredlist.org.

Ben-David, M., and E. A. Flaherty. 2012. Stable isotopes in mammalian research: a beginner's guide. Journal of Mammalogy 93:312-328.

Bowen, G. J., L. I. Wassenaar, and K. A. Hobson. 2005. Global application of stable hydrogen and oxygen isotopes to wildlife forensics. Oecologia 143:337-348.

Boyles J. G., P. M. Cryan, G. F. McCracken, and T. H. Kunz. 2011. Economic importance of bats in agriculture. Science 332:41-42.

Britzke, E. R., S. C. Loeb, K. A. Hobson, C. S. Romanek, and M. J. Vonhof. 2009. Using hydrogen isotopes to assign origins of bats in the eastern United States. Journal of Mammalogy 90:743-751.

Cohn, J. P. 2008. How ecofriendly are wind farms? BioScience 58:576-578.

Constantine, D. G. 1957. Color variation and molt in Tadarida brasiliensis and Myotis velifer. Journal of Mammalogy 38:461-466.

Constantine, D. G. 1958. Color variation and molt in Mormoops megalophylla. Journal of Mammalogy 39:344-347.

Cryan, P. M. 2003. Seasonal distribution of migratory tree bats (Lasiurus and Lasionycteris) in North America. Journal of Mammalogy 84:579-593.

Cryan, P., M. A. Bogan, R. O. Rye, G. P. Landis, and C. L. Kester. 2004. Stable hydrogen isotope analysis of bat hair as evidence for seasonal molt and longdistance migration. Journal of Mammalogy 85:995-1001.

De Ruyck, C., K. A. Hobson, N. Koper, K. W. Larson, and L. I. Wassenaar. 2013. An appraisal of the use of hydrogen-isotope methods to delineate origins of migratory Saw-whet Owls in North America. Condor 115:366-374.

Ethier, D. M., C. J. Kyle, T. K. Kyser, and J. J. Nocera. 2010. Variability in the growth patterns of the cornified claw sheath among vertebrates: implications for using biogeochemistry to study animal movement. Canadian Journal of Zoology 88:1043-1051.

Fleming, T. H., and P. Eby. 2003. Ecology of bat migration. Pages 161-197 in Kunz, T. H. and M. B. Fenton, ed. Bat ecology. University of Chicago Press, Chicago.

Ford, W. M., M. A. Menzel, J. M. Menzel, and D. J. Welch. 2002. Influence of summer temperature on sex ratios in eastern red bats (Lasiurus borealis). American Midland Naturalist 147:179-184.

Fraser, E. E., L. P. McGuire, J. L. Eger, F. J. Longstaffe, and M. B. Fenton. 2012. Evidence of latitudinal migration in tri-colored bats, Perimyotis subflavus. PLoS 
ONE 7:e31419. doi:10.1371/journal.pone.0031419.

Fraser, K. C., T. K. Kyser, R. J. Robertson, and L. M. Ratcliffe. 2008. Seasonal patterns in hydrogen isotopes of claws from breeding wood-warblers (Parulidae): utility for estimating migratory origins. Avian Conservation and Ecology 3:http://www.ace-eco.org/vol3/iss1/art2/.

Fraser, K. C., E. A. McKinnon, and A. W. Diamond. 2010. Migration, diet, or molt? Interpreting stable-hydrogen isotope values in Neotropical bats. Biotropica 42:512-517.

Gonzalez, E., R. Barquez, and J. Arroyo-Cabrales. 2008. Lasiurus cinereus. In: IUCN 2012. IUCN Red List of Threatened Species. Version 2012.1. www.iucnredlist.org.

Hobson, K. A., S. Van Wilgenburg, L. I. Wassenaar, F. Moore, and J. Farrington. 2007. Estimating origins of three species of Neotropical migrant songbirds at a Gulf Coast stopover site: combining stable isotope and GIS tools. Condor 109:256267.

Hofmann, J. E. 2008. Lasiurus borealis. Pages 88-89 in Rice, T. E. ed. Field Manual of Illinois Mammals. Illinois Natural History Survey, Champaign.

Hofmann, J. E. 2008. Lasiurus cinereus. Pages 92-95 in Rice, T. E. ed. Field Manual of Illinois Mammals. Illinois Natural History Survey, Champaign.

Huso, M. M. P. and D. Dalthrop. 2014. A comment on "bats killed in large numbers at United States wind energy facilities." BioScience 64:546-547.

Jain, A. A., R. R. Koford, A. W. Hancock, and G. G. Zenner. 2010. Bat mortality and activity at a northern Iowa wind resource area. American Midland Naturalist 165:185-200.

Kalka, M. B., A. R. Smith, and E. K. V. Kalko. 2008. Bats limit arthropods and herbivory in a tropical forest. Science 320:71.

Langin, K. M., R. W. Reudink, P. P. Marra, D. R. Norris, T. K. Kyser, and L. M. Ratcliffe. 2007. Hydrogen isotopic variation in migratory bird tissues of known origin: implications for geographic assignment. Oecologia 152:449-457.

Mager, K. J., and T. A. Nelson. 2001. Roost-site selection by eastern red bats (Lasiurus borealis). American Midland Naturalist 145:120-126.

Mazerolle, D. F., K. A. Hobson, and L. I. Wassenaar. 2005. Stable isotope and bandencounter analyses delineate migratory patterns and catchment areas of Whitethroated Sparrows at a migration monitoring station. Oecologia 144:541-549.

McGuire, L. P., C. G. Guglielmo, S. A. Mackenzie, and P. D. Taylor. 2012. Migratory stopover in the long-distance migrant silver-haired bat, Lasionycteris noctivagans. Journal of Animal Ecology 81:377-385.

O’Keefe, J. M., S. C. Loeb, J. D. Lanham, and H. S. Hill Jr. 2009. Macrohabitat factors affect day roost selection by eastern red bats and eastern pipistrelles in the southern Appalachian Mountains, USA. Forest Ecology and Management 257:1757-1763.

Ossa, G., S. Kramer-Schadt, A. J. Peel, A. K. Scharf, and C. C. Voigt. 2012. The movement ecology of the straw-colored fruit bat, Eidolon helvum, in SubSaharan Africa assessed by stable isotope ratios. PLoS ONE 7:e45729. doi:10.1371/journal.pone.0045729. 
Perry, W. R., and R. E. Thill. 2007. Roost characteristics of hoary bats in Arkansas. American Midland Naturalist 158:132-138.

Popa-Lisseanu, A. G., K. Sörgel, A. Luckner, L. I. Wassenaar, C. Ibáñez, S. KramerSchadt, M. Ciechanowski, T. Görföl, I. Niermann, G. Beuneux, R. W. Mysłajek, J. Juste, J. Fonderflick, D. H. Kelm, D. D. Voigt. 2012. A triple-isotope approach to predict the breeding origins of European bats. PLoS ONE 7: e30388. doi:10.1371/journal.pone.0030388.

Racey, P.A., and A. C. Entwistle. 2003. Conservation ecology of bats. Pages 682-689 in Kunz, T. H. and M. B. Fenton, ed. Bat ecology. University of Chicago Press, Chicago.

Rocque, D. A., M. Ben-David, R. P. Barry, and K. Winker. 2006. Assigning birds to wintering and breeding grounds using stable isotopes: lessons from two feather generations among three intercontinental migrants. Journal of Ornithology 147:395-404.

Shump Jr., K. A., and A. U. Shump. 1982a. Lasiurus borealis. No. 183 in Mammalian Species. American Society of Mammalogists.

Shump Jr., K. A., and A. U. Shump. 1982b. Lasiurus cinereus. No. 185 in Mammalian Species. American Society of Mammalogists.

Sullivan, A. R., J. K. Bump, L. A. Kruger, and R. O. Peterson. 2012. Bat-cave catchment areas: using stable isotopes $(\delta \mathrm{D})$ to determine the probable origins of hibernating bats. Ecological Applications 22:1428-1434.

Wassenaar, L. I., and K. A. Hobson. 2006. Stable-hydrogen isotope heterogeneity in keratinous materials: mass spectrometry and migratory wildlife tissue subsampling strategies. Rapid Communications in Mass Specitrometry 20:25052510.

Whitaker Jr., J. O., and R. E. Mumford. 2009. Lasiurus cinereus. Pages 305-309 in Whitaker Jr., J. O., and R. E. Mumford, ed. Mammals of Indiana. Indiana University Press, Bloomington.

Williams-Guillén, K., I. Perfecto, and J. Vandermeer. 2008. Bats limit insects in a Neotropical agroforestry system. Science 320:70.

Willis, C. K. R., and R. M. Brigham. 2005. Physiological and ecological aspects of roost selection and reporoduction female hoary bats (Lasiurus cinereus). Journal of Mammalogy 86:85-94.

Winhold, L., A. Kurta, and R. Foster. 2008. Long-term change in an assemblage of North American bats: are eastern red bats declining? Acta Chiropterologica 10:359-366.

Wunder, M. B., C. L. Kester, F. L. Knopf, and R. O. Rye. 2005. A test of geographic assignment using isotope tracers in feathers of known origin. Oecologia 144:607-617. 
CHAPTER II

DEUTERIUM RATIO DIFFERENCES IN BAT HAIR AND CLAW TISSUES 


\section{Introduction}

Deuterium is a heavy isotope of hydrogen, and its chemical behavior is slightly different from hydrogen due to physical properties related to the heavier atomic mass (Ben-David and Flaherty 2012). It falls in precipitation as a ratio with hydrogen $\left(\delta \mathrm{D}_{\mathrm{p}}\right)$. Deuterium is conserved throughout trophic levels and when consumed is incorporated into tissues during their syntheses. Keratinized tissues are metabolically inert after formation, allowing isotope information of the non-exchangeable hydrogen to remain for long periods of time after the initial deposition in the tissue (Fraser et al. 2010). During analysis, standards are used to calibrate a relationship between exchangeable and non-exchangeable hydrogen allowing for the reporting of only non-exchangeable hydrogen in the samples. Standards are also used as a measure of precision during analysis. An accepted range of deviation among standards is no more than $\pm 2 \%$ (C) Macdonald, University of Wyoming Isotope Laboratory, pers. comm. 2014).

Since deuterium is incorporated into the hair during growth, knowledge of molting patterns is very important. Cryan et al. (2004) suggested that the molt for the Hoary bat is between June and August. A three month molt period is a wide range of time and could be problematic when sampling hair for deuterium analysis if the bats are migrating during the latter part of the summer. Constantine $(1957,1958)$ studied the molting patterns of Mormoops megalophylla senicula (Family Mormoopidae), Tadarida brasiliensis (Family Molossidae) and Myotis velifer (Family Vespertilionidae). He found that their molting pattern begins along the sides and progresses into the scapular site and rump then further inward onto the dorsal surface. Therefore, because molting patterns across different families are similar, I assume that 
the molting pattern of Myotis velifer, which is in the same family as the Eastern Red and Hoary bats, is the same for those species. Bats molt once a year, and the newly molted hair reflects the location in which it was grown. Males typically molt earlier than females (Constantine 1957), and there is evidence that females delay molting until their young are weaned (Cryan et al. 2004).

In previous $\delta \mathrm{D}$ studies using bat hair $\left(\delta \mathrm{D}_{\mathrm{h}}\right)$, sampling was done from the scapular site (Cryan et al. 2004, Britzke et al. 2009, Fraser et al. 2010). According to Constantine's molting diagrams $(1957,1958)$, that site is one of the last to molt. A sample from an unmolted site would include deuterium ratios of the previous year, and it is uncertain if these bats exhibit philopatry. If the bat migrates during molt, it could also cause different sections of the bats to have varying $\delta \mathrm{D}_{\mathrm{h}}$, and sampling a site grown during migration could skew the geographic placement away from the summer range.

Using claw tissue is a way to remove the uncertainty of molting time and pattern. Fraser et al. (2008) found that claws in Neotropical warblers had a change in $\delta \mathrm{D}$ of $-0.4 \%$ per day. This information led to the conclusion that it would take $16-17$ weeks for the claw tip to reflect the $\delta \mathrm{D}$ of the local habitat (Fraser et al. 2008). If this change rate in $\delta \mathrm{D}$ is comparable to bats, then the deuterium in the claw tips of bats salvaged in the autumn would show the $\delta \mathrm{D}$ of the summer roosting areas. Fraser et al. (2010) further studied Neotropical bats and found differences in claw tips and hair deuterium ratios. If bat claw growth is similar to other mammalian claw growth, then the keratinized tissue grows outward and forward in layers from the epidermal germinal matrix. This growth pattern allows for a sampling of a continuous time frame of deuterium deposits instead of hair which only shows the $\delta \mathrm{D}$ at one point of time. The 
claw can be divided into two layers. However, the claw consists of more than one tissue type. The subunguis is a soft keratin that forms the ventral side, and the unguis is a harder keratin that forms the dorsal portion. Once at the tip of the claw, both layers are present (Ethier et al. 2010).

In this study, I investigated differences in hair and claw tissues by first determining if there are significant differences in $\delta \mathrm{D} 1)$ among hair from different body sites, and 2) between hair and claw tissues. The results of this study determined the tissue type and sampling procedure of the remaining bats for the other studies.

\section{Methods}

\section{Hair Sampling}

115 Eastern Red and 74 Hoary bats were salvaged at a central Illinois wind farm in the fall of 2008,2009 , and 2010 and stored in a $-80^{\circ} \mathrm{C}$ freezer. I used dissecting scissors to take $1 \mathrm{~cm}^{2}$ hair samples from the interscapular, dorsal rump, and right dorsolateral site from 10 adult female Hoary bats and 9 adult and 1 subadult females from the Eastern Red bats. I cut as close to the skin as possible, and the scissors were cleaned between each sampling in methanol. There is evidence that females molt later than males (Constantine 1957, Cryan et al. 2004). If the results show no significant difference in the hair samples, then it can be infered that there are no significant differences in hair samples from among the hair sites on males. When sampling, there were some specimens where the right side was not in good condition or there was not enough hair to complete the sample. When this occurred, samples were taken from the left dorsolateral side as molting pattern shows symmetry in the molting of the sides 
(Constantine 1957, 1958). The hair was placed in individually labeled aluminum foil packets while awaiting cleaning.

\section{Claw Sampling}

Claw samples were taken for analysis from the same specimens using dissecting scissors that were cleaned with methanol between each sampling. The same foot was used for each bat, and claws were sampled systematically starting from the most lateral toe. Claws were removed at the third joint of the toe and placed in individually marked aluminum foil packets. In the four cases where the claw was lost during sampling, the next toe was sampled and recorded. For Hoary bats, the claws were large enough that two claw tips could be added together for the appropriate weight. However, in Eastern Red bats the claws were too small and so a larger portion of the claw was used. For this, the section of the claw not covered by an ungual skin fold was taken for analysis because the sections of the claw further back contain bone tissue. To understand differences between tips and this larger section and differences among toes, two more claws were sampled from the Hoary bats and the entire portion of the claw not covered by the ungual skin fold was analyzed.

\section{Isotope Analysis}

Hair and claw samples were cleaned in-house in a 2:1 chloroform:methanol solution to remove surface oils. Wet samples were then dried at $50^{\circ} \mathrm{F}$ to prevent any preferential volatilization of the lighter isotope-containing compounds. They were then weighed and packaged into pressed silver capsules. These procedures followed instructions from the Colorado Plateau Isotope Laboratory of Northern Arizona University and the University of Wyoming Stable Isotope Laboratory. Each hair sample was randomly 
split into two samples during encapsulation, creating duplicates to test the precision of analysis. The claw tips of the first two Hoary bat claws, which are composed of only keratinized tissue, were combined into one sample in order to reach the necessary sampling weight needed for analysis. The two Eastern Red bat claws were much smaller than those of the Hoary bats, and needed to be combined to accomplish the weight threshold. These samples were analyzed by the Colorado Plateau Isotope Laboratory of Northern Arizona University. That lab uses a Thermo-Electron temperature conversion elemental analyzer (TC/EA). They used Keratin-SC Lot SJ (powdered), CBS (Caribou hoof, powdered), and KHS (Kudo horn, powdered) as standards for their analysis. Due to subsequent equipment downtime at the Arizona lab, the remaining Hoary claws and hair samples were analyzed by the University of Wyoming Stable Isotope Laboratory. That lab also uses a TC/EA, but uses different standards, to wit, USGS 42 and 43, UWSIF33 (Turkey), and UWSIF34 (Chicken). The equipment at both labs required the same preparation and similar sample weights for analysis.

\section{Statistics}

The resulting $\delta \mathrm{D}_{\mathrm{k}}$ values were organized as a randomized complete block design to test for differences among tissues (hair vs. claw), differences in claw segments, and body sites of hair on the bats. They were analyzed in SAS 9.3 (SAS institute 2008) using a mixed model ANOVA with a Tukey adjustment to correct for multiple pairwise comparisons. This, however, did not answer the question of whether there is significant variation between the duplicates of hair samples from the same site on the bat itself. A nested ANOVA design was used to compare the duplicate samples within each site of a 
bat and determine if there was significant variation among duplicate samples.

\section{Results}

\section{Hoary Bats}

Table 1 shows the results for the hair and claw samples taken from the 10 adult female Hoary bats. Claw refers to the entire part of the claw that is not covered by an ungual skin fold. The claw tip is the end segment that contains only keratinized tissues. The standard deviations from the University of Wyoming are within the limits of $\pm 2 \%$, a standard held by the laboratories, to ensure reliable analysis. One out of three of the standards from Northern Arizona University had a standard deviation slightly higher (2.7) than this $\pm 2 \%$ o threshold once during the analysis.

The Hoary bat samples showed no significant differences when hair from the dorsolateral site was compared to the rump ( $\mathrm{P}=0.6109)$, the dorsolateral site was compared to the interscapular $(\mathrm{P}=0.9964)$, or when the rump was compared to the interscapular $(\mathrm{P}=0.3950)$. There were also no differences among dorsolateral $(\mathrm{P}=0.9920)$, rump $(\mathrm{P}=0.8860)$, or interscapular $(\mathrm{P}=0.9356)$ hair when compared to claw. There was a significant difference between the claw and the claw tip $(\mathrm{P}=0.0136)$. This claw to claw tip difference is reflected also in an ANOVA (Table 4). There was a significant difference between two hair sample sites when compared to claw tip, the dorsolateral $(\mathrm{P}=0.0025)$ and the interscapular $(\mathrm{P}=0.0009)$. The rump was not significantly different from the claw tips $(\mathrm{P}=0.0869)$ (Table 2). The nested ANOVA found no significant variation among hair samples within each site of the bat $\left(\mathrm{F}_{(3,27)}\right.$ $=1.00, \mathrm{P}=0.4093)$ and no significant variation among sites on a bat $\left(\mathrm{F}_{(2,27)}=1.30\right.$, 
$\mathrm{P}=0.2967)$ (Table 3).

\section{Eastern Red Bats}

Table 5 shows the $\delta \mathrm{D}$ for the tissues sampled from the female Eastern Red bats. These were analyzed in the same manner as the aforementioned Hoary bats. There was no significant variation between samples of the dorsolateral and rump $(\mathrm{P}=0.0532)$, the dorsolateral and interscapular $(\mathrm{P}=0.9989)$, or the rump and interscapular $(\mathrm{P}=0.0724)$. There were also no significant differences when comparing hair site to claw; dorsolateral $(\mathrm{P}=0.2542)$, rump $(\mathrm{P}=0.8502)$, or interscapular $(\mathrm{P}=0.3188)$ (Table 6). The nested ANOVA for variation between samples within sites found no variation between samples of the same site $\left(\mathrm{F}_{(2,27)}=0.56, \mathrm{P}=0.6441\right)$, but did find a marginally significant variation among sample sites on the bats $\left(\mathrm{F}_{(2,27)}=3.65, \mathrm{P}=0.0469\right)$ (Table 7).

\section{Discussion}

Hoary and Eastern Red bats showed a similar pattern in differences of the $\delta \mathrm{D}$ of the hair and claw samples. The lack of difference among the body sites in the analyses suggests that they are finished with molting before migrating in early autumn, and that any part of the body is suitable for the remainder of the study. I therefore concluded that the sites of the body from which to sample hair are not significantly different in either species.

The $\delta \mathrm{D}$ for the claw tip of the Hoary bats was consistently more depleted than the $\delta \mathrm{D}$ for the larger claw segment. There are three possible explanations for this pattern. First, the two types of samples contain different tissues. The claw tip is strictly keratinized tissue, while the larger claw segment additionally contains epithelial and 
blood tissues associated with the terminal matrix. These have faster turnover rates, and that may introduce more local $\delta \mathrm{D}_{\mathrm{p}}$ into the sample resulting in a less depleted, hence less negative, result. The second possibility is that because the claw grows in both an inner-to-outer and back-to-front pattern, the tip is composed of older tissue. This may mean that the tip is referencing more northern latitudes. However, it has also been suggested that the tip may be interpreted as showing the wintering range (Burba 2013). This conflicting interpretation is due to not knowing the true growth rates of claws in bats, but also the fact that isotope ratios shift throughout the year. Many of the areas in the south where Hoary bats overwinter are depleted in $\delta \mathrm{D}_{\mathrm{p}}$ (Bowen and Revenaugh 2003, Bowen et al. 2005), and this signal could be incorrectly interrupted as a northern latitude in the summer. Without knowledge of claw growth rates in bats, it is not possible to know which is correct. A third possibility is that since the tip and claw were analyzed at different laboratories, differences in analytical equipment may have led to some of the variation in $\delta \mathrm{D}$. Considering that the two laboratories used the same types of analytical machines, used the same preparation protocols, and required the same sample weight for analysis, it is unlikely that the significant differences between claw tip and claw are due to the different lab analyses.

When hair and claws were examined together, there was also a pattern. There was no significant difference between the hair of the interscapular and dorsolateral sites and the larger claw segments, but there was a significant difference between those body sites and the claw tip. This supports the findings of Fraser et al. (2010) in Neotropical bats. Although the rump was not significantly different from the claw tip, it was marginal. This could show a tendency for the rump site to be slightly more negative 
than the other sites of the bat and, because the claw tips were the most negative, they are more similar. However, because there was no difference among the hair sample sites, this small lack of difference is not an issue. Because there is a demonstrated correlation between $\delta D_{p}$ and $\delta D_{k}$ (Cryan et al. 2004, Fraser et al. 2012, Ossa et al. 2012, Popa-Lisseanu et al. 2012, Sullivan et al. 2012) and a lack of claw growth rates, I chose hair as the most informative tissue for the next phase of this study. Because there are no significant differences among the body sites, I chose the rump due to its large area and long, dense hair which made for easy sampling and preparation. I took only from this site to maintain consistency throughout my sampling procedure.

\section{Conclusions}

Although the claw tips showed a more negative result, I cannot advise their use at this time since claw growth rates are unknown and we cannot know when the tip tissues were synthesized. It is also unlikely that a larger portion of the claw is of use due to the mixture of tissues and tissue turnover rates. As of now, hair is the best sampling tissue and site of the body is not a significant factor. There is also little variation within the hair of a body sampling site. 


\section{Literature Cited}

Ben-David, M., and E. A. Flaherty. 2012. Stable isotopes in mammalian research: a beginner's guide. Journal of Mammalogy 93:312-328.

Bowen, G. J., and J. Revenaugh. 2003. Interpolating the isotopic composition of modern meteoric precipitation. Water Resources Research 39:DOI:10.1029/2003WR002086.

Bowen, G. J., L. I. Wassenaar, and K. A. Hobson. 2005. Global application of stable hydrogen and oxygen isotopes to wildlife forensics. Oecologia 143:337-348.

Britzke, E. R., S. C. Loeb, K. A. Hobson, C. S. Romanek, and M. J. Vonhof. 2009. Using hydrogen isotopes to assign origins of bats in the eastern United States. Journal of Mammalogy 90:743-751.

Burba, E.A. 2013. Estimating bird/bat fatality rates and using stable-hydrogen isotopes to assess Hoary bat migratory patterns associated with a wind-energy facility in western Oklahoma. PhD Dissertation, University of Oklahoma, Norman, Oklahoma.

Constantine, D. G. 1957. Color variation and molt in Tadarida brasiliensis and Myotis velifer. Journal of Mammalogy 38:461-466.

Constantine, D. G. 1958. Color variation and molt in Mormoops megalophylla. Journal of Mammalogy 39:344-347.

Cryan, P., M. A. Bogan, R. O. Rye, G. P. Landis, and C. L. Kester. 2004. Stable hydrogen isotope analysis of bat hair as evidence for seasonal molt and longdistance migration. Journal of Mammalogy 85:995-1001.

Ethier, D. M., C. J. Kyle, T. K. Kyser, and J. J. Nocera. 2010. Variability in the growth patterns of the cornified claw sheath among vertebrates: implications for using biogeochemistry to study animal movement. Canadian Journal of Zoology 88:1043-1051.

Fraser, E. E., L. P. McGuire, J. L. Eger, F. J. Longstaffe, and M. B. Fenton. 2012. Evidence of latitudinal migration in tri-colored bats, Perimyotis subflavus. PLoS ONE 7:e31419. doi:10.1371/journal.pone.0031419.

Fraser, K. C., T. K. Kyser, R. J. Robertson, and L. M. Ratcliffe. 2008. Seasonal patterns in hydrogen isotopes of claws from breeding wood-warblers (Parulidae): utility for estimating migratory origins. Avian Conservation and Ecology 3:http://www.ace-eco.org/vol3/iss1/art2/.

Fraser, K. C., E. A. McKinnon, and A. W. Diamond. 2010. Migration, diet, or molt? Interpreting stable-hydrogen isotope values in Neotropical bats. Biotropica 42:512-517.

Ossa, G., S. Kramer-Schadt, A. J. Peel, A. K. Scharf, and C. C. Voigt. 2012. The movement ecology of the straw-colored fruit bat, Eidolon helvum, in SubSaharan Africa assessed by stable isotope ratios. PLoS ONE 7: e45729. doi:10.1371/journal.pone.0045729.

Popa-Lisseanu, A. G., K. Sörgel, A. Luckner, L. I. Wassenaar, C. Ibáñez, S. KramerSchadt, M. Ciechanowski, T. Görföl, I. Niermann, G. Beuneux, R. W. Mysłajek, J. Juste, J. Fonderflick, D. H. Kelm, D. D. Voigt. 2012. A triple-isotope approach to predict the breeding origins of European bats. PLoS ONE 7: 
e30388. doi:10.1371/journal.pone.0030388.

SAS Institute. 2008. SAS statistical software, release 9.3. Cary, North Carolina.

Sullivan, A. R., J. K. Bump, L. A. Kruger, and R. O. Peterson. 2012. Bat-cave catchment areas: using stable isotopes $(\delta \mathrm{D})$ to determine the probable origins of hibernating bats. Ecological Applications 22:1428-1434. 
Table 1: $\delta \mathrm{D}(\%)$ of hair and claw samples taken from 10 adult female Hoary bats. (mc139 had no more toes to sample)

\begin{tabular}{ccccccc}
\hline Hoary & \multicolumn{3}{c}{$\delta$ D hair } & \multicolumn{3}{c}{$\delta$ claw } \\
\hline Bat & Dorsolateral & Rump & Interscapular & Claw 3 & Claw 4 & Claw Tip \\
cr14 & -22 & -75 & -37 & -46 & -47 & -66.9 \\
kh27 & -87 & -33 & -60 & -2 & -27 & -80.9 \\
kh3 & -71 & -73 & -31 & -37 & -52 & -87.6 \\
mc138 & -88 & -82 & -32 & -57 & -62 & -80.8 \\
mc139 & -47 & -71 & -29 & na & na & -101.6 \\
mc146 & -27 & -87 & -83 & -88 & -86 & -111.1 \\
mc73 & -24 & -49 & -33 & -60.0 & -60 & -86.2 \\
kh2 & -53 & -58 & -56 & -33 & -32 & -79.1 \\
mc136 & -35 & -31 & -52 & -54 & -58 & -81.2 \\
mc158 & -24 & -67 & -39 & -72 & -72 & -92.1 \\
\hline
\end{tabular}

Table 2: Random Complete Block Design analysis of intrasample variation of Hoary bat body sampling sites. Samples taken from 10 adult females.

\begin{tabular}{cccccc}
\hline Site & Site & DF & t Value & Pr $>|t|$ & Adjusted P \\
\hline dorsolateral & rump & 35 & 1.43 & 0.1606 & 0.6109 \\
dorsolateral & interscapular & 35 & -0.36 & 0.7232 & 0.9964 \\
dorsolateral & claw tip & 35 & 4.03 & 0.0003 & 0.0025 \\
dorsolateral & claw & 35 & 0.44 & 0.6642 & 0.9920 \\
rump & interscapular & 35 & -1.79 & 0.0820 & 0.3950 \\
rump & claw tip & 35 & 2.63 & 0.0127 & 0.0869 \\
rump & claw & 35 & -0.92 & 0.3622 & 0.8860 \\
interscapular & claw tip & 35 & 4.38 & 0.0001 & 0.0009 \\
interscapular & claw & 35 & 0.78 & 0.4425 & 0.9356 \\
claw tip & claw & 35 & -3.40 & 0.0017 & 0.0136 \\
\hline
\end{tabular}

Table 3: Hoary bat nested ANOVA analysis of intrasample variation of hair samples within a sampling site. Samples taken from 10 adult females.

\begin{tabular}{cccc}
\hline Source & DF & F Value & Pr $>$ F \\
\hline site & 2 & 1.30 & 0.2967 \\
sample(site) & 3 & 1.00 & 0.4093 \\
Bat & 9 & 0.72 & 0.6853 \\
bat*site & 18 & 13.94 & $<0.0001$ \\
\hline
\end{tabular}

Table 4: ANOVA analysis of 10 adult female Hoary bats for differences between claws of separate toes and differences among claws and the claw tips.

\begin{tabular}{cccc}
\hline Contrast & DF & F Value & Pr $>$ F \\
\hline Claw A vs. Claw B & 1 & 0.38 & 0.5446 \\
Claws A,B vs. Tip & 1 & 91.76 & $<.0001$ \\
\hline
\end{tabular}


Table 5: $\delta \mathrm{D}(\%)$ of hair and claw samples taken from 9 adult female Eastern Red bats. (mc30 is a subadult)

\begin{tabular}{ccccc}
\hline Eastern Red & \multicolumn{3}{c}{$\delta$ D hair } & D claw \\
\hline Bat & dorsolateral & rump & interscapular & Claw \\
mc53 & -40 & -29 & -36 & -53.2 \\
kh5 & -66 & -83 & -32 & -52.9 \\
mc13 & -28 & -60 & -43 & -44.7 \\
mc144 & -23 & -102 & -58 & -62.6 \\
mc57 & -26 & -56 & -49 & -58.1 \\
mc30 & -55 & -101 & -24 & -105.0 \\
mc42 & -57 & -56 & -25 & -58.5 \\
mc51 & -67 & -83 & -34 & -64.2 \\
mc58 & -23 & -33 & -87 & -41.8 \\
mc67 & -58 & -83 & -68 & -71.2 \\
\hline
\end{tabular}

Table 6: Random Complete Block Design analysis of intrasample variation of 9 adult female Eastern Red bat body sampling sites.

\begin{tabular}{cccccc}
\hline Site & Site & DF & t Value & $\operatorname{Pr}>|t|$ & Adjusted P \\
\hline dorsolateral & rump & 27 & 2.71 & 0.0116 & 0.0532 \\
dorsolateral & interscapular & 27 & 0.14 & 0.8861 & 0.9989 \\
dorsolateral & claw & 27 & 1.89 & 0.0690 & 0.2542 \\
rump & interscapular & 27 & -2.56 & 0.0162 & 0.0724 \\
rump & claw & 27 & -0.81 & 0.4263 & 0.8502 \\
interscapular & claw & 27 & 1.75 & 0.0915 & 0.3188 \\
\hline
\end{tabular}

Table 7: Eastern Red bat nested ANOVA analysis of intrasample variation of hair samples within a sampling site. Samples taken from 9 adult Eastern Red bats

\begin{tabular}{cccc}
\hline Source & DF & F Value & Pr $>$ F \\
\hline site & 2 & 3.65 & 0.0469 \\
sample(site) & 3 & 0.56 & 0.6441 \\
bat & 9 & 0.71 & 0.6948 \\
bat*site & 18 & 129.78 & $<.0001$ \\
\hline
\end{tabular}


CHAPTER III

DETERMINATION OF GEOGRAPHIC EXTENTS OF SOURCE POPULATIONS

OF HOARY (LASIURUS CINEREUS) AND EASTERN RED (LASIURUS BOREALIS)

BATS KILLED AT A CENTRAL ILLINOIS WIND FACILITY 


\section{Introduction}

Agricultural fields in the Midwest of the United States can kill an estimated 4.45-7.14 bats per turbine per year (Jain et al. 2010). The Eastern Red and Hoary bats comprised 20.0-60.9\% and 9.0-88.1\% of fatalities at wind facilities, respectively, across the contiguous United States (Arnett et al. 2007).

There is evidence (Winhold et al. 2008) that the Eastern Red bats are showing signs of decline. In a paired netting survey that took place in 1978-1979 and then again in 2004-2006, they reported overall a 52-85\% decline in netting captures per night. This has the potential to have significant influence not only on the ecosystem but also the agricultural economy. It is estimated that bats can save U.S. agriculture $\$ 22.9$ billion per year through decreasing insect pest populations, reducing the cost of pesticide use (Boyles et al. 2011). With their impact on ecosystems and economies, the loss of bat populations is a phenomenon that needs to be further understood.

Estimating populations of bat species can be problematic for various reasons. The Eastern Red and Hoary bats are largely solitary for much of the year, even during the pupping season when many other species form large maternity colonies. It is this solitary behavior that makes censuses of these two species difficult (Whitaker Jr. and Mumford 2009). Banding studies have been attempted in bats, but recapture rates of banded individuals are extremely rare, making the amount of information gathered considerably less than the effort and cost involved. Radio transmitters have also been attempted, but models light enough to be carried by bats without disrupting their behaviors or putting them at risk do not have enough range for migratory species (Cryan et al. 2004). It is these difficulties that make deuterium ratio analysis an 
enticing method for migration studies of bats, especially when coupled with the large sample sizes available from wind turbine mortality.

Deuterium, a heavy form of hydrogen, can be used in migration studies if the organism moves between sites of different deuterium:hydrogen ratios $(\delta \mathrm{D})$. It can then provide a way to reconstruct their movements through time (Bowen et al. 2005). Many researchers have utilized deuterium in keratinized tissues $\left(\delta \mathrm{D}_{\mathrm{k}}\right)$ to track migrating birds to their seasonal geographic origins using feathers and other tissues (Hobson et al. 2007, Mazerolle et al. 2005, Wunder et al. 2005, Rocque et al. 2006, Langin et al. 2007, Fraser et al. 2008, De Ruyck et al. 2013). It has also been increasing in popularity as a method to track migration and distribution patterns of bats (Britzke et al. 2009, Fraser et al. 2010, Fraser et al. 2012, Ossa et al. 2012, PopaLisseanu et al. 2012, Sullivan et al. 2012). However, $\delta D_{k}$ does not reflect deuterium levels of precipitation $\left(\delta \mathrm{D}_{\mathrm{p}}\right)$ at a one-to-one ratio. Due to multiple fractionation events in the food web, tissue levels typically are more depleted that precipitation levels (Fraser et al. 2010). Even with this phenomenon, the use of deuterium has been effective for many wildlife forensic studies (Bowen et al. 2005). One of the ways this discrimination can be compensated for is through the use of regression equations that convert $\delta \mathrm{D}_{\mathrm{k}}$ values to $\delta \mathrm{D}_{\mathrm{p}}$ values which can then be mapped onto a deuterium precipitation isoscape.

Cryan et al. (2004) sampled hair from 265 live and museum specimen Hoary bats and created a regression model that correlated deuterium in the bats' hair $\left(\delta \mathrm{D}_{\mathrm{h}}\right)$ with $\delta \mathrm{D}_{\mathrm{p}}, \delta \mathrm{D}_{\mathrm{p}}=\delta \mathrm{D}_{\mathrm{h}}+24.81 / 0.7884$. This technique was also used more recently by Ossa et al. (2012). They used six non-migratory species and sampled in a similar way 
to Cryan et al. (2004). They had mixed correlations between $\delta \mathrm{D}_{\mathrm{h}}$ and $\delta \mathrm{D}_{\mathrm{p}}$, with some exhibiting a positive correlation and some with none or a negative correlation. Even with these differences, they derived a regression equation from the six species $\left(\delta \mathrm{D}_{\mathrm{p}}=35.7+0.66^{*} \delta \mathrm{D}_{\mathrm{h}}\right)$ that had a significant slope. They discussed several possible explanations for the mixed results, notably small sample size, high variability in $\delta \mathrm{D}_{\mathrm{p}}$ within a sampling location, using annual $\delta \mathrm{D}_{\mathrm{p}}$ instead of the $\delta \mathrm{D}_{\mathrm{p}}$ for the molting months, and/or the bats being more prone to migration movements than believed. Fraser et al. (2012) used museum specimens of Tri-colored bats (Perimyotis subflavus), a North American species, to conduct deuterium ratio analysis and to determine their molting period. They derived quadratic regression equations linking $\delta \mathrm{D}_{\mathrm{h}}$ and $\delta \mathrm{D}_{\mathrm{p}}$ for males $\left(\delta \mathrm{D}_{\mathrm{h}}=-0.036 * \delta \mathrm{D}_{\mathrm{p}}{ }^{2}-1.789 * \delta \mathrm{D}_{\mathrm{p}}-45.607\right)$ and females $\left(\delta \mathrm{D}_{\mathrm{h}}=-0.034 * \delta \mathrm{D}_{\mathrm{p}}{ }^{2}-1.606 * \delta \mathrm{D}_{\mathrm{p}}-40.375\right)$ separately. Although the equation from Ossa et al. (2012) was made using six species, these four different equations suggest that the relationship between $\delta \mathrm{D}_{\mathrm{h}}$ and $\delta \mathrm{D}_{\mathrm{p}}$ might be different for each species.

In this study, I examined the geographic extents of specimens killed at a single wind facility in central Illinois. The analysis determined how much of their summer range is affected by the mortality and gave insight into the migratory behaviors of the Eastern Red and Hoary bats that migrate through central Illinois in the autumn. The extents also showed possible areas where multiple bats originated and how much of the summer range is overlapped by males and females of the same species. These analyses increased the understanding of the migratory behaviors of these bats and give insight into mortality patterns and possible effects. To do this, deuterium isoscapes were constructed using Isoscapes Modeling, Analysis, and 
Prediction (http://www.isomap.org), a web-based isotope model building program.

The bats were mapped onto the isoscape, and the resulting isotope extent maps were then refined by using summer range predictions developed by the Genetic Algorithm for Rule-set Prediction (GARP), a machine-learning based analytical package for ecological niche modeling.

Isomap.org uses a spatial interpolation method because there are many areas around the world where isotopic data is unavailable. Models are created using deuterium ratio as the dependent variable and a series of independent variables such as latitude, longitude, precipitation and elevation. Depending on the focus of the research, some independent variables are more useful than others. The models can also be tailored to the study's temporal and geographic focus by selecting data from certain months and years and different parts of the world. As models are created, the researcher can explore each one to compare the P-values of model variables and residual plots of both the regression and geostatistical models and decide which variables are significant to the model and therefore appropriate for their project. These models are then used to create the isoscapes (Figure 1). It is also possible, using the assignment tool, to assign $\delta \mathrm{D}$ values of tissue samples to geographic origin with their statistical uncertainties on the isoscapes. This tool uses Bayes theorem, which was used instead of simple regression in migration studies by Wunder et al. (2005) to evaluate the probability of sample origin. It uses the isoscape selected by the user and the isotopic ratio and standard deviation associated with the sample to map the probability of origin (Bowen et al. 2013). The resulting map gives the percent probability that the specimen originated from each individual pixel. 
GARP predicts the geographic extents of organisms and has been highly useful for estimating ranges of various vertebrate species (Peterson et al. 2002, McNyset 2005, Kostelnick et al. 2007). GARP uses known species occurrence data in the form of geographic coordinates and chosen environmental raster data sets to predict an ecological niche for a species. Peterson et al. (2002) found that GARP was robust in species prediction even when there were a low number of species occurrence points to create the model. It works using a process of repeating steps: rule selection, evaluation, testing and, based on that rule's performance, integration or rejection. This process is done using a subset of the species' occurrence data, the training data. A second subset is used to test that prediction (Peterson et al 2002). These variables are then subjected to a rule-based prediction system of if-then relationships. Each rule is tested for its importance in the prediction through a $\chi^{2}$ test that looks at the probability differences of predicting the presence or absence of the species in question. The probability of presence and absence is tested before the rule is applied and after application (Stockwell and Peters 1999). The tested occurrence data can then test the overall accuracy of the prediction model. GARP performs these rule-based predictions for 20 iterations. Following these tests, a " 10 best model set" is selected by GARP and typically summed to generate a raster grid ranging from 0 (i.e., 0 of 10 models predicted presence) to 10 (10 of 10 models predicted presence).

These two methods, deuterium stable isotope analysis and GARP, have been used in the past to answer questions about migration and/or species' ranges. Using isoscapes alone is limited because the longitudinal range of each isotopic extent is very wide and is most helpful for limiting latitudinal possibilities. To alleviate this 
problem, researchers must use other methods to decrease the potential extents. Van Wilgenburg and Hobson (2011) combined deuterium with band recovery to assign migrant birds to their geographic origins. Hobson et al. (2007) used GIS to combine known breeding ranges with deuterium analysis to estimate origins of migrating songbirds. Mazerolle et al. (2005) combined band recovery, deuterium, and breeding range data to understand migratory movements of White-throated Sparrows. For Hoary and Eastern Red bats, the known ranges are generalized and lack seasonal detail. There is also a lack of band recovery information due to the difficulty in recovering banded bats (Cryan et al. 2004). GARP has the capabilities of estimating ranges for species during specific times of the year. In this study, it is essential that the species' ranges are specific to the summer months when they are molting. GARP's ability to do this decreases the longitudinal range by restricting the isotopic assignment to the eastern and western boundaries of the species' summer ranges. Peterson et al. (2002) used GARP to predict distributions of 25 species of Mexican birds. Kostelnick et al. (2007) estimated suitable Black-tailed Prairie Dog (Cynomys ludovicianus) habitat using GARP, and GARP was used by McNyset (2005) to predict distributions of 12 freshwater fish species. The combination of these two model methods in this study (GARP and Isomap) is a novel technique that provides a better understanding of the bats' geographic extents than either could provide separately. 


\section{Methods}

\section{Isoscape Development and Assignment}

I used Isomap.org to develop an interpolated $\delta \mathrm{D}_{\mathrm{p}}$ model using latitude and elevation as independent variables. This involved data collected from 452 stations throughout the Northern Hemisphere from 1960 to 2010, June through August (U.S. National Geophysical Data Center 1998, Welker 2000, IAEA/WMO 2011). More years than the time period that covered bat sampling (2008-2010) were used in the model creation to decrease any bias created by short-term climate variation in those three years (Bowen and Revenaugh 2003). Results of Fraser et al. (2012) also supports the use of long-term isotope data in building isoscapes for migration studies. Once the years of data, independent and dependent variables, and the geographic area were selected, I submitted all the variables into the Isomap precipitation modeling program. Upon completion, the P-values of each variable and the residuals for both the regression and geostatistical models were checked for their significance in the model. The model was then used to create the isoscape that was imported into ArcMap 10.2 (Figure 1).

\section{GARP Model Development}

I chose the environmental variables for the GARP models based on literature about Eastern Red and Hoary bat habitat requirements and on the availability of continentwide or global data sets. Detailed information on each data set can be found in Table 12. The environmental data included $1-\mathrm{km}$ global average monthly precipitation and temperature which were generated by interpolating climate data from weather stations around the world using a 30 arc-second grid (Hijmans et al 2005). These variables 
were selected because precipitation and temperature are key factors in determining vegetation and insect species of an area. There is also evidence that temperature is an important factor in summer area selection by both male and female Eastern Red bats (Ford et al. 2002). This data was imported through WorldClim, a free climate data website for ecological modeling and GIS (http://www.worldclim.org/). A North America 1-km digital elevation model (DEM) (NASA et al. 2010) was also used and imported through Data Basin (http://databasin.org/datasets/d2198be9d2264de19cb93fe6a380b69c). The last environmental data was Global Map-Percent Tree Cover at 1-km resolution, developed from the MODIS images from the Terra satellite (ISCGM 2008), and imported through the ISCGM Global Map Data Download Service (http://www.iscgm.org/gmd/download/ptc.html) (Table 12). Elevation and percent tree cover were selected as important variables because Willis and Brigham (2005) found that when females have pups, they tend to choose roosts that are below 1,200 meters in elevation and that the percentage of canopy cover was also an important factor for maternity roost site selection (Willis and Brigham 2005).

Precipitation and temperature were imported into ArcMap10 as separate months, and new rasters were created using the raster calculator tool to find the average precipitation and temperature of June, July, and August to show the average precipitation during the time when the bats are most likely in molt (Cryan et al. 2004). Percent tree cover was imported as multiple rasters and mosaicked together to form a single data file. A DEM raster file was then imported and clipped using the raster clip tool in ArcMap to create a raster that had an extent that only included the continental 
North America. I then projected all of the environmental rasters into the WGS 1984 World Mercator projection coordinate system, making sure that the cell size $(1 \mathrm{~km})$ was the same for each. This projection was chosen because the study area encompassed the North American continent, and many of the environmental raster files could be easily converted. Although the Mercator projection distorts area, because this study focuses on the proportions of areas (Isotope-determined area: GARP-predicted area) and not simply on specific areal measurements of a species' range, each raster is distorted the same amount and therefore the distortion had no effect on the final results. Once projected, each data file was then clipped to the same geographic extent using the DEM raster as a mask, a requirement for GARP.

To create the training and testing points for the model, specimen occurrence data were downloaded from the Mammal Networked Information System (MaNIS.org). Only specimen data for Lasiurus borealis borealis (Wieczorek 2001a) and Lasiurus cinereus cinereus (Wieczorek 2001b) were used. This prevents any of the specimens of the Western Red bat (Lasiurus borealis teliotis), found on the west coast of the U.S., or the Hawaiian Hoary bat (Lasiurus cinereus semotus), found only in Hawaii, from being part of the GARP model. Separate datasets were created that only had these specimens from June, July, and August to develop the summer ranges, and any records where sex or coordinates were unknown were removed. The species' files were used to create $(x, y)$ coordinate shapefiles. These files were then projected into the same projection as the environmental dataset and the coordinates transformed from latitude/longitude coordinates into meters, the coordinate system of the WGS 1984 World Mercator projection. The Geostatistical toolbar was used to randomly 
assign points either to be used to create the GARP model or test it later in ArcMap, with $80 \%$ in training and $20 \%$ in testing (Figures 2-3). The rasters and training points were then uploaded into GARP, which also randomly splits the occurrence points into $80 \%$ training and $20 \%$ testing points for internal model training and testing to insure the most statistically sound results. Once the models were completed, each model was converted to a raster, and the ten were added together using map algebra (Figures 45). The results displayed the areas where $9-10$ of the best 10 models agreed was suitable summer habitat. The models were then relabeled to be either unsuitable or suitable. Only areas where 9-10 out of the best 10 model set agreed were considered suitable. All other areas were labeled unsuitable and not used in later mapping. The testing points that were randomly separated from the GARP training points before the model were then added. The Extract Values to Points tool was used to determine how many occurrence points were within pixels that had been determined to be suitable habitat.

\section{Sampling and Analysis}

Based on the study described in Chapter 2, I took hair samples from the rump. I sampled 27 adult Eastern Red bats (24 males, 2 females, 1 unknown) and 34 adult Hoary bats ( 23 males, 7 females, 4 unknowns). I was selective in my choice of salvaged specimens and did not sample those that were highly decayed or had severe damage to the body. For many, the amount of decay and drying caused the hair to fall off the body. There were also several bats that suffered loss of skin and fur on their backs. Both of these factors would have made sampling from the selected region difficult and prone to error. I sampled a $1 \mathrm{~cm}^{2}$ section of hair from each specimen and 
cleaned, weighed, and packaged it as described in the previous chapter. These were then sent to the University of Wyoming Stable Isotope Laboratory for $\delta \mathrm{D}_{\mathrm{h}}$ analysis, and every third sample was duplicated to ensure precision in the analysis.

The resulting $\delta \mathrm{D}_{\mathrm{h}}$ values were then examined, and the Hoary bat values were converted to $\delta D_{p}$ using the regression equation derived from Cryan et al. (2004): $\delta \mathrm{D}_{\mathrm{p}}=\delta \mathrm{D}_{\mathrm{h}}+24.81 / 0.7884$. This equation was not used for the Eastern Red bats because the studies by Cryan et al. (2004), Ossa et al. (2012), and Fraser et al. (2012) suggest that these regression equations might be different for each species. The converted Hoary bat ratios and raw Eastern Red bat ratios that were both analyzed with duplicates were then analyzed statistically with ANOVA to determine if there were significant differences within the samples among the bats (SAS Institute 2008). Raw and converted $\delta \mathrm{D}_{\mathrm{h}}$ and sample duplicates for Hoary bats are in Tables 8-9. Raw $\delta \mathrm{D}_{\mathrm{h}}$ and sample duplicates for Eastern Red bats are in Tables 10-11.

The $\delta \mathrm{D}_{\mathrm{h}}$ of these bats and those of the bats from the previous study were then mapped individually by the Isomap.org assignment tool. With these, there were a total of 11 adult female $(2+9$ from previous study) and 24 adult male Eastern Red bats, and 17 adult female $(7+10$ from previous study) and 23 adult male Hoary bats. Each assignment map was then imported into ArcMap 10.2 and converted from an ASCII file to a raster file. Not all bats were used to create the origin maps. Of the female Hoary bats, 3 were not used due to extremely enriched deuterium ratios, a possible contamination of the sample, and 1 male adult Hoary was not used in mapping due to this same uncertainty. Of the female Eastern Red bats, 1 was excluded due to her status of being a subadult and 2 were not used due to extremely enriched $\delta \mathrm{D}_{\mathrm{h}}$. The 
subadult was not used because there is some evidence of differences in deuterium ratios between adults and juveniles in birds (De Ruyck et al. 2013), such as in juvenile Merlins (Falco columbarius) which have deuterium ratios placing them far outside the breeding range for the species (Wittenberg et al. 2013). For male Eastern Red bats, 7 samples were not mapped due to extremely enriched $\delta D_{h}$ (see Appendix for maps of all bats not used due to extremely enriched deuterium ratios). A reason for not using the bats with the highly enriched $\delta \mathrm{D}_{\mathrm{h}}$ is that I could not be certain that contamination did not occur with these samples. Although diet affects the $\delta \mathrm{D}_{\mathrm{h}}$ and the enriched $\delta \mathrm{D}_{\mathrm{h}}$ could have been caused by a diet rich in insects from aquatic habitats (Britzke et al. 2009), I had no certain biological explanation for these enriched samples. The 5 bats that had unassigned sexes were not used in mapping because it was suggested by Britzke et al. (2009) that combining the sexes should be avoided. Those without an assigned sex risked being mapped with the wrong group. Therefore, 14 female Hoary, 22 male Hoary, 9 female Eastern Red, and 17 male Eastern Red bats were used to create the resulting maps (Table 13).

The maps were then each reclassified so that only the pixels of highest probability were given a value of 1 for present; all other pixels were assigned a 0 for absent. Reclassified rasters of the same species and sex were then added together in the raster calculator, and the resulting isotope prediction maps were then projected into the WGS 1984 World Mercator projection so that they would overlay with the GARP range models (Figure 6). The GARP maps were reclassified and multiplied by the resulting species and sex specific isotope prediction maps. This allowed for pixels covered both by the isotope prediction map and GARP map to be distinguished from 
all other pixels and for the isotope prediction map to be clipped to probable summer ranges. The resulting maps are in Figures 7-10.

These were then reclassified again so that pixels were either 0 (absent) or 1 (present) and overlaid onto the GARP models. The proportion of the range affected by the wind facility was determined by the proportion of the GARP range covered by the isotope geographic extents. This was done by a simple ratio of the number of pixels given the assignment of presence in the isotope raster to the number of pixels assigned presence in the GARP range raster (Figures 11-14). I also added the maps of males and females together, keeping species separate, to determine the amount of overlap in extents between the sexes by the proportion of overlapping pixels:nonoverlapping pixels (Figures 15-16).

\section{Results}

Table 8 shows the raw $\delta \mathrm{D}_{\mathrm{h}}$ and converted $\delta \mathrm{D}_{\mathrm{h}}$ to $\delta \mathrm{D}_{\mathrm{p}}$ for the Hoary bat hair samples. Table 10 shows the raw $\delta \mathrm{D}_{\mathrm{h}}$ for the Eastern Red bat hair samples. The results of these analyses had low standard deviation within the standards used by the University of Wyoming as follows: USGS42, 0.5; USGS43, 0.4; UWSIF33, 1.0; UWSIF34, 1.0. These are all within the $\pm 2 \%$ range to ensure reliability of the analysis (C. Macdonald, University of Wyoming Isotope Laboratory, pers. comm. 2014). When duplicates were analyzed, there were significant differences among the samples for both the Eastern Red and Hoary bats (Eastern Red: $\mathrm{F}_{(1,12)}=15.60, \mathrm{P}=0.0019$; Hoary: $\left.F_{(1,7)}=14.91, P=0.0062\right)$. When the differences were further investigated, the average difference in the Hoary bat samples was 0.875 (minimum=0; maximum=2.0). For the 
Eastern Red bat samples, the average difference was 1.0 (minimum=0; maximum=3.0).

The results of the GARP models can be seen in Figures 4-5. They show the resulting best 10 models developed and the resulting predicted summer range for both species. In testing the GARP models with the testing points shown in Figures 2 and 3, I found that the model accurately predicted the presence of the bats $98.93 \%$ of the time for Hoary bats and $96.85 \%$ of the time for Eastern Red bats. In cases where they were not, the specimens occurred within 1-3 pixels of a predicted area.

The female Hoary bats' isotope-generated extent covered $73.87 \%$ of their predicted summer range (Figure 11). The male Hoary bats' extent covered $64.40 \%$ of their predicted summer range (Figure 12). Female Eastern Red bats' extent covered $54.15 \%$ of their predicted summer range (Figure 13), and male Eastern Red bats' extent covered $72.33 \%$ of their predicted summer range (Figure 14). Male and female Hoary bats overlapped $45.13 \%$ of their extents (Figure 15). Male and female Eastern Red bats overlapped $63.49 \%$ of their extents (Figure 16). The map for female Hoary bats showed an area where 6 out of the 13 bats overlapped in their extents (Figure 7). Out of the 20 male Hoary bat specimens mapped, 16 bats overlapped in extents (Figure 8). In the female Eastern Red bats, there were portions of the map where 4 out of the 10 bats mapped overlapped their extents (Figure 9). Out of 19 male bats, 9 specimens overlapped in their extents (Figure 10). 


\section{Discussion}

When a subsample of the specimens was analyzed with their duplicates, there was a significant difference between them (Hoary $\mathrm{F}_{(1,7)}=14.91, \mathrm{P}=0.0062$, Eastern Red $\left.F_{(1,12)}=15.60, P-0.0019\right)$. However, the amount of difference (Hoary, 0.875; Eastern Red, 1.0) is within the accepted range of variability expected within biological samples due to natural variability within growing tissues. Chickens fed a homogeneous diet still had differences within feather samples, and it was determined that a variation of $\pm 3 \%$ was to be expected due to laboratory measurements and metabolic effects (Wassenaar and Hobson 2006). Variability within samples is most common in tissues like hair, which are difficult to pulverize into a homogeneous powder.

The equation $\left(\delta \mathrm{D}_{\mathrm{p}}=\delta \mathrm{D}_{\mathrm{h}}+24.81 / 0.7884\right)$ for Hoary bats by Cryan et al. (2004), used to convert $\delta \mathrm{D}_{\mathrm{h}}$ to $\delta \mathrm{D}_{\mathrm{p}}$, was not used for the Eastern Red bats. Ossa et al. (2012) did a similar study using 6 species and developed very a different regression equation, suggesting that the relationship between $\delta \mathrm{D}_{\mathrm{h}}$ and $\delta \mathrm{D}_{\mathrm{p}}$ may be species specific. I cannot assume that because the Hoary bat and Eastern Red bat are within the same genus that they would have the same discrimination of deuterium in their tissues. For this study, I did not have enough salvaged specimens during their molting period, and it was beyond the scope of this project to gather samples from other collections across the country to develop a regression model for the Eastern Red bats. However, this does not affect the conclusion regarding the proportion of range or yearly and monthly overlap of extents. It only shifts the mapped range north or south depending on whether the tissue is more enriched or depleted in deuterium than the precipitation. 
The success of the GARP models offers support to this method's use in estimating a species occurrence. For the specimens that were not within a predicted pixel, they were within 1-3 pixels (that is, $1-3 \mathrm{~km}$ ) of the predicted pixel. This error is most likely due to data uncertainty in the environmental dataset and not a function of the model itself. Another potential error is that GARP overestimated the range possibilities and predicted areas where the species would not be found. Based on both possible errors, GARP models are more prone to overestimate than underestimate a range. The success of combining isotope analysis through Isomap with GARP methods supports their use and their ability to be integrated. The advantage of using them together is demonstrated well by the Eastern Red bats. Isotope mapping alone created possible geographic extents that covered the entire continent, but when GARP was implemented with Isomap, these isotope predicted maps were restricted and the geographic extents reflected a more probable extent map.

The female Hoary bats' estimated geographic extents cover $73.87 \%$ of their predicted summer range. It also appears that they are originating north of the wind facility, with many of them coming from near the northern boundary of the U.S. and southern Canada. Although their range extends into the Rocky Mountains and the western coastal states, it is unlikely that they would migrate over the mountains into the Midwest, and then south to their wintering areas. More likely, they originated in the Midwest or Northeast. There is a large expanse of Canada that was a possible geographic extent due to the $\delta \mathrm{D}_{\mathrm{p}}$ of the area, and this very northern part of the range cannot be ruled out as a possible area of origin.

The male Hoary bats' geographic extents show a similar pattern, but with 
some being potentially local summer residents. Their extents cover $64.40 \%$ of their predicted range and dip down into the southern Midwest, and it appears that they moved northward in the autumn. Another explanation is that this is a result of the deuterium isoscape (Figure 1). The location of the wind facility is at the edge of two isoclines, and it is possible that even with the more enriched $\delta \mathrm{D}_{\mathrm{h}}$, they could have originated just a few kilometers south of the wind facility. It is also possible that the enrichment of deuterium in the bats' hair is derived from their diet. If the bats fed on insects from aquatic habitats, their $\delta \mathrm{D}_{\mathrm{h}}$ would not correlate as tightly with $\delta \mathrm{D}_{\mathrm{p}}$. Evaporation causes water in lakes and similar bodies of water to become more deuterium enriched. Insects emerging out of the water would then have a more enriched signature (Britzke et al. 2009), and this would be incorporated into the bat's hair, giving it a seemingly more southern origin.

When the females' and males' extents were added together, they overlapped by $45.13 \%$. This suggests a separation in male and female summer habitats and supports the finding that the males and females of the Hoary bats separate at a continental scale during the pup-rearing season (Cryan 2003). Based on his map of specimen locations, there is a tendency for more females to be in the northern Midwest and Canada, while males are in the western and Midwest regions (Cryan 2003). However, there is substantial overlap and not a distinct geographic area of clear separation.

The female Eastern Red bats' isotope extents covered $54.15 \%$ of their predicted summer range with a likelihood that some may have been local residents during the summer. Because there was no conversion of $\delta \mathrm{D}_{\mathrm{h}}$ to $\delta \mathrm{D}_{\mathrm{p}}$, the location of 
the specimens' extents might not be as reflective of their true extent location as in the Hoary bats. It is likely that the Eastern Red bats' extents are further south because the tissues of Hoary bats are more depleted than the precipitation. The map in Figure 8 shows areas in the northern part of Mexico as possible origins, but this is highly unlikely. The mountains in that area often have depleted $\delta \mathrm{D}_{\mathrm{p}}$ due to the elevation and geological influences on precipitation, and this probably resulted in the inclusion of Mexico as a possible origin area.

Male Eastern Red bats covered $72.33 \%$ of their potential summer range. However, like the male Hoary bats, they have several individuals which had more enriched $\delta \mathrm{D}_{\mathrm{h}}$, and this placed them in the isocline that dips into the southern U.S. (Figure 1), but also comes just south of the wind facility. It is also possible that, like the Hoary bats, this enriched $\delta \mathrm{D}_{\mathrm{h}}$ signature is due to a diet of aquatic insects. Britzke et al. (2009) found potential northern movements of Eastern Red bats, but also noted that the bats' diet may have been the influencing factor, if they consume a large proportion of aquatic insects (Britzke et al. 2009). The male Eastern Red bats' northern restriction is similar to the females and there is a high possibility that some may have been summer residents. As with the female Eastern Red bats, because there was no conversion of $\delta \mathrm{D}_{\mathrm{h}}$ to $\delta \mathrm{D}_{\mathrm{p}}$, the location of concentration might not be as accurate as in the Hoary bats. It is likely that the extent is slightly further south. However, this does not affect conclusions about the portion of the range covered. When male and female extents were added together, they overlapped $63.49 \%$ of their extents. This suggests that they are using the same areas during the puprearing season and supports the findings of Cryan (2003) that males and female are 
dense both in the Midwest and near the Canadian border. They are especially dense in the states of Illinois, Iowa, Wisconsin, and Minnesota.

Maps of all bats that were not mapped due to highly enriched $\delta \mathrm{D}_{\mathrm{h}}$ are shown in Appendix. Although it is possible that these samples were contaminated during the sampling or analysis process, it is also possible that their $\delta \mathrm{D}_{\mathrm{h}}$ signature is due to these individuals displaying unusual movements, having become wayward in their migrations, or having consumed highly enriched prey. However, not adding these bats into the mapping process does not change the overall conclusion that the bats killed at the wind facility in Illinois are coming from a large expanse of their summer range. It would only increase the percent of summer range affected.

\section{Conclusions}

The GARP models' ability to estimate the occurrence of these bats based on the testing points overlapping with predicted pixels suggests that this modeling process is highly accurate and has great potential to predict a species' range. GARP is much more likely to overestimate than underestimate a range and therefore predict the presence of a species where that species does not occur. For this study, such an error makes the maps a more conservative estimate of geographic extents. The success of combining isotope analysis, through Isomap, with GARP methods supports their use and their ability to be integrated.

The large portion of the extents of the males and females of both species shows that the bats killed at a single central Illinois wind facility are coming from across the species' ranges. This suggests that mortality suffered at this single wind 
facility might not have strong impacts on local populations by itself. However, if other wind facilities developed and developing throughout the Midwest display this pattern of widespread source extents, there could be significant cumulative effects of those facilities on multiple populations. The male and female overlap of these two species also shows an interesting pattern. The Hoary bats did not overlap between the sexes as much as the Eastern Red bats. The Eastern Red bats overlapped a larger portion of their range, suggesting they occupy similar areas during the pup-rearing.

This study shows the importance of specimen salvage from these wind facilities, a method underutilized in bat biology. Wind facilities offer a means of sampling specimens that cannot be easily duplicated but can give insight into many different aspects of bat biology, such as migratory timing and pathways, summer roosting grounds, wintering grounds, sex separation, and mating. While the desire is to reduce such mortality, we should not waste the mortality that does occur. 


\section{Literature Cited}

Arnett, E. B., W. K. Brown, W. P. Erickson, J. K. Feidler, B. L. Hamilton, T. H. Henry, A. Jain, G. D. Johnson, J. Kerns, R. R. Koford, C. P. Nicholson, T. J. O’Connell, M. D. Piorkowski, and R. D. Tankersley Jr. 2007. Patterns of bat fatalities at wind energy facilities in North America. Journal of Wildlife Management 72:61-78.

Bowen, G. J., and J. Revenaugh. 2003. Interpolating the isotopic composition of modern meteoric precipitation. Water Resources Research 39:DOI:10.1029/2003WR002086

Bowen, G. J., L. I. Wassenaar, and K. A. Hobson. 2005. Global application of stable hydrogen and oxygen isotopes to wildlife forensics. Oecologia 143:337-348.

Bowen, G. J., L. Zhongfang, H. B. Vander Zanden, L. Zhao, and G. Takahashi. 2013. Geographic assignment with stable isotopes in IsoMAP. Methods in Ecology and Evolution 5:DOI: 10.1111/2041-210X.12147.

Boyles J. G., P. M. Cryan, G. F. McCracken, and T. H. Kunz. 2011. Economic importance of bats in agriculture. Science 332:41-42.

Britzke, E. R., S. C. Loeb, K. A. Hobson, C. S. Romanek, and M. J. Vonhof. 2009. Using hydrogen isotopes to assign origins of bats in the eastern United States. Journal of Mammalogy 90:743-751.

Cryan, P. M. 2003. Seasonal distribution of migratory tree bats (Lasiurus and Lasionycteris) in North America. Journal of Mammalogy 84:579-593.

Cryan, P., M. A. Bogan, R. O. Rye, G. P. Landis, and C. L. Kester. 2004. Stable hydrogen isotope analysis of bat hair as evidence for seasonal molt and longdistance migration. Journal of Mammalogy 85:995-1001.

De Ruyck, C., K. A. Hobson, N. Koper, K. W. Larson, and L. I. Wassenaar. 2013. An appraisal of the use of hydrogen-isotope methods to delineate origins of migratory saw-whet owls in North America. Condor 115:366-374.

Ford, M. W., M. A. Menzel, J. M. Menzel and D. J. Welch. 2002. Temperature on sex ratios in eastern red bats (Lasiurus borealis). American Midland Naturalist 147:179-187.

Fraser, E. E., L. P. McGuire, J. L. Eger, F. J. Longstaffe, and M. B. Fenton. 2012. Evidence of latitudinal migration in tri-colored bats, Perimyotis subflavus. PLoS ONE 7:e31419. doi:10.1371/journal.pone.0031419.

Fraser, K. C., T. K. Kyser, R. J. Robertson, and L. M. Ratcliffe. 2008. Seasonal patterns in hydrogen isotopes of claws from breeding wood-warblers (Parulidae): utility for estimating migratory origins. Avian Conservation and Ecology 3:http://www.ace-eco.org/vol3/iss1/art2/.

Fraser, K. C., E. A. McKinnon, and A. W. Diamond. 2010. Migration, diet, or molt? Interpreting stable-hydrogen isotope values in Neotropical bats. Biotropica 42:512-517.

ISCGM. 2008. Global Map-Percent Tree Cover. Geospatial Information Authority of Japan, China University and collaborating organizations.

Hijmans, R.J., S.E. Cameron, J.L. Parra, P.G. Jones and A. Jarvis. 2005. Very high resolution interpolated climate surfaces for global land areas. International 
Journal of Climatology 25:1965-1978.

Hobson, K. A., S. Van Wilgenburg, L. I. Wassenaar, F. Moore, and J. Farrington. 2007. Estimating origins of three species of Neotropical migrant songbirds at a Gulf Coast stopover site: combining stable isotope and GIS tools. Condor 109:256267.

International Atomic Energy Agency and World Meteorological Organization. 2011. Global Network of Isotopes in Precipitation. The GNIP Database.

Jain, A. A., R. R. Koford, A. W. Hancock, and G. G. Zenner. 2010. Bat mortality and activity at a norhtern Iowa wind resource area. American Midland Naturalist 165:185-200.

Kostelnick, J. C., D. L. Peterson, S. L. Egbert, K. M. McNyset, and J. F. Cully. 2007. Ecological niche modeling of black-tailed prairie dog habitats in Kansas. Transactions of the Kansas Academy of Science. 110:187-200.

Langin, K. M., R. W. Reudink, P. P. Marra, D. R. Norris, T. K. Kyser, and L. M. Ratcliffe. 2007. Hydrogen isotopic variation in migratory bird tissues of known origin: implications for geographic assignment. Oecologia 152:449-457.

Mazerolle, D. F., K. A. Hobson, and L. I. Wassenaar. 2005. Stable isotope and bandencounter analyses delineate migratory patterns and catchment areas of Whitethroated Sparrows at a migration monitoring station. Oecologia 144:541-549.

McNyset, K. M. 2005. Use of ecological niche modelling to predict distributions of freshwater fish species in Kansas. Ecology of Freshwater Fish 14:243-255.

National Aeronautics and Space Administration, the United Nations Environment Program/Global Resource Information Database, U.S. Agency for International Development, Instituto Nacional de Estadistica Geografica e Informatica of Mexico, Geographical Survey Institute of Japan, Manaaki Whenua Landcare Research of New Zealand, and Scientific Committee on Antarctic Research . 2010. 30 arc-sec DEM North America.

Ossa, G., S. Kramer-Schadt, A. J. Peel, A. K. Scharf, and C. C. Voigt. 2012. The movement ecology of the straw-colored fruit bat, Eidolon helvum, in SubSaharan Africa assessed by stable isotope ratios. PLoS ONE 7: e45729. doi:10.1371/journal.pone.0045729.

Peterson, A. T., L. G. Ball, and K. P. Cohoon. 2002. Predicting distributions of Mexican birds using ecological niche modelling methods. Ibis 144(online):E27E32.

Popa-Lisseanu, A. G., K. Sörgel, A. Luckner, L. I. Wassenaar, C. Ibáñez, S. KramerSchadt, M. Ciechanowski, T. Görföl, I. Niermann, G. Beuneux, R. W. Mysłajek, J. Juste, J. Fonderflick, D. H. Kelm, D. D. Voigt. 2012. A triple-isotope approach to predict the breeding origins of European bats. PLoS ONE 7:e30388. doi:10.1371/journal.pone.0030388.

Rocque, D. A., M. Ben-David, R. P. Barry, and K. Winker. 2006. Assigning birds to wintering and breeding grounds using stable isotopes: lessons from two feather generations among three intercontinental migrants. Journal of Ornithology 147:395-404.

SAS Institute. 2008. SAS statistical software, release 9.3. Cary, North Carolina. Stockwell, D., and D. Peters. 1999. The GARP modelling system: problems and 
solutions to automated spatial prediction. International Journal of Geographical Information Science 13:143-458.

Sullivan, A. R., J. K. Bump, L. A. Kruger, and R. O. Peterson. 2012. Bat-cave catchment areas: using stable isotopes $(\delta \mathrm{D})$ to determine the probable origins of hibernating bats. Ecological Applications 22:1428-1434.

U.S. National Geophysical Data Center. 1998. ETOPO-5 five minute gridded world elevation. NGDC, Boulder, Colorado, U.S.A.

Van Wilgenburg, S. L., and K. A. Hobson. 2011. Combining stable-isotope ( $\delta D)$ and band recovery data to improve probabilistic assignment of migratory birds to origin. Ecological Applications 21:1340-1351.

Wassenaar, L. I., and K. A. Hobson. 2006. Stable-hydrogen isotope heterogeneity in keratinous materials: mass spectrometry and migratory wildlife tissue subsampling strategies. Rapid Communications in Mass Spectrometry 20:25052510.

Welker, J. M. 2000. Isotopic (d180) characteristics of weekly precipitation collected across the USA: an initial analysis with application to water source studies. Hydrological Processes, 14:1449-1464.

Whitaker Jr., J. O., and R. E. Mumford. 2009. Lasiurus cinereus. Pages 305-309 in Whitaker Jr., J. O., and R. E. Mumford, ed. Mammals of Indiana. Indiana University Press, Bloomington.

Wieczorek, J. 2001a. Lasiurus borealis borealis. Mammal Networked Information System (MaNIS), University of California.

Wieczorek, J. 2001b. Lasiurus cinereus cinereus. Mammal Networked Information System (MaNIS), University of California.

Willis, C. K. R., and R. M. Brigham. 2005. Physiological and ecological aspects of roost selection by reproductive female hoary bats (Lasiurus cinereus). Journal of Mammalogy 86:85-94.

Winhold, L., A. Kurta, and R. Foster. 2008. Long-term change in an assemblage of North American bats: are eastern red bats declining? Acta Chiropterologica 10:359-366.

Wittenberg, S. R., S. E. Lehnen, and K. Smith. 2013. Use of stable isotopes of hydrogen to predict natal origins of juvenile Merlins and Northern Harriers migrating through the Florida Keys. The Condor 115:451-455.

Wunder, M. B., C. L. Kester, F. L. Knopf, and R. O. Rye. 2005. A test of geographic assignment using isotope tracers in feathers of known origin. Oecologia 144:607-617. 
Table 8: The raw and converted $\delta \mathrm{D}_{\mathrm{h}}$ for Hoary bat hair. Ratios were converted using Cryan et al. (2004) equation $\delta \mathrm{D}_{\mathrm{p}}=\delta \mathrm{D}_{\mathrm{h}}+24.81 / 0.7884$.

\begin{tabular}{|c|c|c|}
\hline Specimen & $\operatorname{Raw} \delta \mathrm{D}_{\mathrm{h}}$ & Converted $\delta \mathrm{D}_{\mathrm{h}}$ \\
\hline mc137 & -36 & -14 \\
\hline t136ews7 & -46 & -27 \\
\hline t1601 & -46 & -27 \\
\hline t0522 & -49 & -30 \\
\hline $\mathrm{t} 1365$ & -49 & -30 \\
\hline $\mathrm{mc} 03$ & -53 & -36 \\
\hline $\operatorname{mc1} 16$ & -55 & -37 \\
\hline 1088 & -56 & -38 \\
\hline 13915 & -55 & -38 \\
\hline $\mathrm{t} 1364$ & -58 & -41 \\
\hline $\mathrm{t} 2261$ & -58 & -41 \\
\hline $\mathrm{t} 2264$ & -57 & -41 \\
\hline $\mathrm{t} 4592$ & -58 & -42 \\
\hline mc63 & -60 & -44 \\
\hline $\operatorname{mc} 114$ & -61 & -46 \\
\hline mc141 & -62 & -47 \\
\hline $\mathrm{t} 13912$ & -62 & -47 \\
\hline $\mathrm{t} 1607$ & -62 & -47 \\
\hline $\mathrm{t} 2224$ & -65 & -50 \\
\hline $\mathrm{t} 2312$ & -64 & -50 \\
\hline $\mathrm{t} 2313$ & -65 & -50 \\
\hline $\mathrm{mc} 77$ & -65 & -51 \\
\hline $\mathrm{t} 1112$ & -66 & -51 \\
\hline $\mathrm{t} 1638$ & -66 & -51 \\
\hline $\mathrm{mc} 75$ & -68 & -54 \\
\hline $\mathrm{t} 1361$ & -68 & -54 \\
\hline $\mathrm{t} 225102$ & -69 & -55 \\
\hline t1606 & -70 & -56 \\
\hline t16320 & -69 & -56 \\
\hline t19617 & -76 & -64 \\
\hline cr17 & -76 & -65 \\
\hline 19392 & -77 & -66 \\
\hline $\mathrm{t} 742$ & -89 & -81 \\
\hline mc65 & -102 & -97 \\
\hline
\end{tabular}


Table 9: Duplicates of selected specimens of Hoary bat hair in Table 8.

\begin{tabular}{ccc}
\hline Specimen & Raw $\delta D_{\mathrm{h}}$ & Converted $\delta \mathrm{D}_{\mathrm{h}}$ \\
\hline $\mathrm{d}-\mathrm{t} 1364$ & -58 & -41 \\
$\mathrm{~d}-\mathrm{mc} 63$ & -59 & -43 \\
$\mathrm{~d}-\mathrm{mc} 141$ & -61 & -45 \\
$\mathrm{~d}-\mathrm{t} 2312$ & -65 & -51 \\
$\mathrm{~d}-\mathrm{t} 1638$ & -67 & -52 \\
$\mathrm{~d}-\mathrm{t} 225102$ & -70 & -56 \\
d-cr17 & -76 & -64 \\
d-mc65 & -104 & -100 \\
\hline
\end{tabular}


Table 10: Raw $\delta \mathrm{D}_{\mathrm{h}}$ for Eastern Red bat hair.

\begin{tabular}{cc}
\hline Specimen & Raw $\delta D_{\mathrm{h}}$ \\
\hline $\mathrm{mc} 124$ & -11 \\
$\mathrm{t} 25$ & -12 \\
$\mathrm{cr} 12$ & -17 \\
$\mathrm{t} 23161$ & -20 \\
$\mathrm{t} 742$ & -20 \\
$\mathrm{mc} 176$ & -21 \\
$\mathrm{t} 1603$ & -22 \\
$\mathrm{mc} 171$ & -25 \\
$\mathrm{mc} 122$ & -26 \\
$\mathrm{kh} 4$ & -28 \\
$\mathrm{t} 1653$ & -28 \\
$\mathrm{~s} 10$ & -29 \\
$\mathrm{mc} 140$ & -30 \\
$\mathrm{t} 2264$ & -30 \\
$\mathrm{t} 2261$ & -31 \\
$\mathrm{t} 744$ & -31 \\
$\mathrm{t} 2261$ & -32 \\
$\mathrm{t} 7410$ & -34 \\
$\mathrm{t} 1332$ & -35 \\
$\mathrm{mc} 145$ & -36 \\
$\mathrm{mc66}$ & -40 \\
$\mathrm{t} 741$ & -42 \\
$\mathrm{mc} 47$ & -44 \\
$\mathrm{t} 0741$ & -45 \\
$\mathrm{mc} 33$ & -46 \\
$\mathrm{t} 1361$ & -50 \\
$\mathrm{mc} 117$ & -57 \\
\hline &
\end{tabular}


Table 11: Duplicates of selected specimens of Eastern Red bat hair in Table 10.

\begin{tabular}{cc}
\hline Specimen & Raw $\delta D_{\mathrm{h}}$ \\
\hline $\mathrm{d}-\mathrm{t} 25$ & -13 \\
$\mathrm{~d}-\mathrm{cr} 12$ & -15 \\
$\mathrm{~d}-\mathrm{mc} 176$ & -21 \\
$\mathrm{~d}-\mathrm{kh} 4$ & -25 \\
$\mathrm{~d}-\mathrm{mc} 140$ & -29 \\
$\mathrm{~d}-\mathrm{t} 2261$ & -31 \\
$\mathrm{~d}-\mathrm{t} 1332$ & -34 \\
$\mathrm{~d}-\mathrm{t} 7410$ & -34 \\
$\mathrm{~d}-\mathrm{mc} 145$ & -35 \\
$\mathrm{~d}-\mathrm{mc} 66$ & -39 \\
$\mathrm{~d}-\mathrm{mc} 33$ & -45 \\
$\mathrm{~d}-\mathrm{t} 0741$ & -45 \\
$\mathrm{~d}-\mathrm{mc} 47$ & -46 \\
\hline
\end{tabular}

Table 12: Details of GARP variable sources including scale and years.

\begin{tabular}{|c|c|c|c|}
\hline Variable & Year & Scale & Data Source/Program \\
\hline $\begin{array}{l}\text { Precipitation } \\
\text { Deuterium } \\
\text { Ratio }\end{array}$ & $1960-2000$ & $13 \mathrm{~km}$ & $\begin{array}{l}\text { IsoMAP } \\
\text { www.isomap.org }\end{array}$ \\
\hline $\begin{array}{l}\text { Global } \\
\text { Average } \\
\text { Precipitation }\end{array}$ & $1950-2000$ & $1 \mathrm{~km}$ & $\begin{array}{l}\text { WorldClim } \\
\text { www.worldclim.org }\end{array}$ \\
\hline $\begin{array}{l}\text { Global } \\
\text { Average } \\
\text { Temperature }\end{array}$ & $1950-2000$ & $1 \mathrm{~km}$ & $\begin{array}{l}\text { WorldClim } \\
\text { www.worldclim.org }\end{array}$ \\
\hline DEM & & $1 \mathrm{~km}$ & $\begin{array}{l}\text { Data Basin } \\
\text { http://databasin.org/datasets/ } \\
\text { d2198be9d2264de19cb93fe6a380b69c }\end{array}$ \\
\hline $\begin{array}{l}\text { Percent } \\
\text { Tree Cover }\end{array}$ & 2008 & $1 \mathrm{~km}$ & $\begin{array}{l}\text { ISCGM Global Map Data Download Service } \\
\text { http://www.iscgm.org/gmd/download/ptc } \\
\text {.htm1 }\end{array}$ \\
\hline $\begin{array}{l}\text { Species } \\
\text { Occurrence }\end{array}$ & & & $\begin{array}{l}\text { Mammal Networked Information System } \\
\text { MaNIS } \\
\text { http://manisnet.org/ }\end{array}$ \\
\hline
\end{tabular}

Table 13: Number of specimens analyzed for $\delta \mathrm{D}_{\mathrm{h}}$ and the number of specimens mapped 
to create geographic extents.

\begin{tabular}{llll}
\hline \multicolumn{1}{c}{ Species } & Sex & Total Specimens & Mapped Specimens \\
\hline Hoary & Female & 17 & 14 \\
Hoary & Male & 23 & 22 \\
Eastern Red & Female & 11 & 09 \\
Eastern Red & Male & 24 & 17 \\
\hline
\end{tabular}




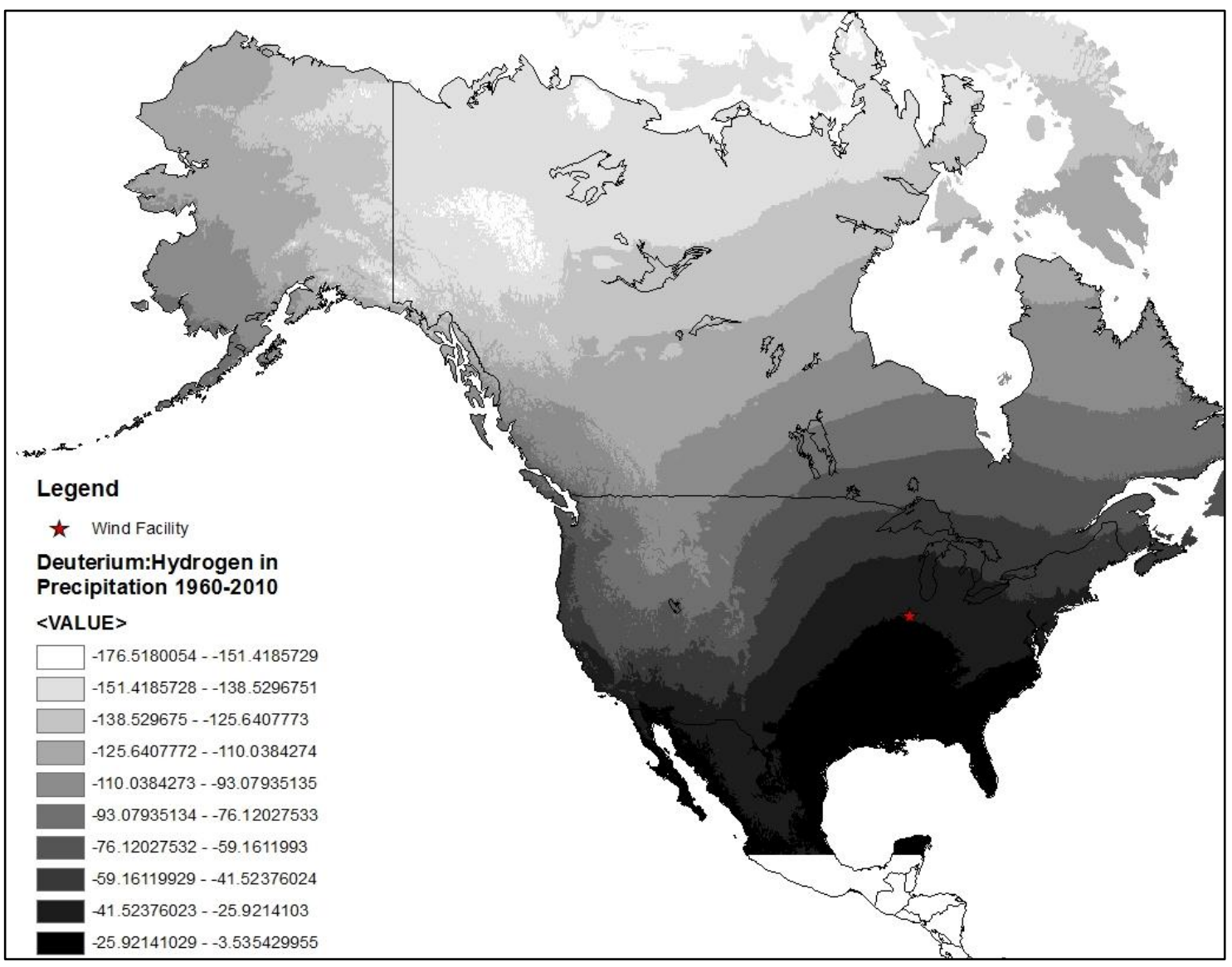

Figure 1: Deuterium of precipitation from 1960-2010 modeled in Isomap.org. Darker tones signify more deuterium:hydrogen in precipitation (enriched), and lighter tones represent less deuterium:hydrogen in precipitation (depleted). 


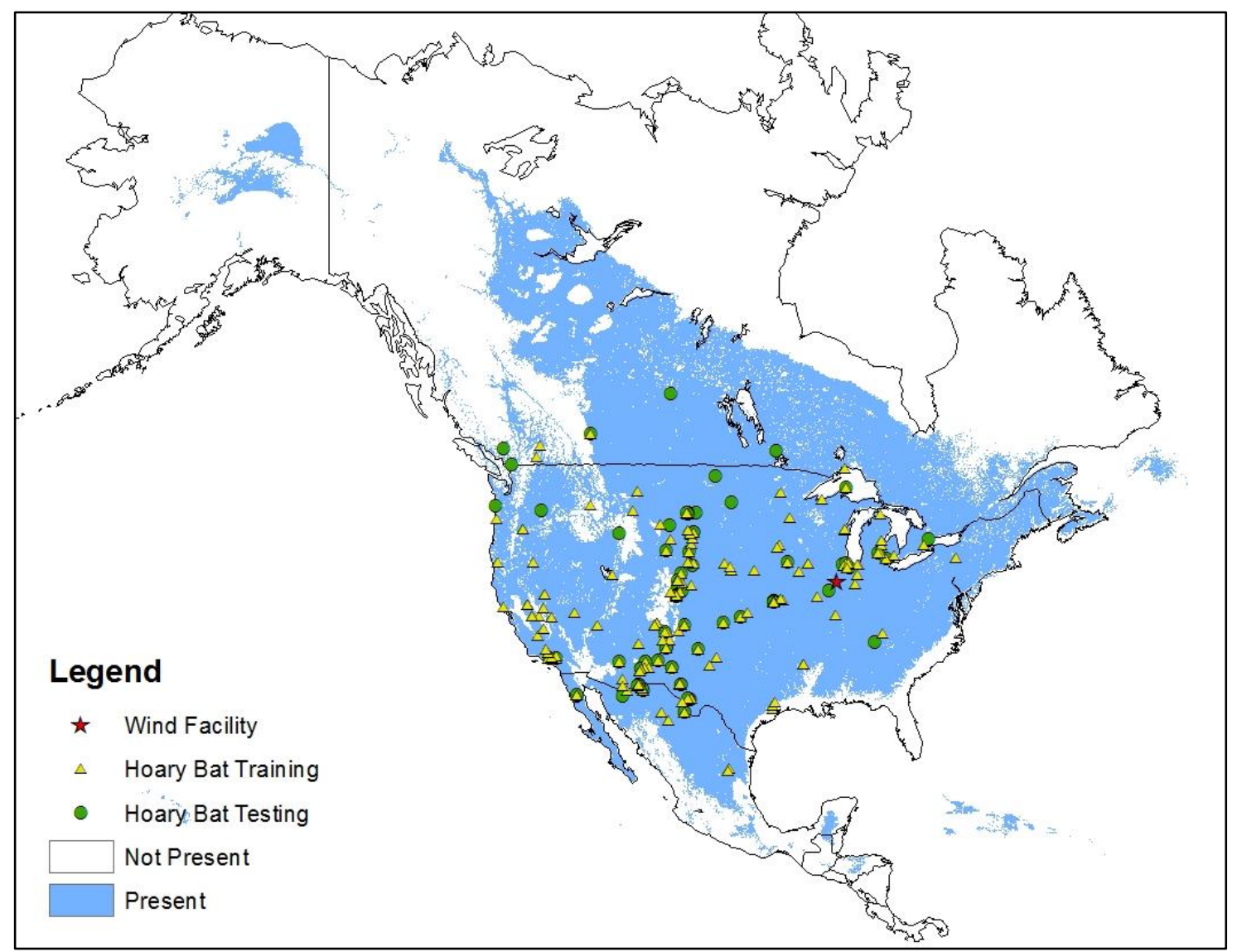

Figure 2: Georeferenced Hoary bat specimen locations used to train and test the GARP model. GARP successfully predicted occurrence for 93 out of 94 testing points (98.93\%). 


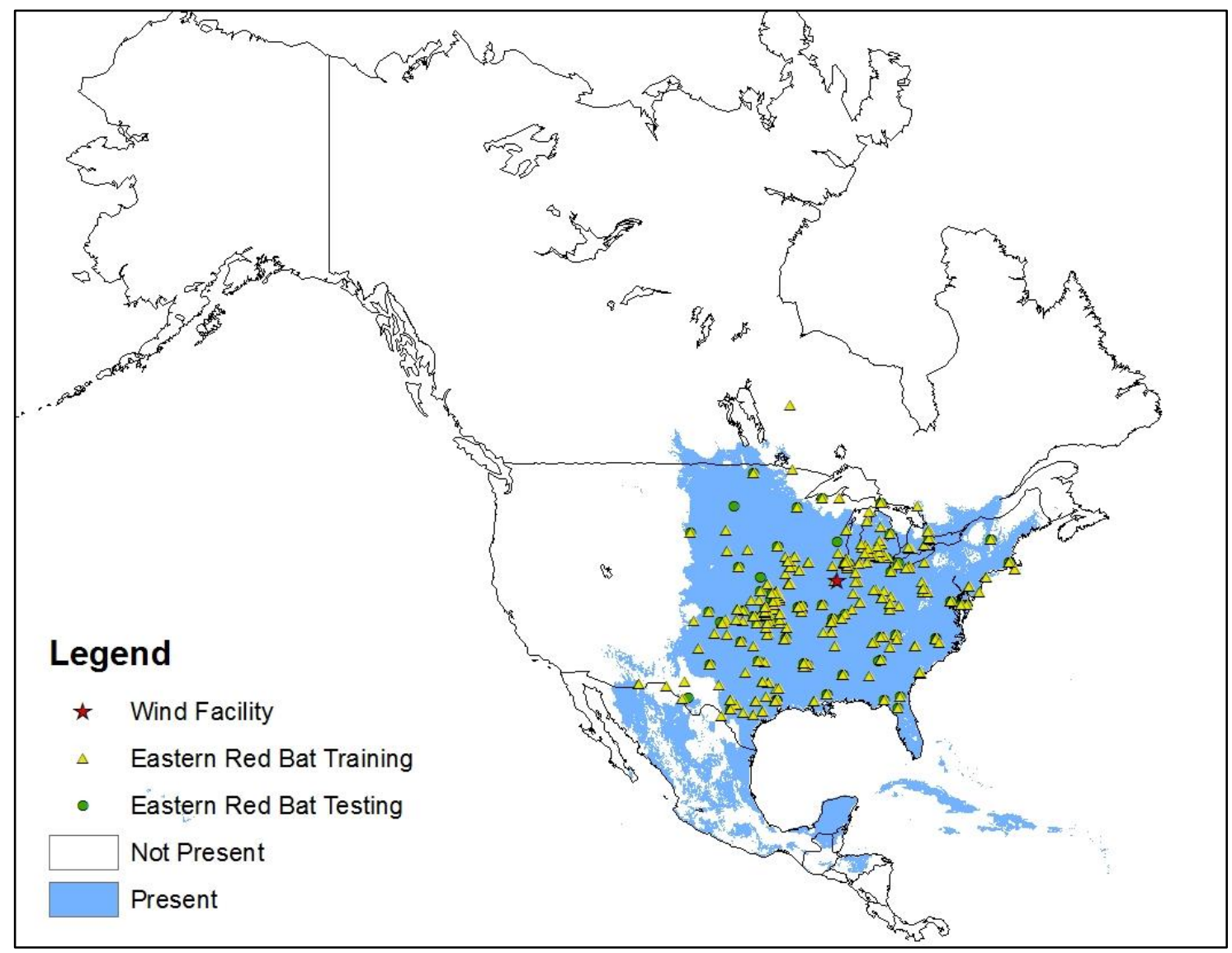

Figure 3: Georeferenced Eastern Red bat specimen locations used to train and test the GARP model. GARP successfully predicted occurrence for 154 out of 159 testing points $(96.85 \%)$. 


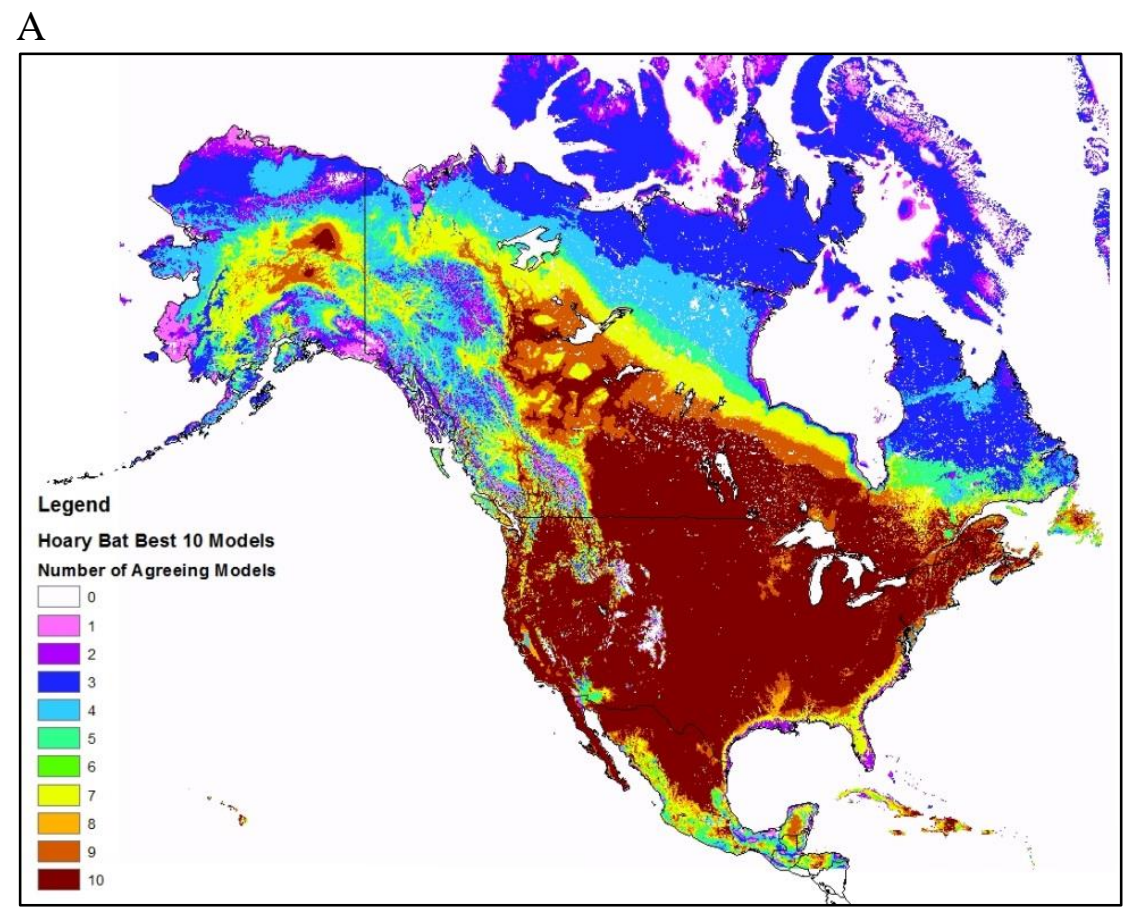

$\mathrm{B}$

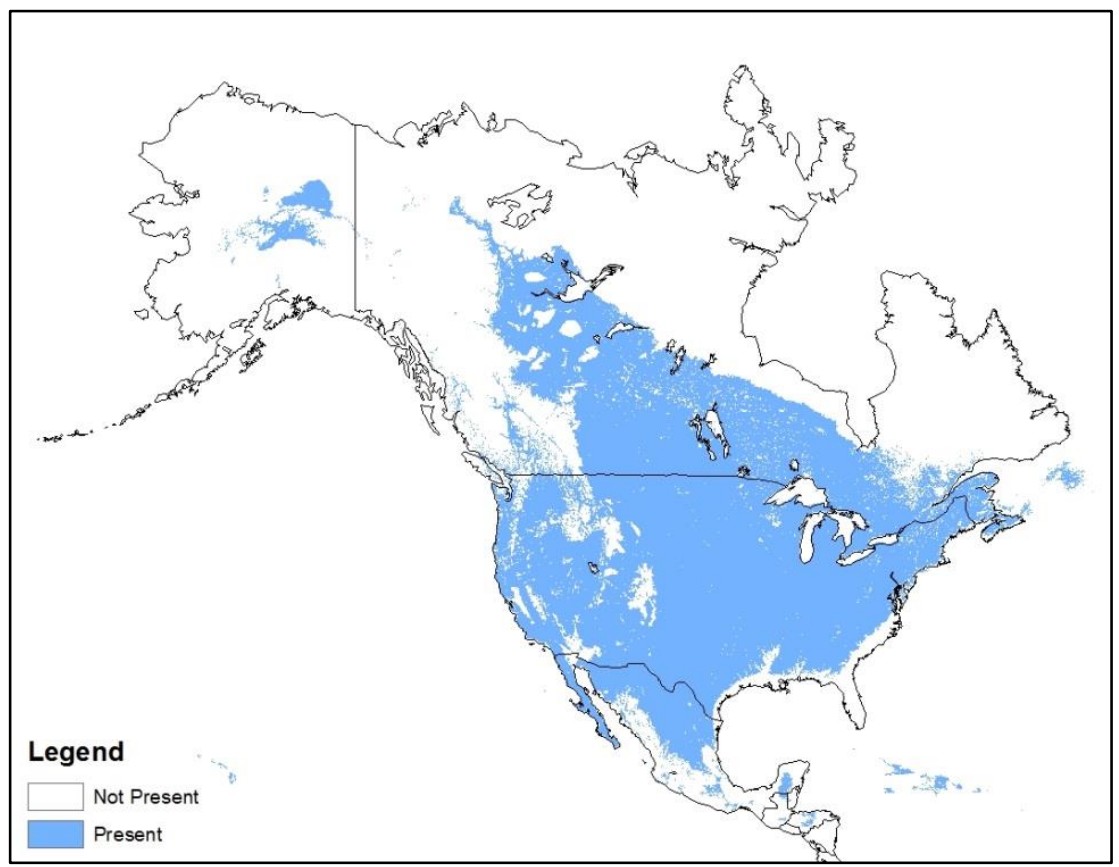

Figure 4: GARP Hoary bat best 10 models. A. GARP best 10 models for the summer range. $\mathrm{B}$. The reclassified models using areas where 9-10 of the best 10 models agree that the area is potential habitat (Present). 


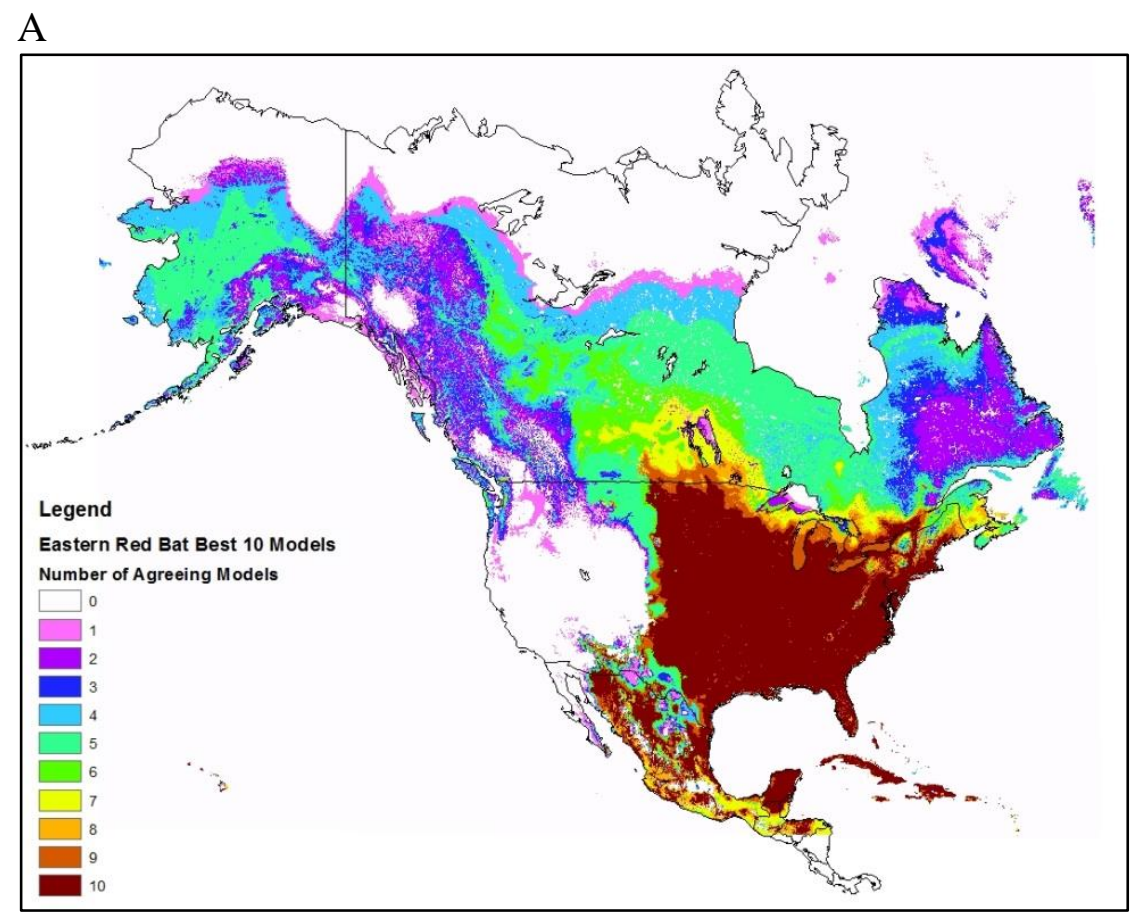

B

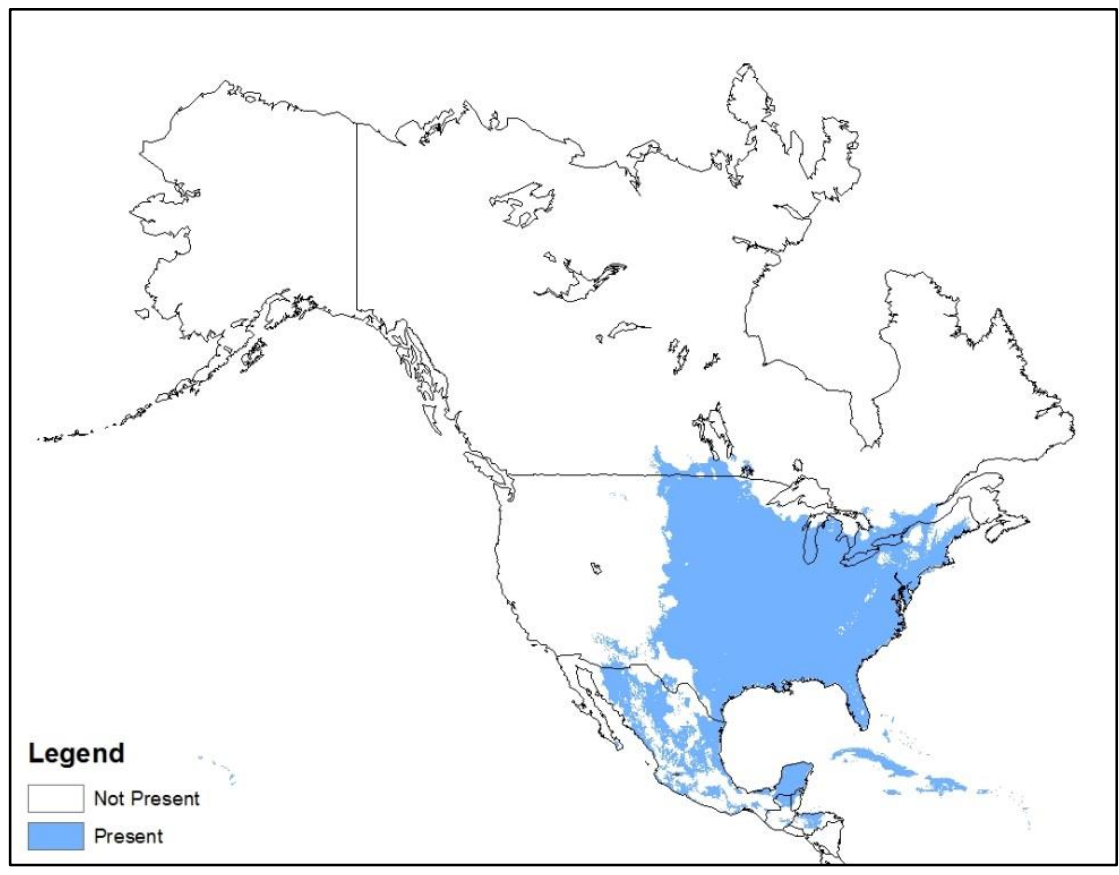

Figure 5: GARP Eastern Red bat best 10 models. A. GARP best 10 models for the summer range. B. The reclassified models using areas where 9-10 of best 10 models agree that the area is potential habitat (Present). 

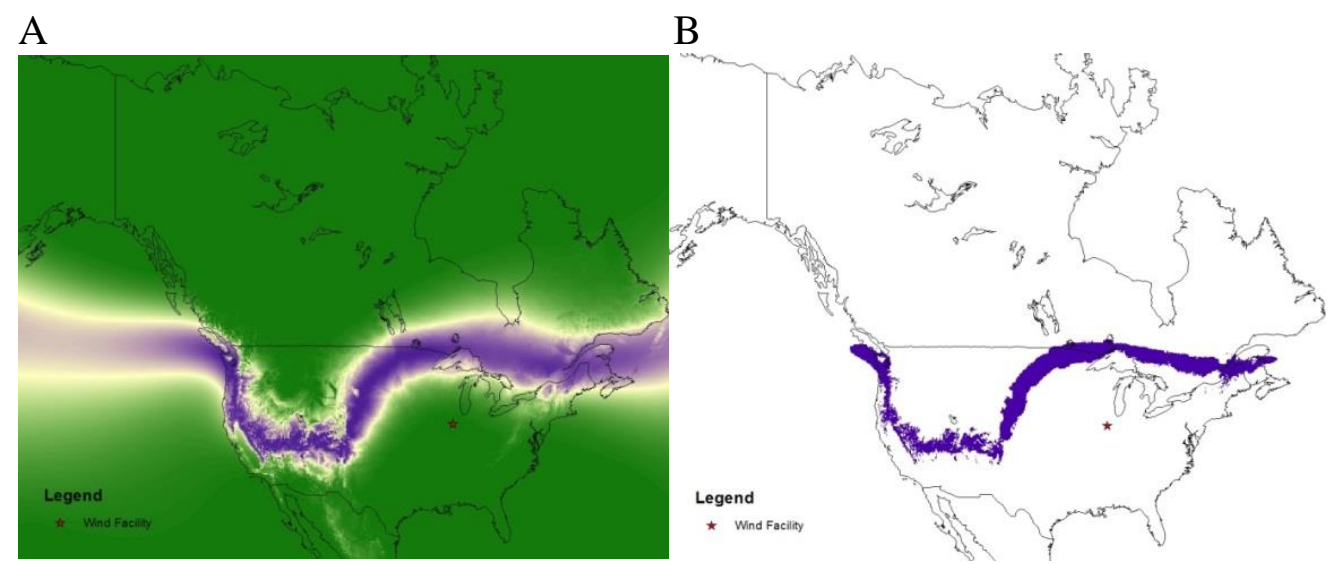

$\mathrm{C}$

$\mathrm{D}$

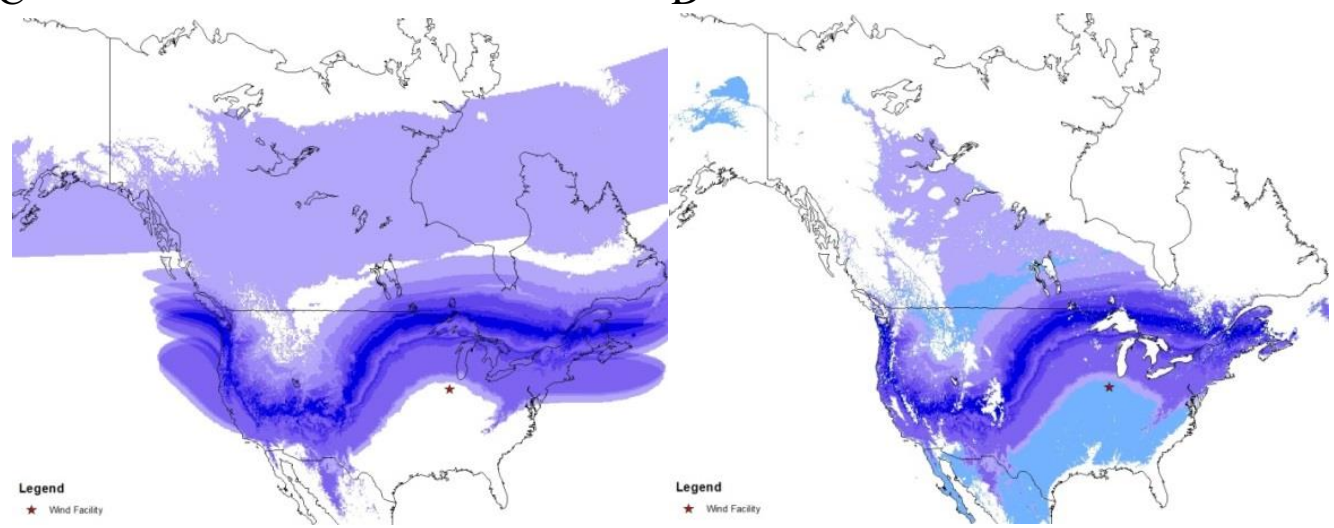

Figure 6 A-D: The ArcMap process used for each specimen. A. The isotope assignment of a single specimen downloaded from Isomap.org. B. Reclassified single specimen assignment. C. Specimens of the same species and sex added together.

D. Area from C overlaid onto GARP to clip their extents to the bats' potential summer range. 


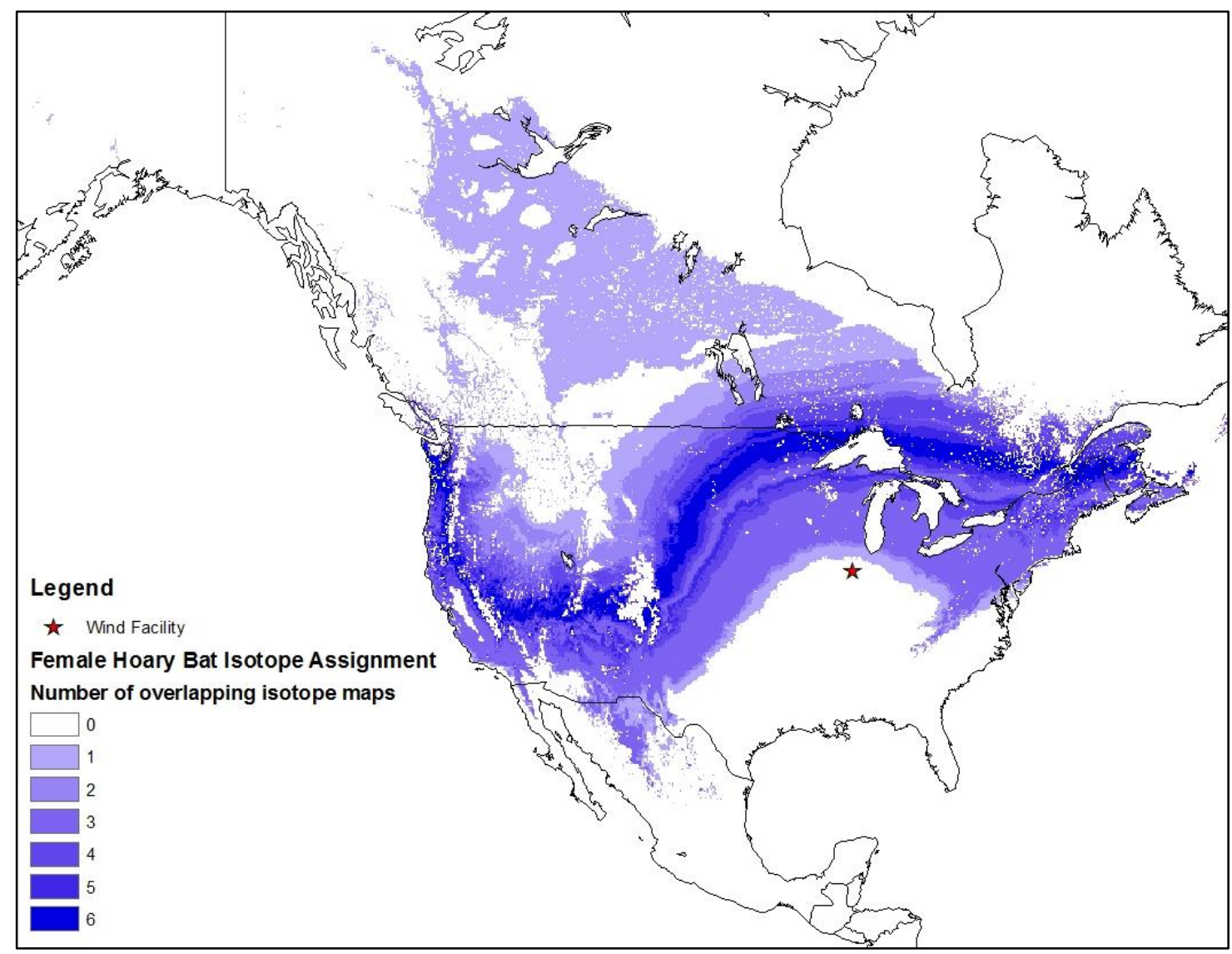

Figure 7: The isotope assignment maps of 14 female adult Hoary bats. They are added together to show the degree of overlap of their possible geographic extents. Areas that are darker have more bats overlapping extents. 


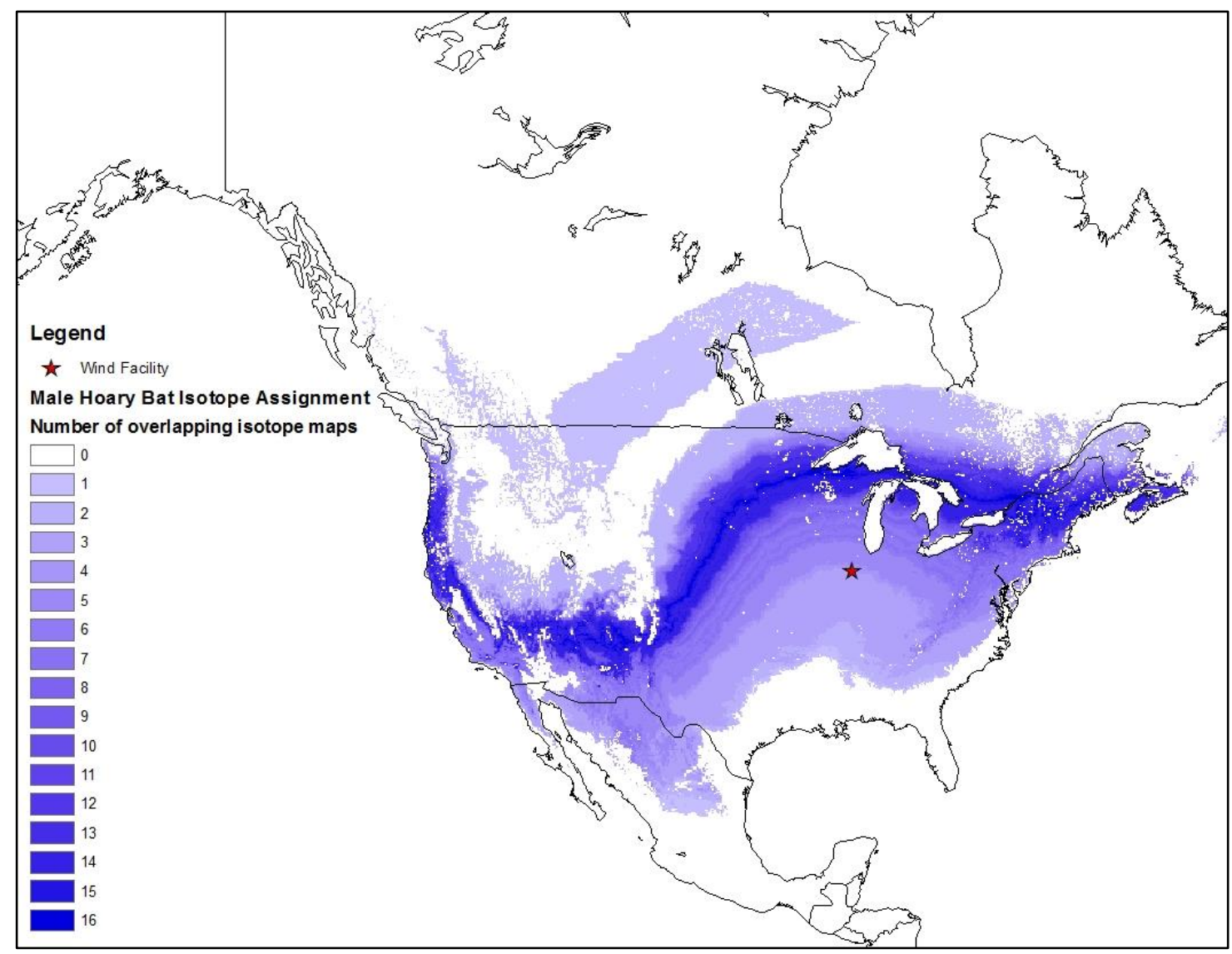

Figure 8: The isotope assignment maps of 22 male adult Hoary bats. They are added together to show the degree of overlap of their possible geographic extents. Areas that are darker have more bats overlapping extents. 


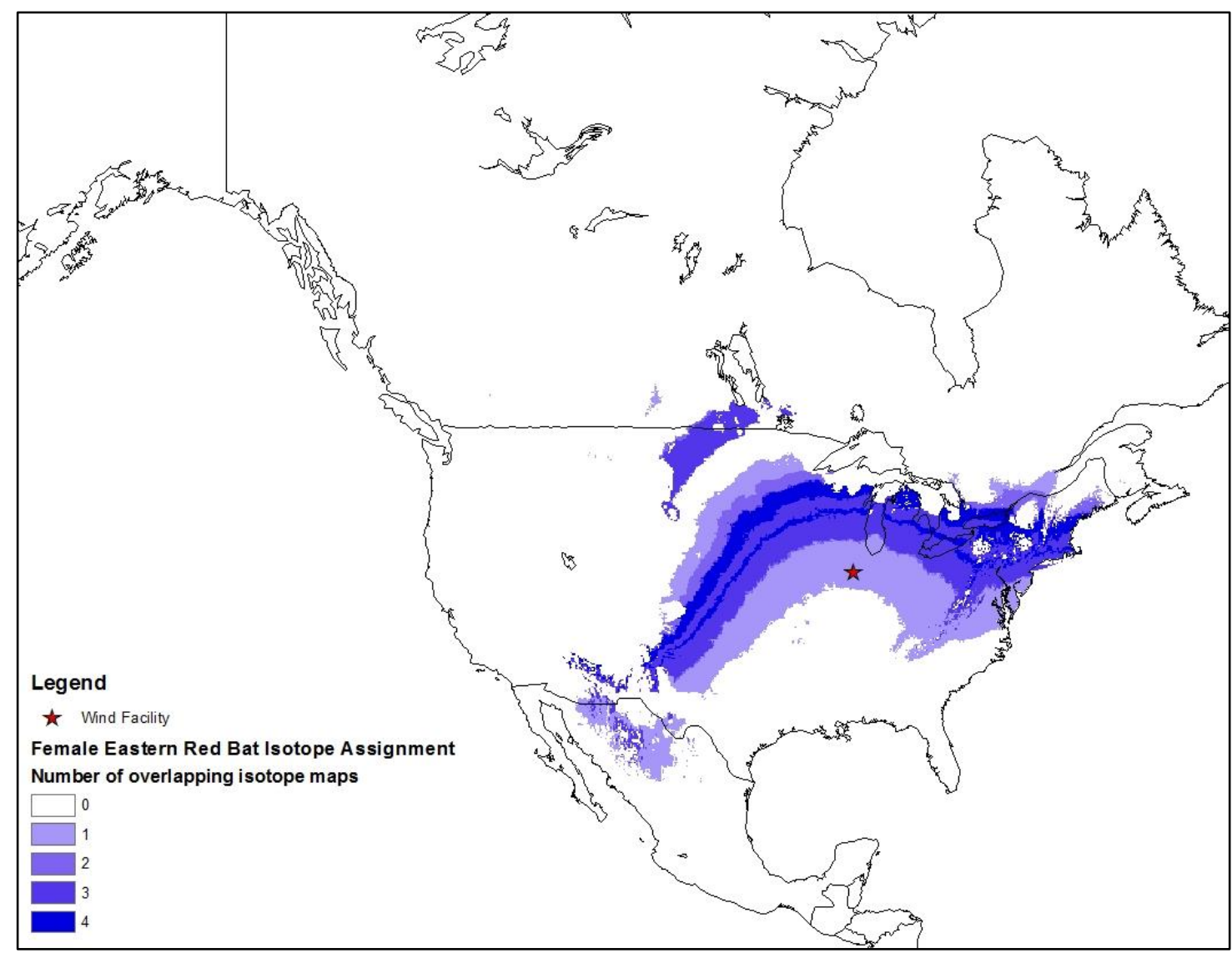

Figure 9: The isotope assignment maps of 9 female adult Eastern Red bats. They are added together to show the degree of overlap of their possible geographic extents. Areas that are darker have more bats overlapping extents. 


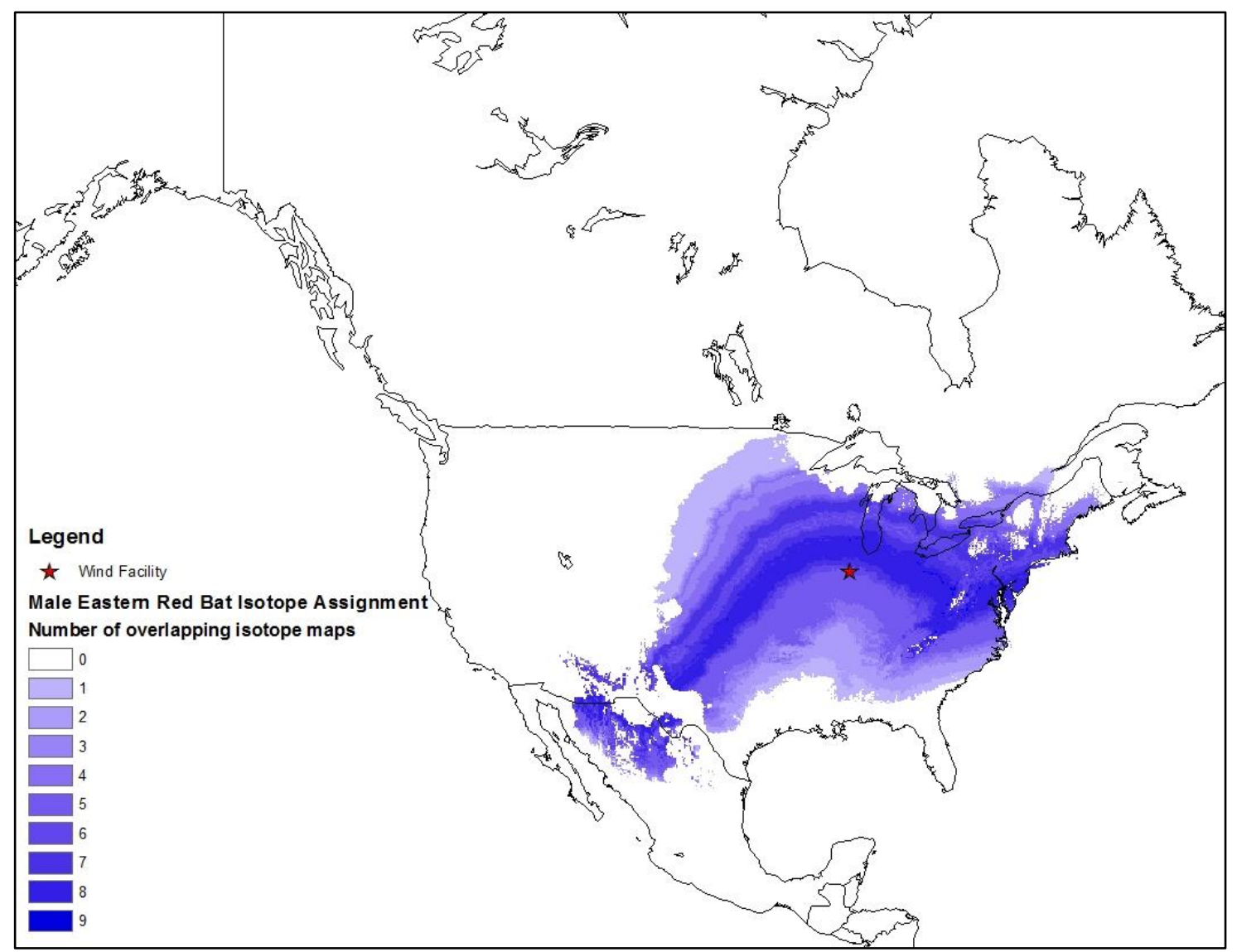

Figure 10: The isotope assignment maps of 17 male adult Eastern Red bats. They are added together to show the degree of overlap of their possible geographic extents. Areas that are darker have more overlapping extents. 


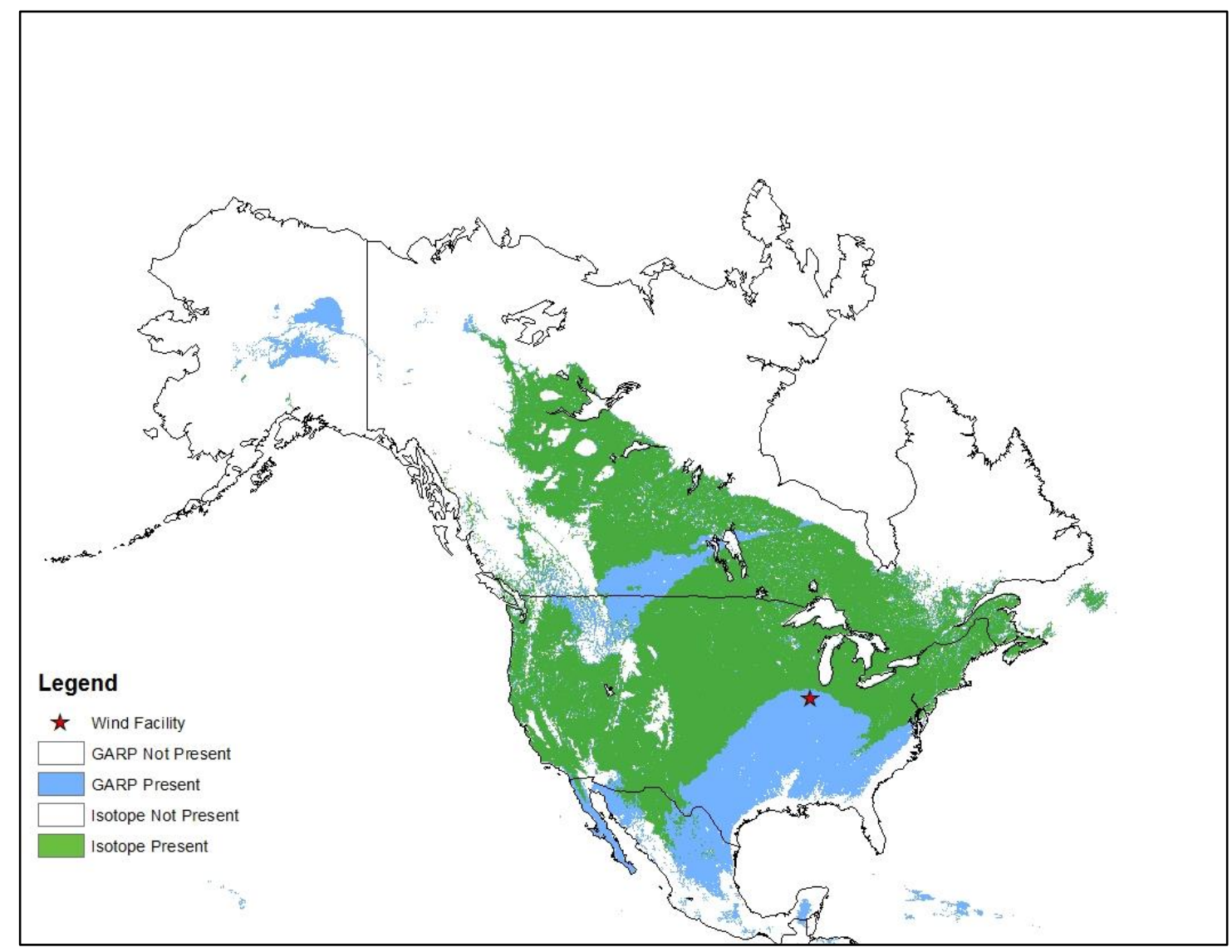

Figure 11: The isotope assignments for female Hoary bats (green) overlaid onto the Hoary bat GARP model (blue). The isotope-generated geographic extent covers $73.87 \%$ of the GARP predicted summer range. 


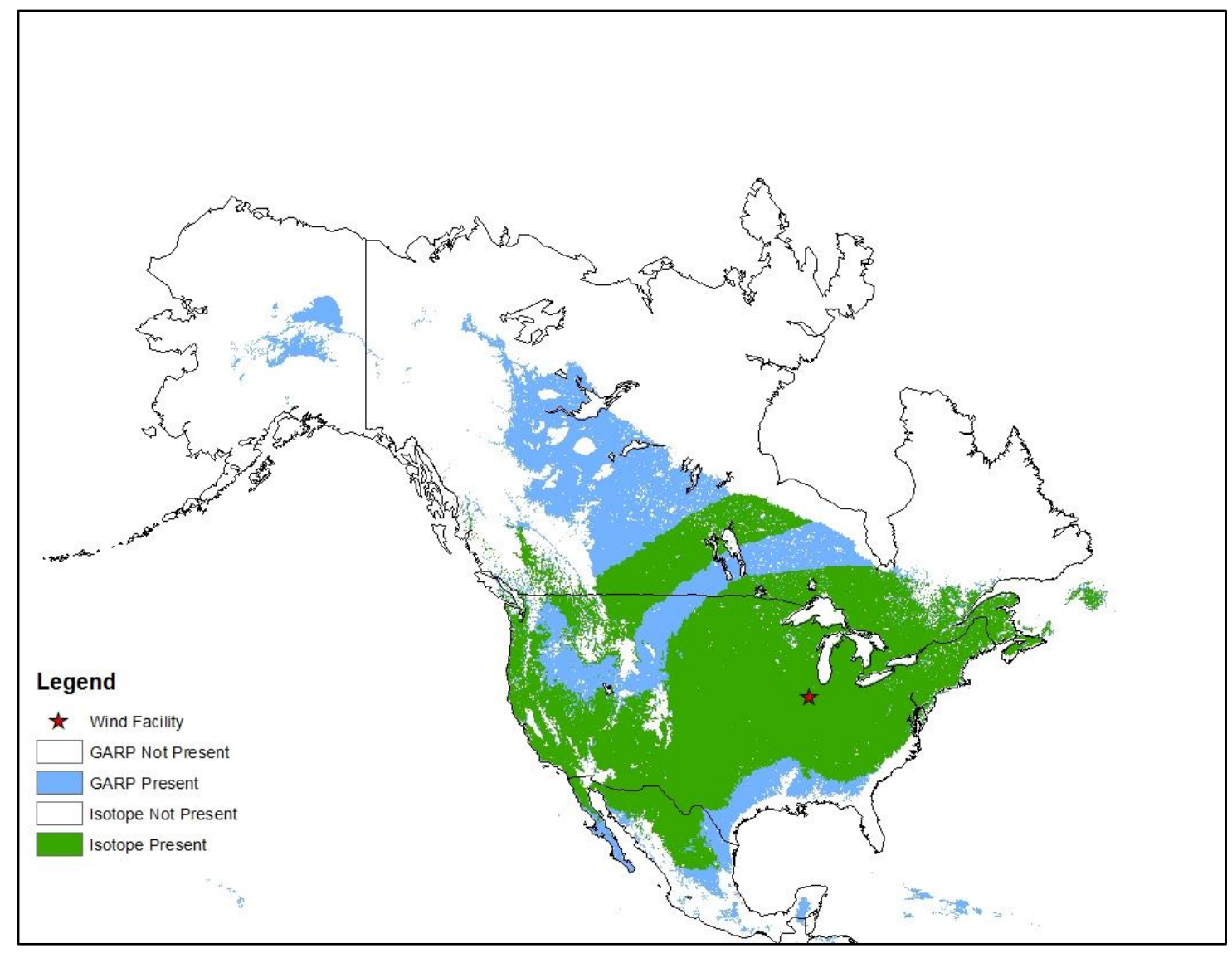

Figure 12: The isotope assignments for male Hoary bats (green) overlaid onto the Hoary bat GARP model (blue). The isotope-generated geographic extent covers $64.40 \%$ of the GARP predicted summer range. 


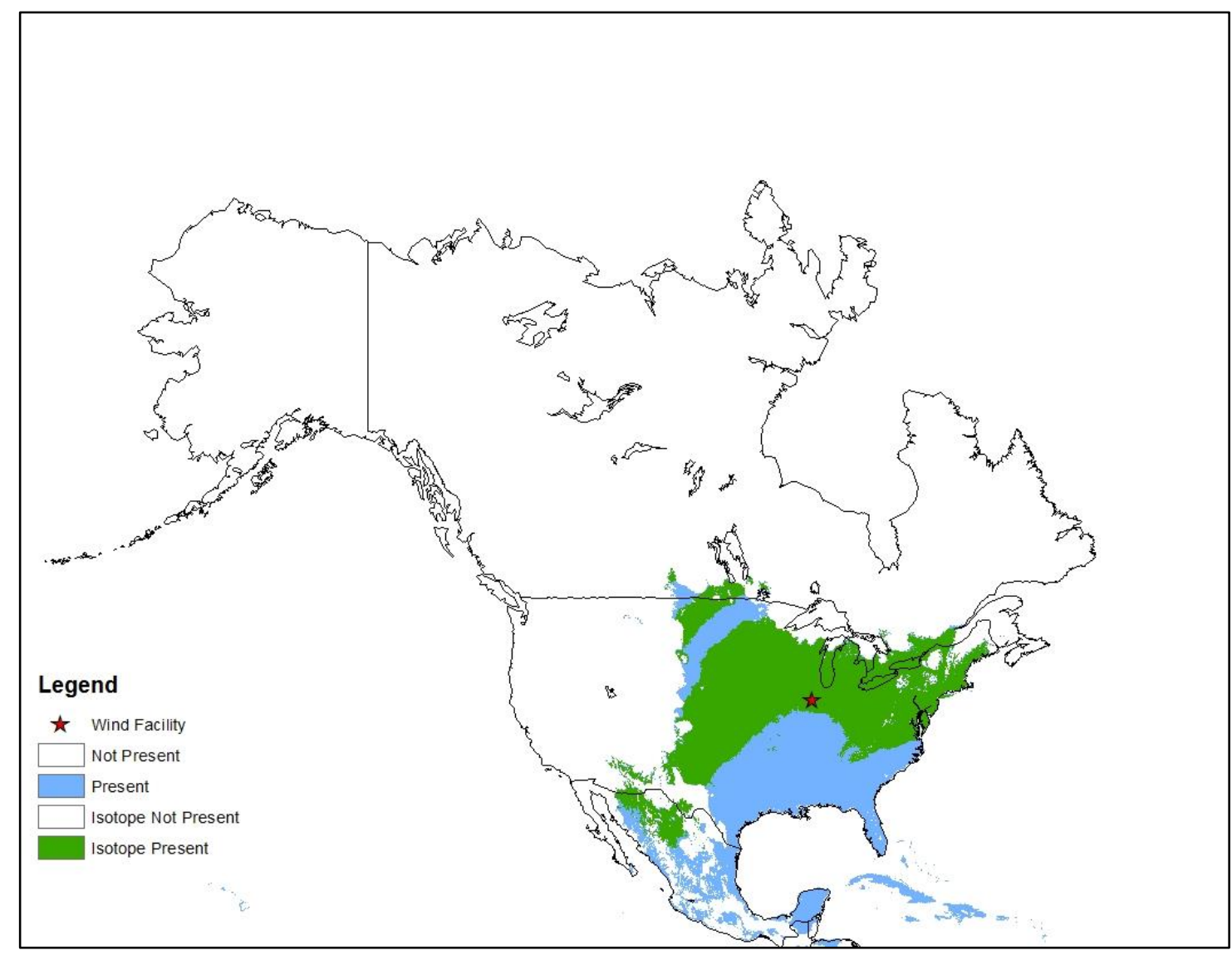

Figure 13: The isotope assignments for female Eastern Red bats (green) overlaid onto the Eastern Red bat GARP model (blue). The isotope-generated geographic extent covers $54.15 \%$ of the GARP predicted summer range. 


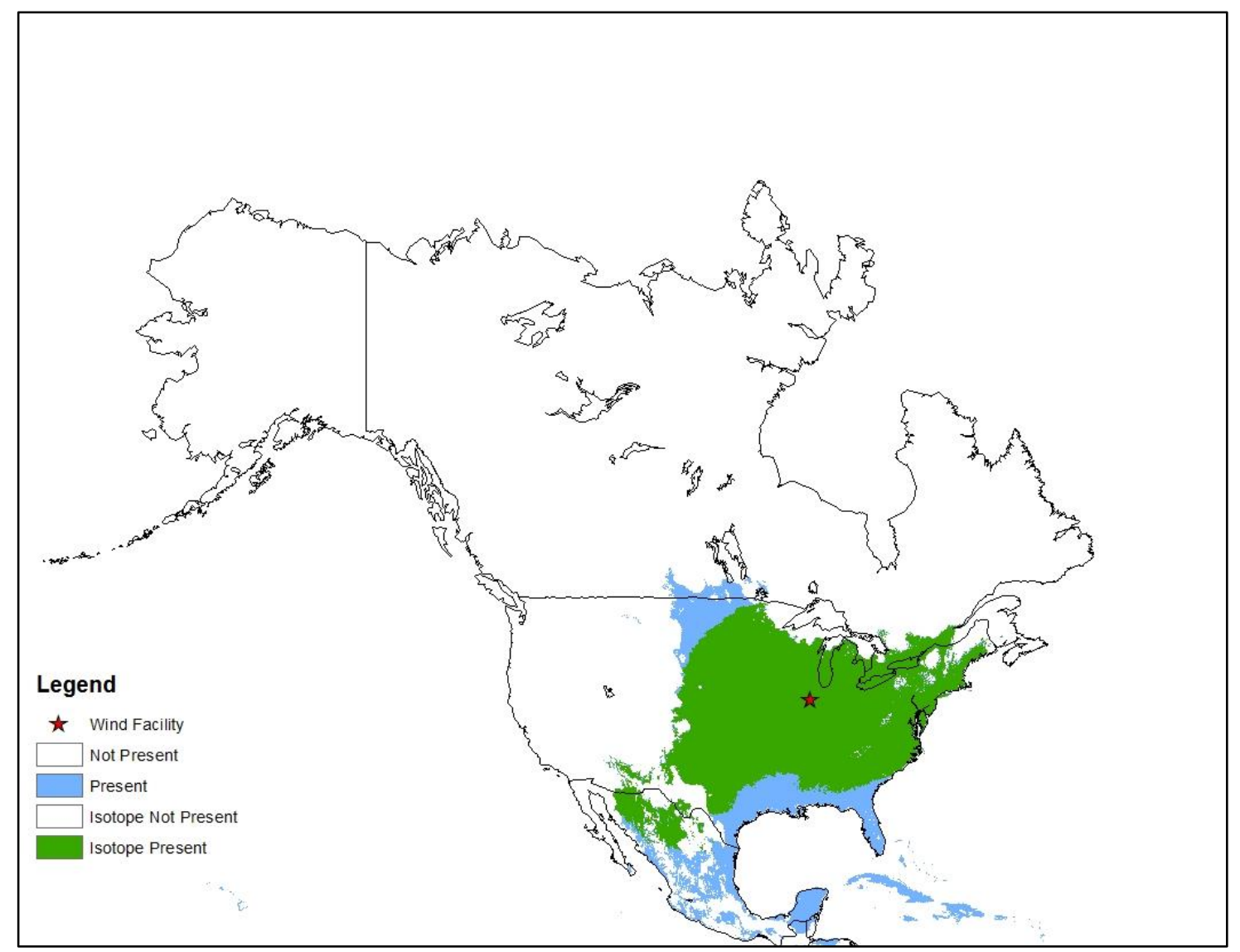

Figure 14: The isotope assignments for male Eastern Red bats (green) overlaid onto the Eastern Red bat GARP model (blue). The isotope-generated geographic extent covers $72.33 \%$ of the GARP predicted summer range. 


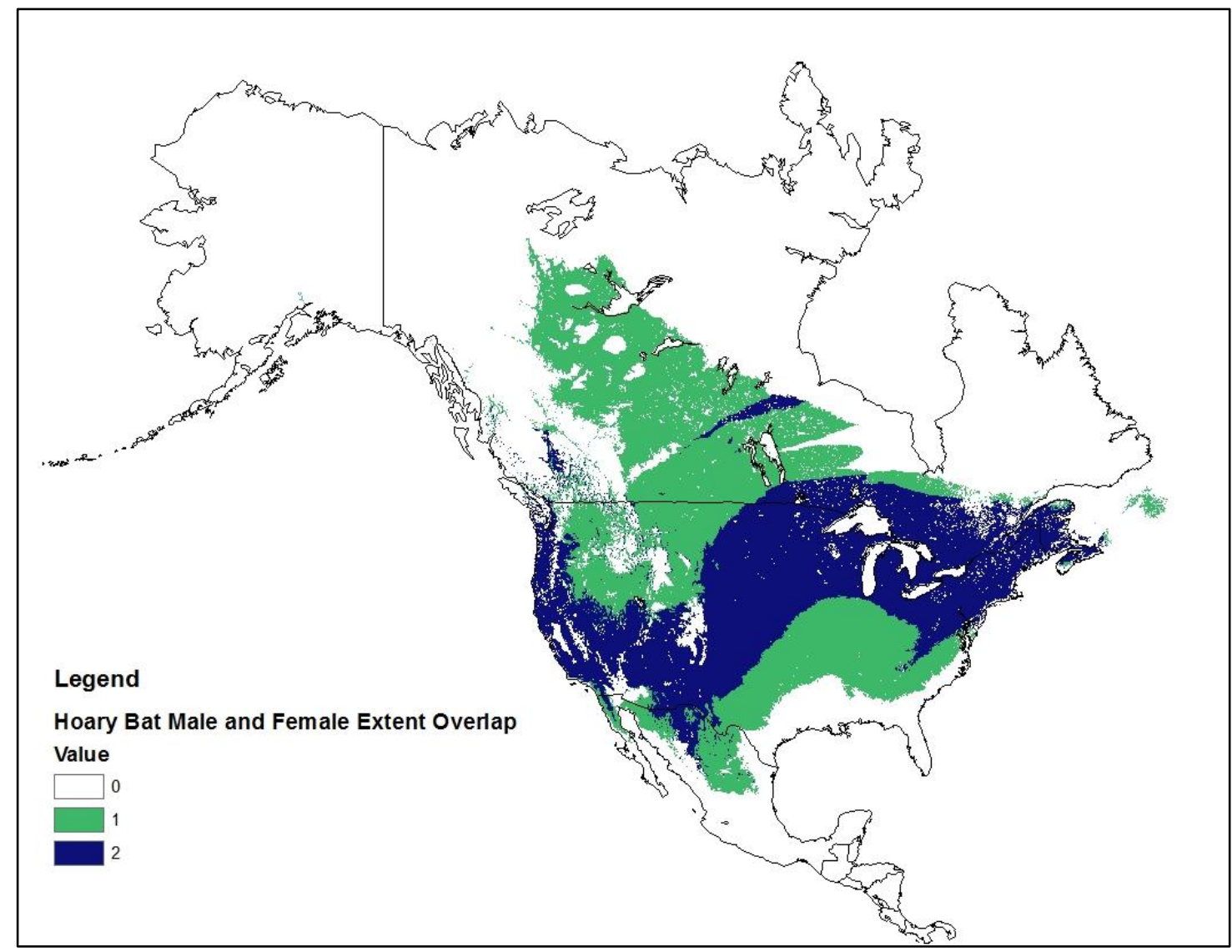

Figure 15: The $45.13 \%$ overlap of geographic extents of male and female Hoary bats. 


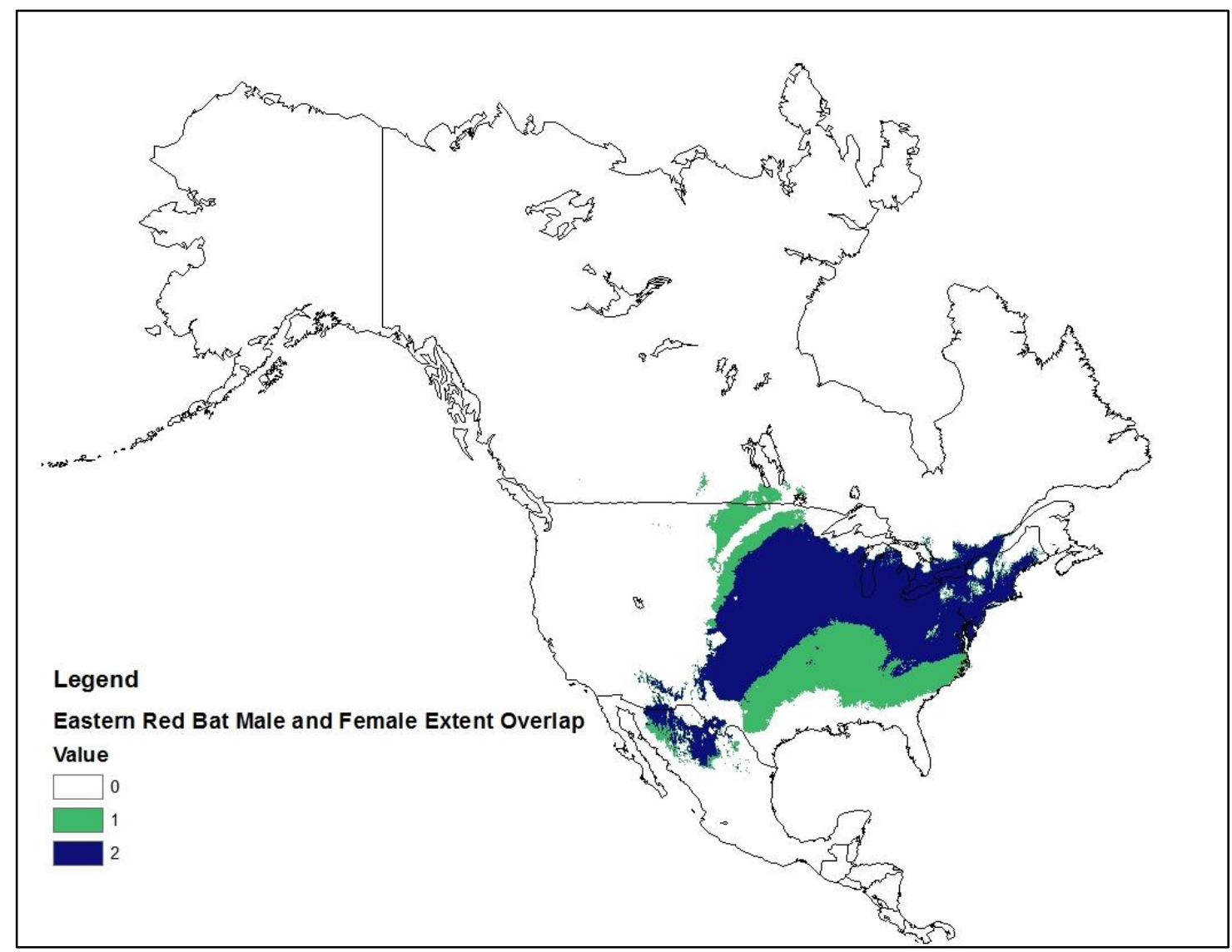

Figure 16: The $63.49 \%$ overlap of geographic extents of male and female Eastern Red bats. 


\section{CHAPTER IV \\ YEARLY AND MONTHLY VARIATIONS IN GEOGRAPHIC EXTENTS OF \\ HOARY (LASIURUS CINEREUS) AND EASTERN RED (LASIURUS BOREALIS) \\ BAT SPECIMENS}




\section{Introduction}

In North America, the Eastern Red and Hoary bats travel over 1,000 km between seasonal roosting regions. They migrate at night and require frequent stopover sites to rest during the day. They typically stay at these sites just one day, and feed upon arrival or just before departure (McGuire et al. 2012). The Hoary bat is a species found throughout Illinois (Hofmann 2008), and its range encompasses the U.S. and large portions of Canada. Although they are long-distance migrants, they can be found throughout most of their range all year, albeit with changes in densities among the areas. During the months from June to August, they can be found throughout the Midwest and western states and Canada. Throughout Illinois during this time there is a high density of females with some males as well (Cryan 2003). As they migrate in the autumn, they move southward back into wintering grounds (Cryan 2003); however, there are reports that some individuals stay north and hibernate (Shump and Shump $1982 a)$

The Eastern Red bat is found throughout the central and eastern U.S. and southern Canada (Shump \& Shump 1982b) and is common throughout Illinois (Hofmann 2008). According to Cryan (2003), Eastern Red bats are most commonly found in the eastern and southeastern states during the winter months of December through February. In the spring, they move northward and westward up to the Midwest and Canada (Cryan 2003). In Illinois during the summer months, both males and females are found in high densities, and in autumn they migrate back towards eastern and southeastern states (Cryan 2003).

Very little is known about the migratory habits of these bats from year to year or 
how an individual's summer geographic location affects the timing of their migration. Banding studies have been attempted in bats, but recapture rates of banded individuals are extremely rare, making the amount of information gathered considerably less than the effort and cost involved. Radio transmitters have also been attempted, but models light enough to be carried by bats without disrupting their behaviors or putting them at risk do not have enough range for migratory species (Cryan et al. 2004). In this study, I used deuterium isotope analysis of bats collected from a single wind facility in central Illinois in different autumn months (August-October) and from three separate years (2008-2010) to understand yearly and monthly patterns in migratory timing and patterns.

\section{Methods}

\section{Mapping of Separate Years}

For this study, the same results from Chapter III were used and separated by year of salvage, sex, and species. For female Hoary bats, I had 7 specimens from 2008, 6 specimens from 2009, and 1 from 2010. I had 8 male Hoary bats from 2008, and 14 from 2009. For female Eastern Red bats, I had 7 from 2008 and only 2 specimens from 2010. I had 9 male Eastern Red bats from 2008, 7 from 2009, and 1 from 2010. Each sex/species group of a given year was mapped and then reclassified again so that if a bat was predicted to originate from that pixel it was given a 1 ; if not, it was given a 0 . The two or three maps of different years were then added together (Figures 17-20). I then determined the percentage of overlap among years by looking at the ratio of overlapping extent pixels to total extent pixels. I also added each year separately to the 
others to understand the overlap of each year to the next (2008 and 2009, 2008 and 2010, and 2009 and 2010) and performed the same ratios.

\section{Mapping of Separate Months}

Specimens' individual geographic extents from Chapter III were separated by sex, species, and month of salvage. Female Hoary bats had 2 specimens from August, 11 from September, and 1 from October. Male Hoary bats had 4 specimens from August and 18 from September. Female Eastern Red bats had 6 from August and 3 from September. Male Eastern Red bats had 1 specimen from July, 3 from August, 11 from September, and 2 from October. The groups of specimen extents were then added together and reclassified with 1 representing specimens' extent and 0 representing nonextent. The months were then added together, keeping sex and species separate, to show the proportion of overlap among the salvage months (Figures 21-24). Each month was then added to the others separately to evaluate month-to-month overlap (August and September, September and October, and August and October). I then determined the proportion of range overlap by the ratio of overlapping pixels and total number of extent pixels.

\section{Results}

\section{Yearly}

For the female Hoary bats, the total extent overlapped by multiple years (two or three years) was $61.09 \%$ (Figure 17). The percentage of the extent covered by any two years (2008 and 2009, 2008 and 2010, or 2009 and 2010) was 60.35\%. The percentage of area overlapped by all three years together was $0.74 \%$. In male Hoary bats, there were 
only samples from 2008 and 2009, and their geographic extents overlapped by $63.84 \%$ (Figure 18). Female Eastern Red bats only had specimens from 2008 and 2010, and they overlapped their extents by $43.61 \%$, and the two 2010 specimens' extents were completely enclosed in the area for the seven specimens from 2008 (Figure 19). Male Eastern Red bats had a total yearly overlap of their extents of 90.94\% (Figure 20). Any two years overlapped $45.99 \%$ of their extents, and all three years overlapped $44.95 \%$ of their extents.

\section{Monthly}

The female Hoary bat had specimens from August through October with the most collected in September. Areas where any two months (August and September, September and October, or August and October) overlapped covered 37.81\%, and areas where all three months overlapped covered $5.03 \%$. When added together, the total monthly overlap was $42.85 \%$ (Figure 21 ). Male Hoary bats were only salvaged in August and September. These two months overlapped by $74.91 \%$ (Figure 22). Female Eastern Red bats were only salvaged in August and September. These two months overlapped by $52.59 \%$ (Figure 23). Male Eastern Red bats were salvaged from July through October. The percentage of area covered by any two months was $40.17 \%$. Percentage of area overlapped by any three months was $8.17 \%$, and the percentage of area covered by all four months was $43.57 \%$. When these percentages were added together, the total monthly overlap for male Eastern Red bat was 91.91\% (Figure 24). 


\section{Discussion}

\section{Yearly}

Hoary bats migrating in the autumn through central Illinois had a large overlap of geographic areas throughout the years. This pattern suggests that these bats as a whole are not migrating to different areas each year. Male Eastern Red bats showed the same pattern of a large portion of their geographic areas overlapping each year. However, female Eastern Red bats only overlapped $43.61 \%$ of their yearly extent. This is most likely a reflection of only having 2 specimens from 2010. Both of those extents, however, are completely covered by the specimens' extents from 2008 . So although there is only $43.61 \%$ overlap between the two, 2008 covers a significantly large area of 2010. It is likely that with more specimens, we would see a larger area of overlapping extents. These results indicate that, as a whole, both the Hoary and Eastern Red bats passing through the wind facility do not shift summer regions year to year. Therefore, this single wind facility has a constant effect on these areas every year.

\section{Monthly}

The small area of monthly overlap of the female Hoary bats' geographic extents suggests that each month bats are coming from different areas of the continent. When I examined the months layered together in ArcGIS, they did not show a pattern that would correlate month of arrival at the wind facility to geographic extent. Bats salvaged in September had extents from areas covering the entire female Hoary extent. Specimens from August covered two separate areas within the total extent. The October specimen's extent was in between those salvaged in August. Male Hoary bat specimens from August and September overlapped large portions of their extents, and there was 
no north-south pattern between the two months.

Female Eastern Red bats overlapped a large portion of their extents between August and September with no patterns that might correlate location of summer geographic extents to time of salvage at the wind facility. Male Eastern Red bats also had a large portion of overlap and showed no pattern to the extent overlap. However, the bat killed in July originated in the deuterium band that includes the wind facility. It is possible that this early kill was a local bat and not a migrating male.

The lack of overall pattern among months suggests that the bats are moving across a variety of distances and yet arriving at the same place in relatively the same month. This suggests that the timing of migration is variable and not always correlated with geographic location.

\section{Conclusions}

The percentage of overlap among specimen salvage years suggest that these bats utilize their complete range every summer and do not select among geographic areas from year to year. The variation in degrees of overlap and pattern of geographic extents suggest that the bats originating from further north of the wind facility did not always begin migration earlier than more southern bats. There are bats that come from very different extent locations but arrive in the same month. The lack of pattern in proportion of overlap and lack of correlation with geographic extent suggests that there is no obvious correlation between month of arrival at the wind facility and the geographic extent of summer location. This likely means that the timing of migration is variable and not solely dependent on summer location. Although the sample size was 
variable in the number of specimens each year and month, the data reveals patterns for these two species that should be further examined in future studies with larger sample sizes. The yearly and monthly analysis also introduces an interesting new area of study using deuterium isotope analysis and specimens salvaged from wind facilities. 


\section{Literature Cited}

Cryan, P. M. 2003. Seasonal distribution of migratory tree bats (Lasiurus and Lasionycteris) in North America. Journal of Mammalogy 84:579-593.

Cryan, P., M. A. Bogan, R. O. Rye, G. P. Landis, and C. L. Kester. 2004. Stable hydrogen isotope analysis of bat hair as evidence for seasonal molt and longdistance migration. Journal of Mammalogy 85:995-1001.

Hofmann, J. E. 2008. Lasiurus borealis. Pages 88-89 in T. E. Rice, ed. Field Manual of Illinois Mammals. Illinois Natural History Survey, Champaign.

McGuire, L. P., C. G. Guglielmo, S. A. Mackenzie, and P. D. Taylor. 2012. Migratory stopover in the long-distance migrant silver-haired bat, Lasionycteris noctivagans. Journal of Animal Ecology 81:377-385.

Shump Jr., K. A., and A. U. Shump. 1982a. Lasiurus borealis. No. 183 in Mammalian Species. American Society of Mammalogists

Shump Jr., K. A., and A. U. Shump. 1982b. Lasiurus cinereus. No. 185 in Mammalian Species. American Society of Mammalogists. 


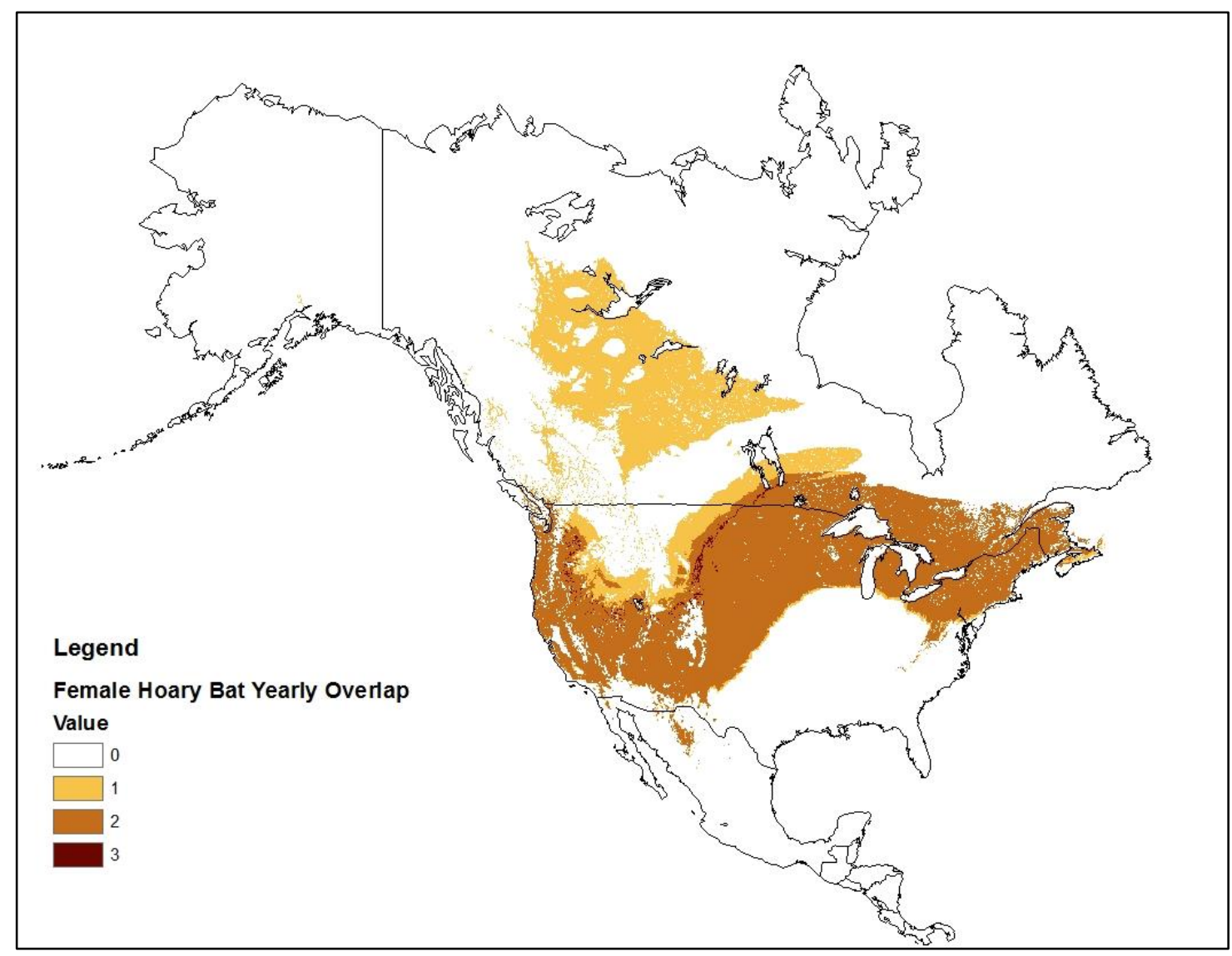

Figure 17: Number of specimen sample years (2008-2010) overlapping extents for female Hoary bats. Total percentage of area overlapped by two out of three or all three years is $61.09 \%$. 


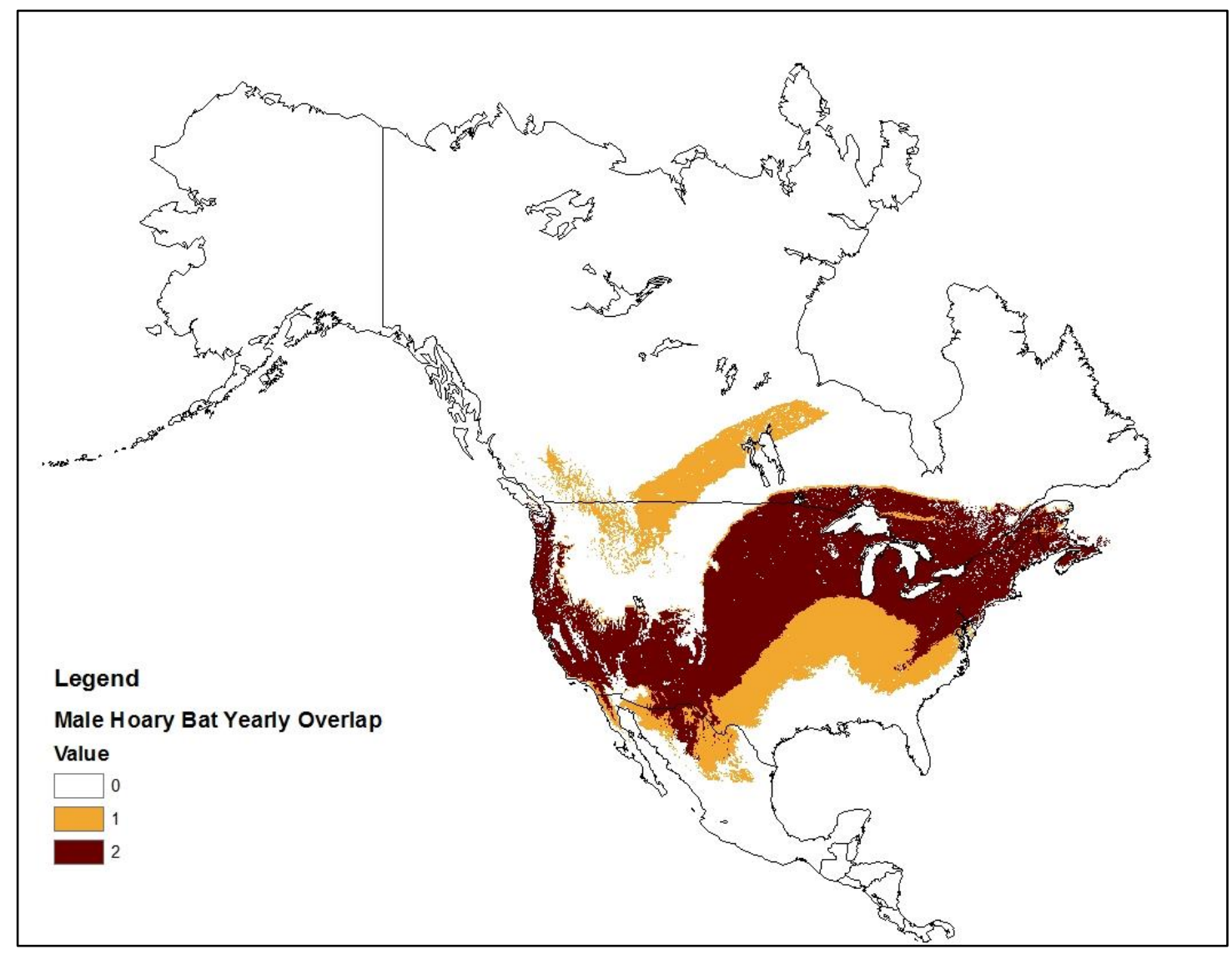

Figure 18: Number of specimen sample years (2008 and 2009) overlapping extents for male Hoary bats. Overlap in geographic origin is $63.84 \%$. 


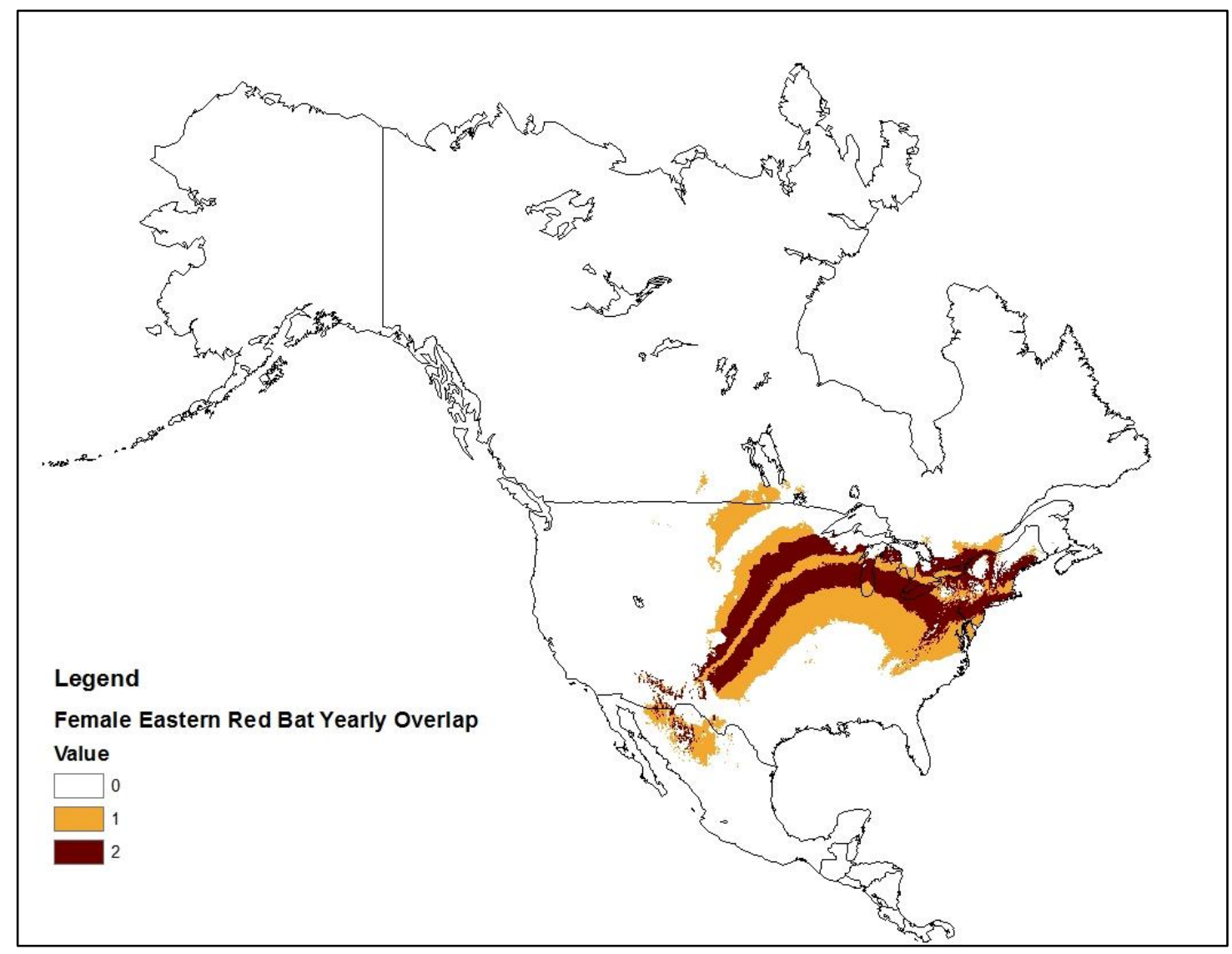

Figure 19: Number of specimen sample years (2008 and 2010) overlapping extents for female Eastern Red bats. Overlap in geographic origin is $43.61 \%$. 


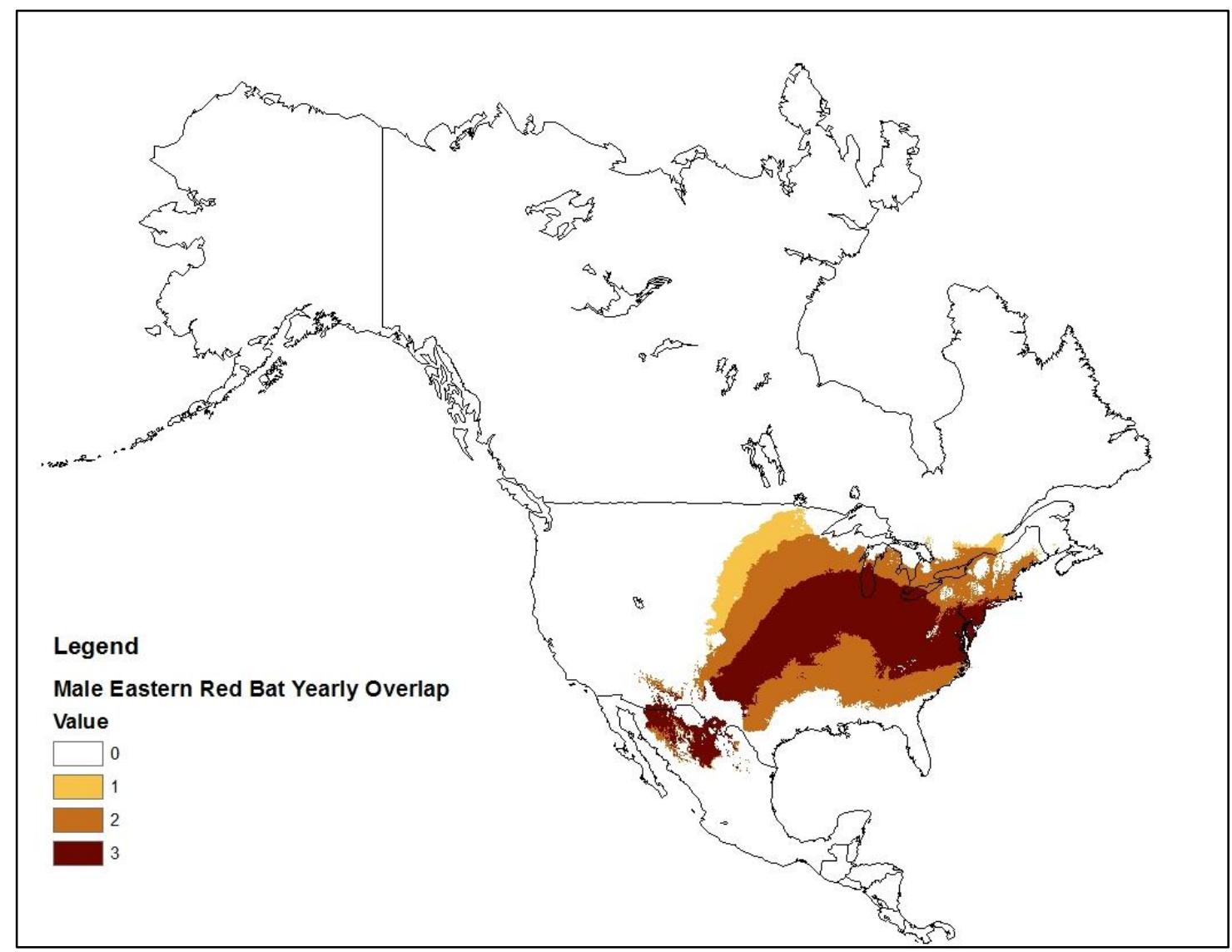

Figure 20: Number of specimen sample years (2008-2010) overlapping extents for male Eastern Red bats. Total overlap in geographic origin is $90.94 \%$. 


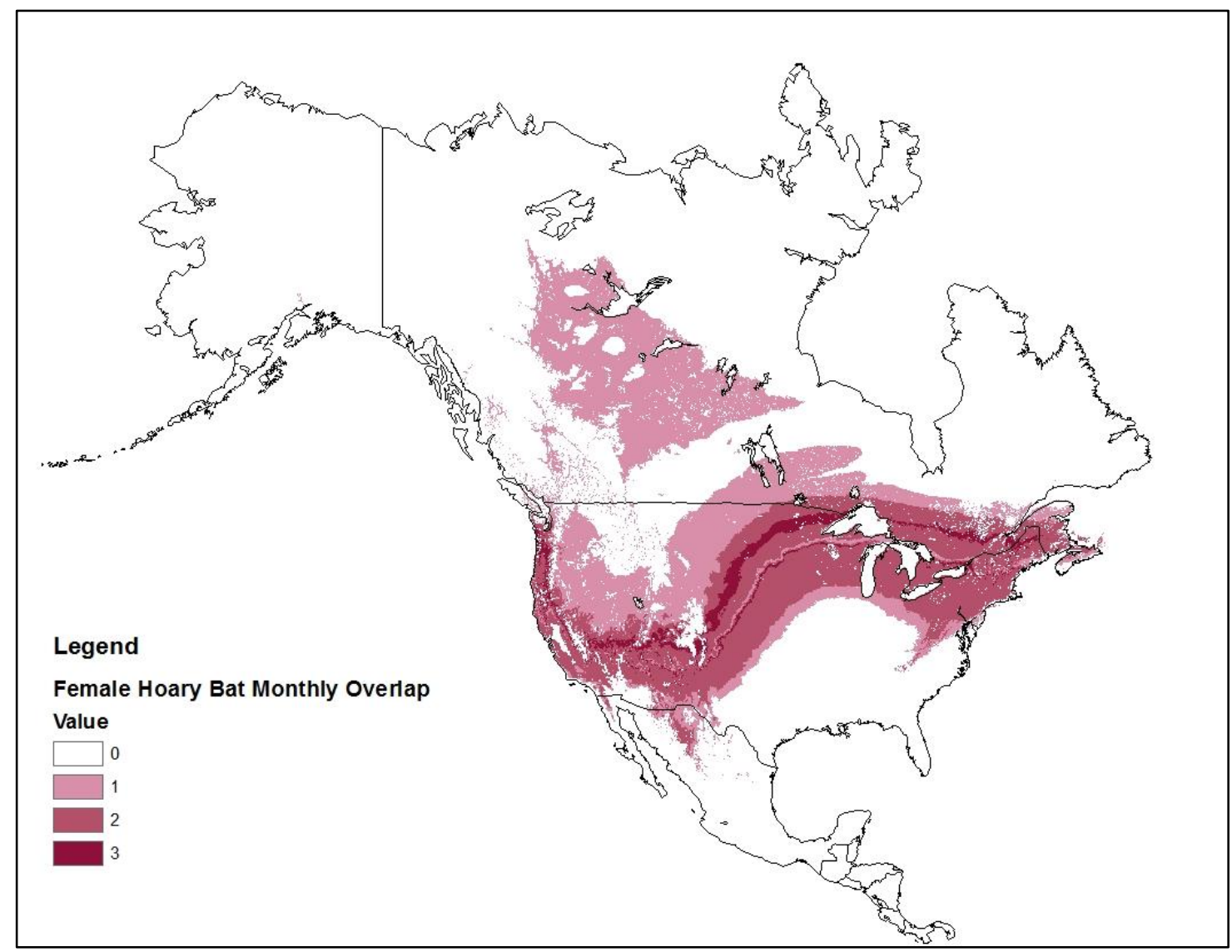

Figure 21: Overlap of specimen sample months (August-October) for female Hoary bats. Total overlap in geographic origin is $42.85 \%$. 


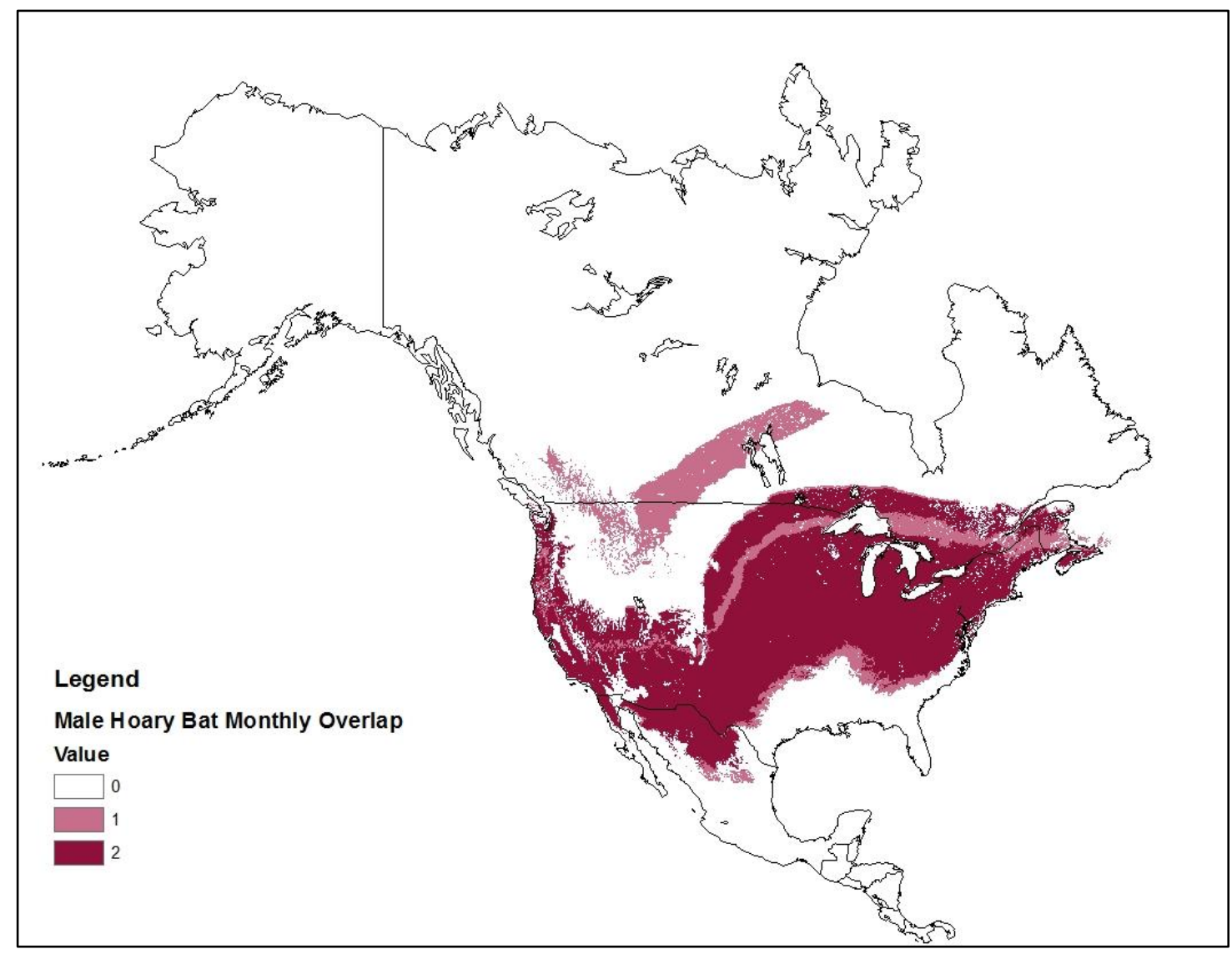

Figure 22: Overlap of specimen sample months (August and September) for male Hoary bats. Overlap in geographic origin is $74.91 \%$. 


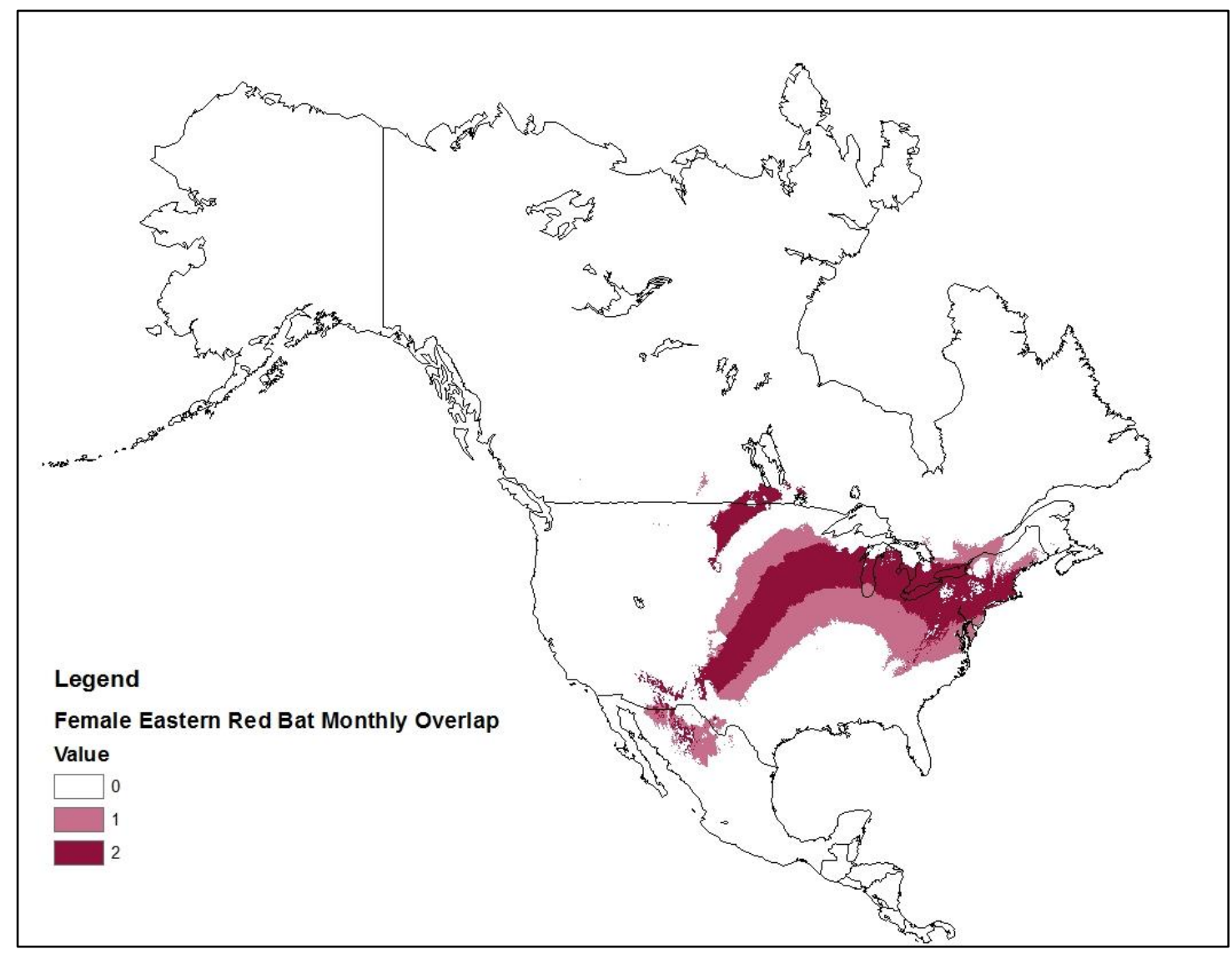

Figure 23: Overlap of specimen sample months (August and September) for female Eastern Red bats. Overlap in geographic origin is $52.59 \%$. 


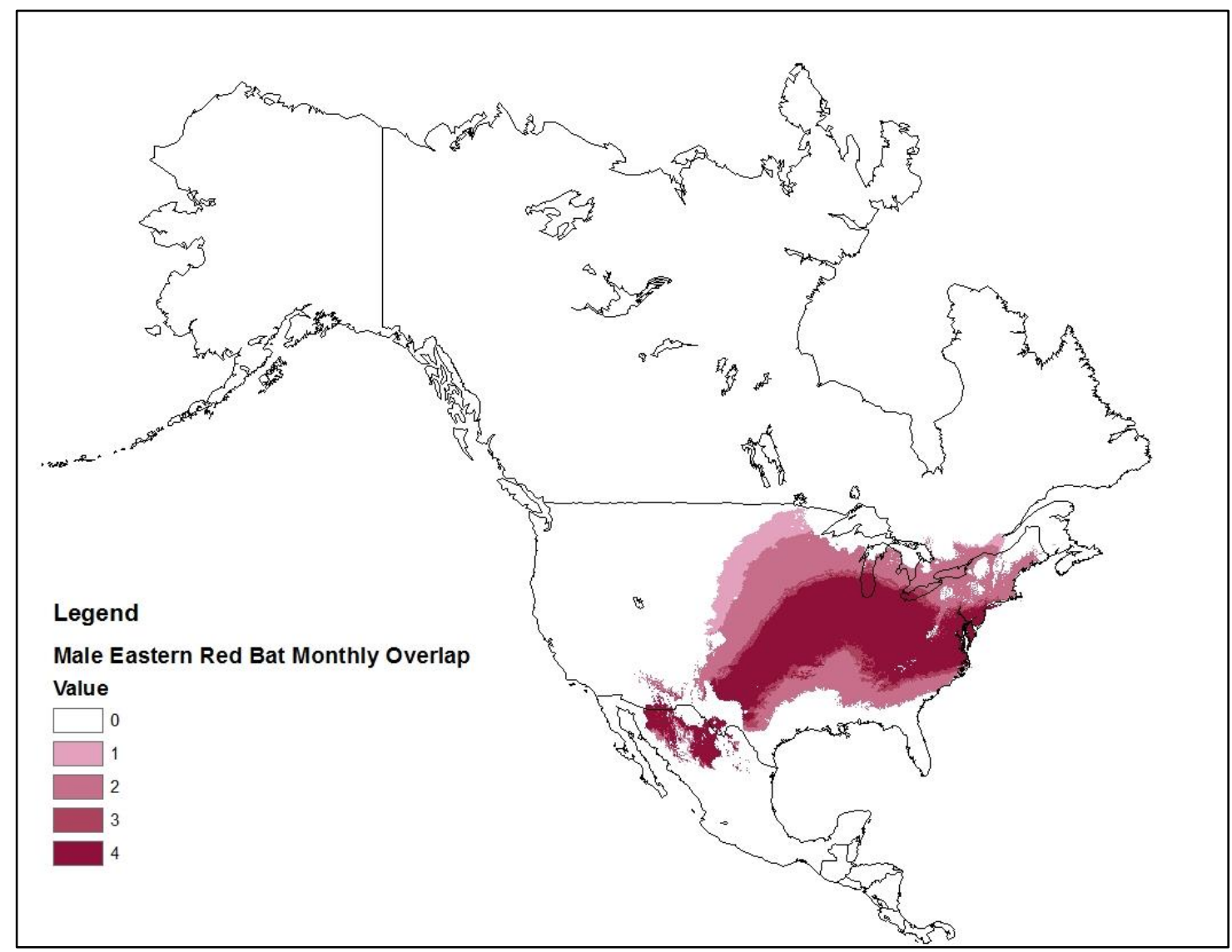

Figure 24: Overlap of specimen sample months (July-October) for male Eastern Red bats. Total overlap in geographic origin is $91.92 \%$. 
APPENDIX

GEOGRAPHIC EXTENTS OF BATS NOT USED IN ANALYSIS 


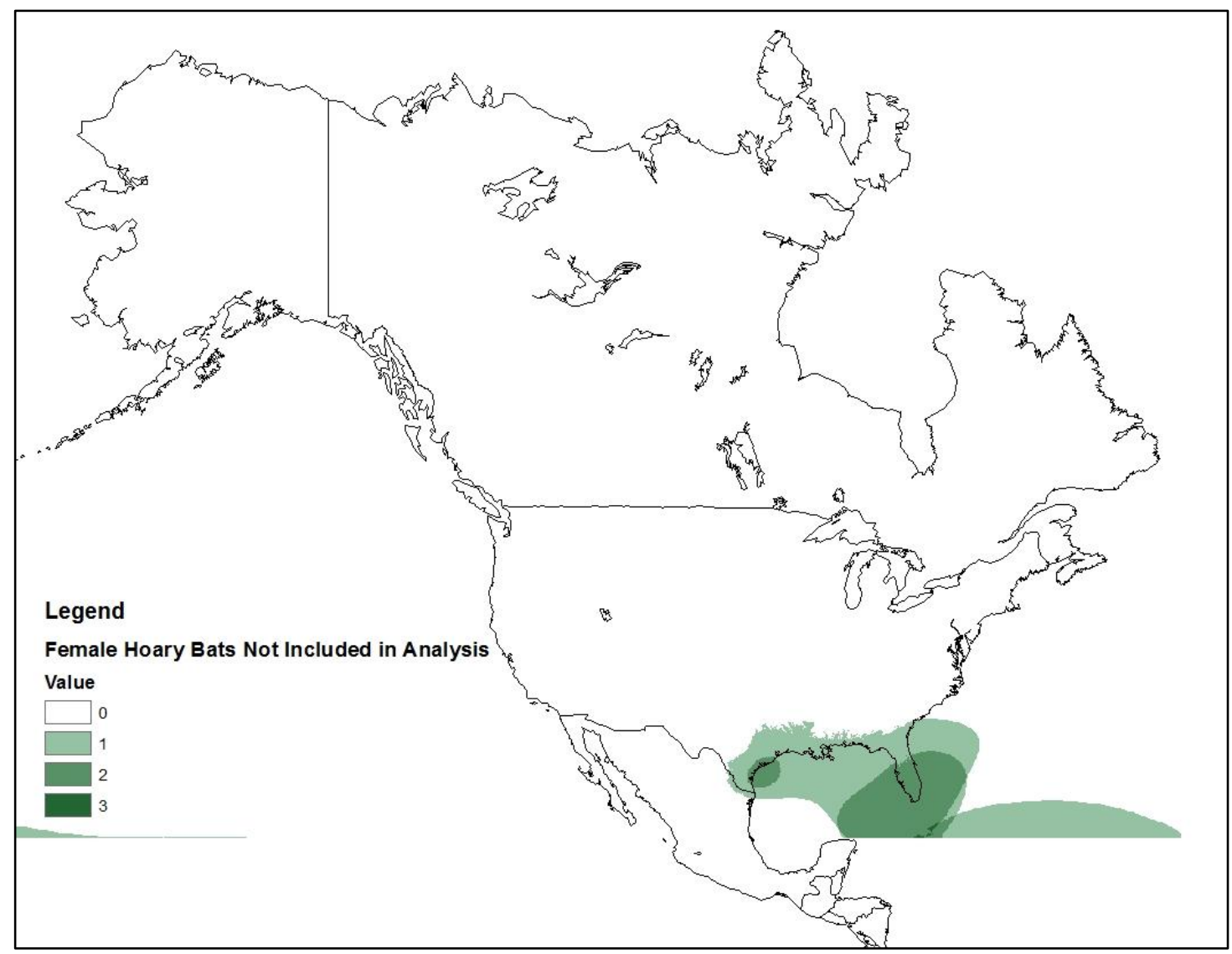

Figure 25: The three female Hoary bats not included in the analysis. 


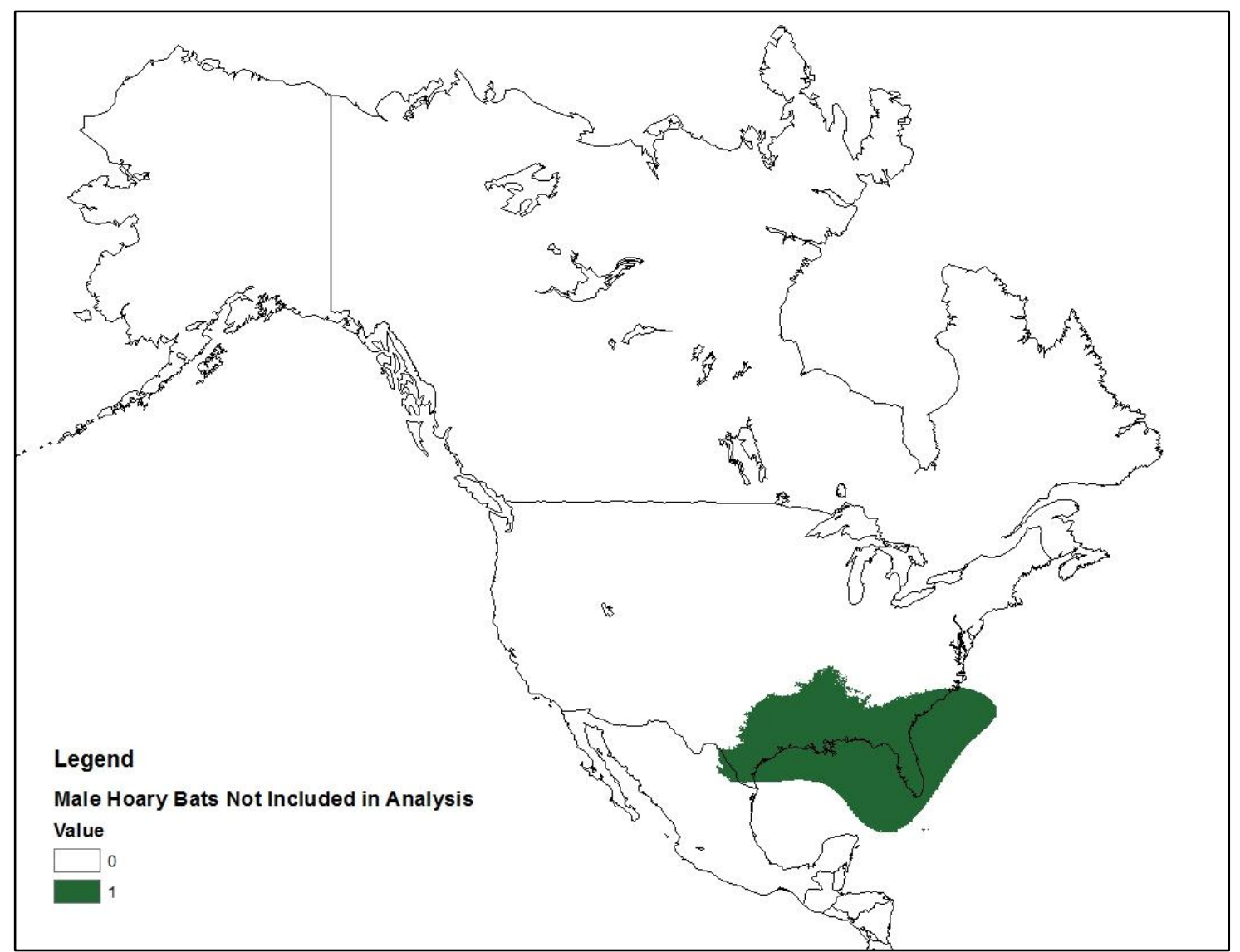

Figure 26: The single male Hoary bat specimen not included in the analysis. 


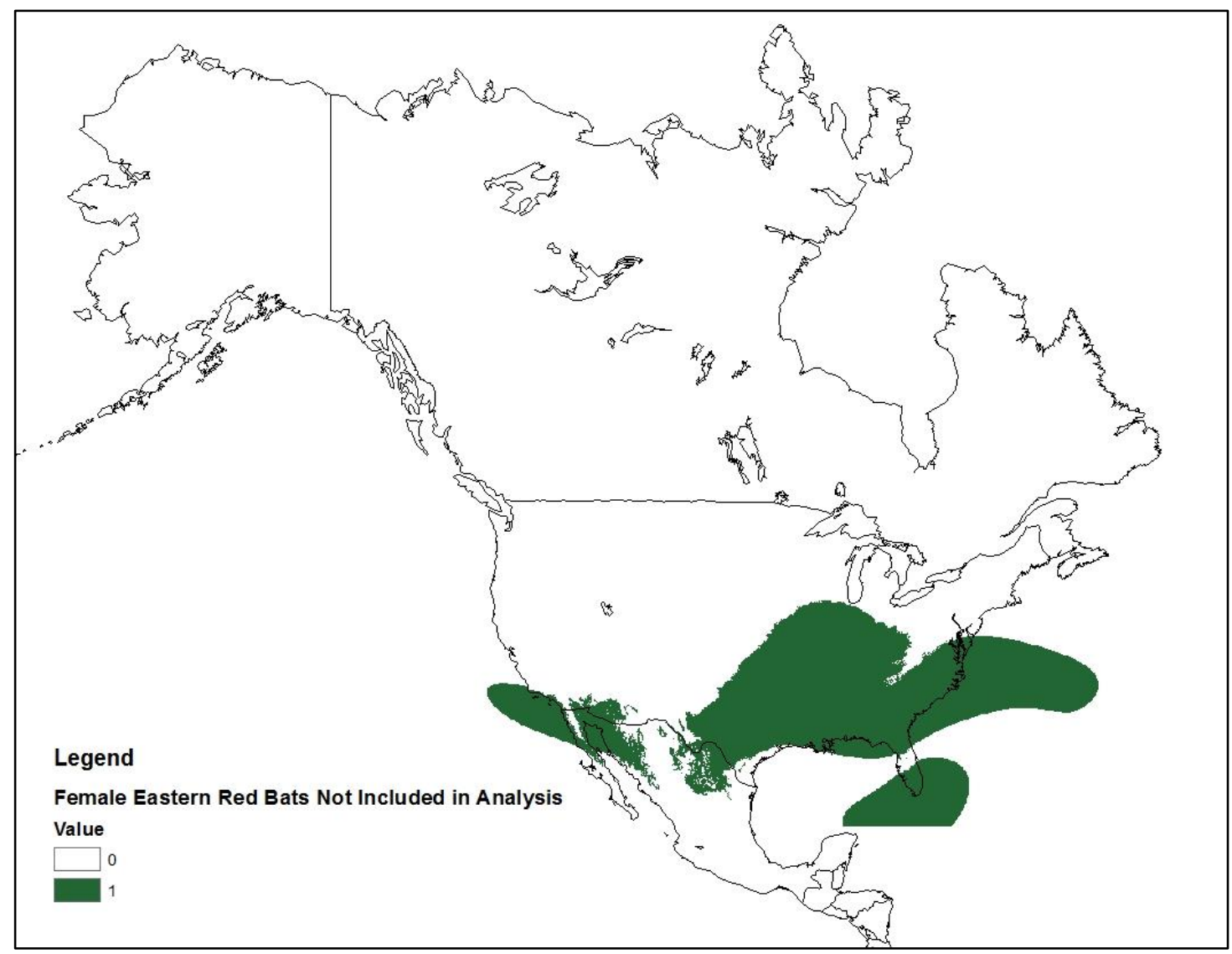

Figure 27: The two female Eastern Red bats not included in the analysis. 


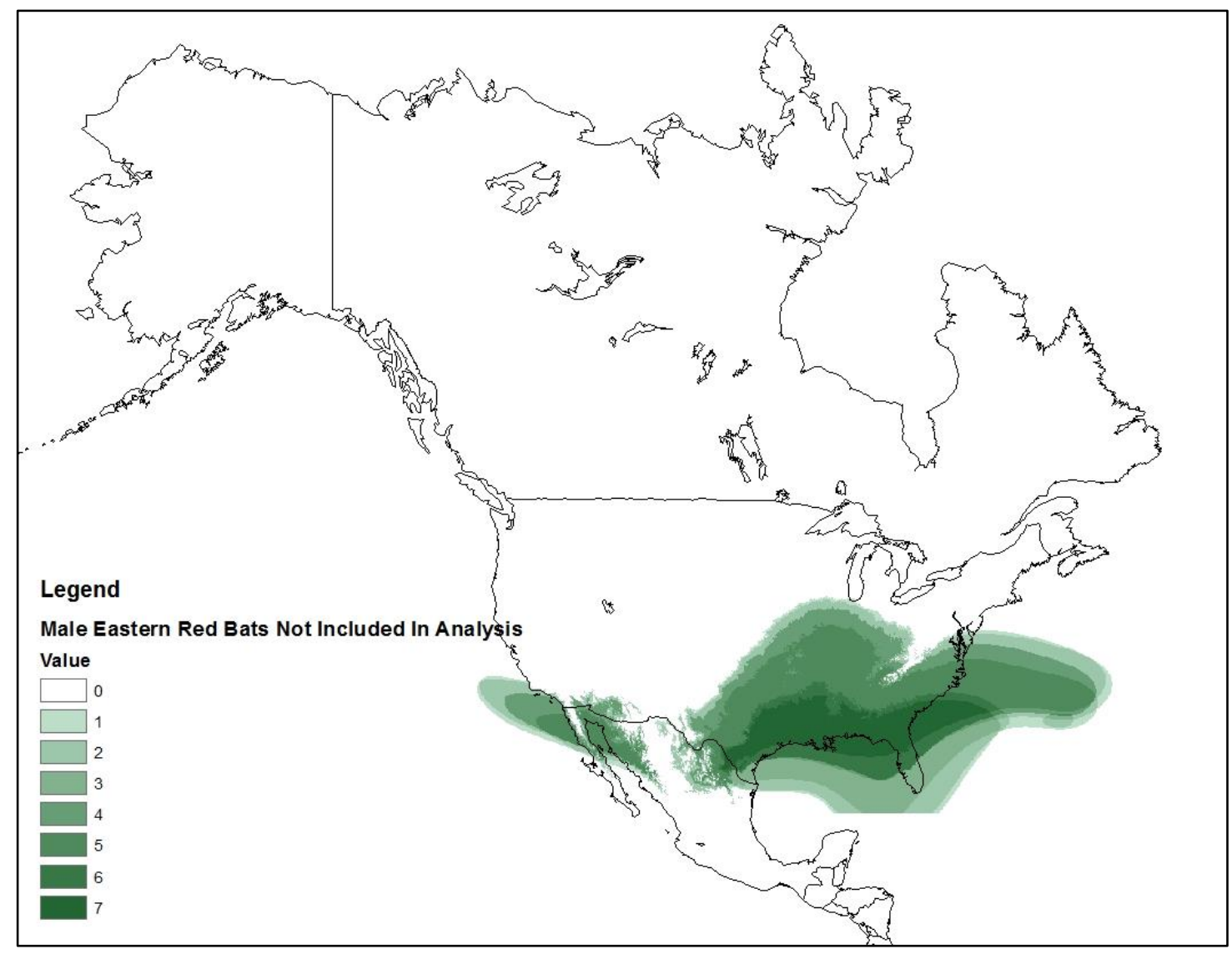

Figure 28: The seven male Eastern Red bats not included in the analysis. 